Eduardo Oliveira dos Santos

\title{
DIMENSIONAMENTO E AVALIAÇÃO DO CICLO DE REFRIGERAÇÃO DE SISTEMA DE CLIMATIZAÇÃO AUTOMOTIVO
}

Trabalho de conclusão de curso apresentado à Escola Politécnica da Universidade de São Paulo para obtenção do título de Mestre em Engenharia Automotiva (Mestrado Profissionalizante)

São Paulo 
Eduardo Oliveira dos Santos

\section{DIMENSIONAMENTO E AVALIAÇÃO DO CICLO DE REFRIGERAÇÃO DE SISTEMA DE CLIMATIZAÇÃO AUTOMOTIVO}

Trabalho de conclusão de curso apresentado à Escola Politécnica da

Universidade de São Paulo para obtenção

do título de Mestre em Engenharia Automotiva (Mestrado Profissionalizante)

Área de Concentração:

Engenharia Automotiva

(Mestrado Profissionalizante)

Orientador:

Arlindo Tribess

São Paulo

2005 
Este exemplar foi revisado e alterado em relação à versão original, sob responsabilidade única do autor e com a anuência do orientador.

São Paulo, 30 de setembro de 2005.

Eduardo Oliveira dos Santos

Autor

Arlindo Tribess

Orientador

Santos, Eduardo Oliveira dos

Dimensionamento e avaliação do ciclo de refrigeração de sistema de climatização automotivo. Eduardo Oliveira dos Santos. São Paulo, 2005. $109 \mathrm{p}$.

Trabalho de final de curso (Mestrado Profissionalizante em Engenharia Automotiva) - Escola Politécnica da Universidade de São Paulo.

1. Engenharia automotiva 2. Ar condicionado 3. Refrigeração. 4. Conforto térmico 5. Carga térmica 6. Tecnologia I. Universidade de São Paulo. Escola Politécnica. II. t 
À minha esposa, Elaine, que me encorajou e incentivou a dedicar-me aos estudos, ainda que soubesse que a tarefa me iria privar do convívio consigo, com a família e os amigos.

Somente por amor alguém abre mão de si pelo outro, por isso com amor lhe faço esta dedicatória.

Aos meus pais, José e Isabel, que me ensinaram a sempre aprender, e o que se aprende nunca nos pode ser subtraído (incluindo esta pequena lição da vida). 


\section{AGRADECIMENTOS}

Ao orientador, Prof. Dr. Arlindo Tribess, pela dedicação ao trabalho, pela paciência que teve com este autor, e pela orientação precisa e impecável durante a execução desta dissertação.

Aos colegas Chengcai Yao e Vilson Rebecchi, pelas diversas contribuições técnicas nos assuntos de sistemas de refrigeração e trocadores de calor.

À Visteon Sistemas Automotivos pelo apoio e incentivo.

A todos que direta ou indiretamente contribuíram com a realização deste trabalho. 


\section{SUMÁRIO}

\section{LISTA DE TABELAS}

LISTA DE FIGURAS

LISTA DE SÍMBOLOS

RESUMO

ABSTRACT

1 - INTRODUÇÃO

1.1 - OBJETIVOS E OBJETO DE ESTUDO 4

1.2 - ORGANIZAÇÃO DO TRABALHO 5

2 - CONFORTO TÉRMICO E SEGURANÇA 6

2.1 - CONFORTO TÉRMICO 7

2.2 - DESCONFORTO TÉRMICO LOCAL 13

2.3 - AVALIAÇÃO DE CONFORTO TÉRMICO EM VEÍCULOS 13 AUTOMOTIVOS

3 - CARGA TÉRMICA 21

3.1 - GANHOS DE CALOR 22

3.1 .1 - Condução através de paredes e vidros 22

3.1 .2 - Radiação solar através de janelas 23

3.1.3 - Condução de calor do compartimento do motor 23

3.1 .4 - Pessoas no interior do veículo 24

3.1.5 - Equipamentos internos (motores, ventiladores e iluminação) 24

3.1.6 - Infiltração e renovação de ar 24

3.2 - CONDIÇÕES DE OPERAÇÃO 27

3.3 - DADOS DE ENSAIO EM TÚNEL DE VENTO 30

3.4 - CARACTERÍSTICAS DO VEÍCULO 30

3.4.1 - Materiais das superfícies opacas 31

3.4.2 - Materiais das superfícies transparentes 33

3.5 - RESULTADOS DOS CÁLCULOS DOS GANHOS DE CALOR 33

3.6 - DETERMINAÇÃO DA CARGA TÉRMICA EFETIVA 37

3.7 - CONCLUSÕES 38

3.7.1 - Considerações para estudos futuros 39 
4.1 - CICLO DE REFRIGERAÇÃO POR COMPRESSÃO DE VAPOR 41

4.1.1 - O ciclo ideal de Carnot 41

4.1.2 - O ciclo ideal de refrigeração por compressão de vapor 43

4.1.3 - O ciclo real de refrigeração por compressão de vapor 45

4.1.4 - Fluido refrigerante 46

4.2 - COMPONENTES DO CICLO DE REFRIGERAÇÃO 48

4.3 - COMPRESSOR 50

4.3.1 - Construção mecânica 50

4.3.2 - Funcionamento e características

4.3.3 - Deslocamento volumétrico $\quad 54$

4.3.4 - Eficiência volumétrica

4.3.5 - Vazão mássica de refrigerante 55

4.3.6 - Capacidade de refrigeração 56

4.3.7 - Eficiência isoentrópica $\quad 57$

$4.4-$ CONDENSADOR $\quad 58$

4.4.1 - Construção mecânica 58

4.4.2 - Funcionamento e características $\quad 60$

4.4.3 - Coeficiente global de transferência de calor 61

4.4.4 - Avaliação de trocadores de calor pelo método da Efetividade-NUT ( $\varepsilon$-NUT) 61

4.5 - EVAPORADOR 62

4.5.1 - Construção mecânica

4.5.2 - Funcionamento e características 63

4.5.3 - Capacidade de refrigeração $\quad 64$

4.6 - DISPOSITIVO DE EXPANSÃO

4.6.1 - Construção mecânica 64

4.6.2 - Funcionamento e características $\quad 65$

4.7 - ACUMULADOR DE LÍQUIDO 65

4.7.1 - Construção mecânica 66

4.7.2 - Funcionamento e características 66

4.8 - CONTROLE DO SISTEMA

4.8.1 - Controle de temperatura 68

4.8.2 - Controle do ciclo de refrigeração 68 
5 DIMENSIONAMENTO DO CICLO DE REFRIGERAÇÃO 70

5.1 - CONDIÇÕES DE ENTRADA DE PROJETO 70

5.2 - PROCEDIMENTO DE PROJETO 71

5.2.1 - Evaporador 71

5.2.2 - Ciclo de refrigeração 71

5.2.3 - Compressor 72

5.2.4 - Condensador $\quad 72$

5.2.5 - Dispositivo de expansão 73

5.2.6 - Carga Térmica 73

5.2.7 - Fluxograma 74

5.3 - DADOS DE ENTRADA E RESULTADOS 74

$5.4-$ CONCLUSÃO 80

6 - AVALIAÇÃO DE DESEMPENHO DO CICLO DE REFRIGERAÇÃO 82

6.1 - PARÂMETROS DE ENTRADA PARA A SIMULAÇÃO 83

6.1.1 - Parâmetros de operação 83

6.1.2 - Parâmetros estimados 83

6.2 - PROCEDIMENTO DA SIMULAÇÃO 83

6.2.1 - Ciclo de Refrigeração

6.2.2 - Evaporador $\quad 85$

6.2.3 - Compressor $\quad 87$

6.2.4 - Condensador 87

6.2.5 - Tubo de Orifício 89

6.2.6 - Fluxograma do Processo 89

6.3 - DADOS DE ENTRADA E RESULTADOS

6.4 - RESULTADOS DO TÚNEL DE VENTO 93

6.5 - COMPARAÇÃO DOS RESULTADOS 96

6.5.1 - Fluxos de Calor 96

6.5.2 - Temperaturas 97

6.5.3 - Pressões de Trabalho 97

6.5.4 - Coeficiente de Performance 97

6.6 - AJUSTES DO MODELO DE SIMULAÇÃO 98

$\begin{array}{ll}6.7-\text { CONCLUSÕES } & 101\end{array}$ 
7 - CONCLUSÃO

8 - REFERÊNCIAS BIBLIOGRÁFICAS

APÊNDICE A

APÊNDICE B

APÊNDICE C

APÊNDICE D 


\section{LISTA DE TABELAS}

$\begin{array}{lll}\text { Tabela 2-1 Escala de sensação térmica } & 10\end{array}$

Tabela 2-2 Determinação do voto médio estimado - PMV 11

$\begin{array}{lll}\text { Tabela 2-3 Escala de sensação de conforto térmico } & 19\end{array}$

Tabela 3-1 Dados obtidos em teste de túnel de vento 32

Tabela 3-2 Características das superfícies opacas 32

Tabela 3-3 Características dos materiais transparentes (vidros) do veículo 33

Tabela 3-4 Ganhos de calor para veículo a 50km/h 34

Tabela 3-5 Ganhos de calor para veículo a 100km/h 35

Tabela 3-6 Ganhos de calor para veículo em marcha lenta 36

$\begin{array}{lll}\text { Tabela 3-7 } & \text { Quadro resumo dos ganhos de calor }\end{array}$

$\begin{array}{lll}\text { Tabela 3-8 Carga térmica efetiva } & 38\end{array}$

Tabela 3-9 Quadro comparativo de carga térmica de veículos compactos 39

Tabela 5-1 Dados de entrada para o projeto do sistema de refrigeração $\quad 76$

Tabela 5-2 Resultados do cálculo do evaporador 76

Tabela 5-3 Condições de operação do ciclo de refrigeração 77

$\begin{array}{lll}\text { Tabela 5-4 Resultados dos cálculos do compressor } & 78\end{array}$

$\begin{array}{lll}\text { Tabela 5-5 } & \text { Resultados dos cálculos do condensador } & 79\end{array}$

Tabela 5-6 Vazões de refrigerante para cada diâmetro de tubo para os $\quad 80$ pontos de operação do projeto

Tabela 6-1 Dados de entrada para a simulação do sistema 91

Tabela 6-2 Resultados dos pontos de equilíbrio da simulação 92

Tabela 6-3 Valores reais medidos no ensaio em túnel de vento 94

Tabela 6-4 Resultados da análise termodinâmica do sistema medido no 95 túnel de vento 
Tabela 6-5 Quadro comparativo dos resultados da simulação e de testes reais

Tabela 6-6 Ajustes no modelo de simulação do sistema 99

Tabela 6-7 Resultados da simulação do sistema após ajuste do modelo 100

Tabela 6-8 Quadro comparativo dos resultados da simulação após ajustes do 101 modelo 


\section{LISTA DE FIGURAS}

Figura 1-1 Primeiro sistema de ar condicionado desenvolvido pela Packard 3 Motor Car em 1939

Figura 2-1 Modelo cilíndrico da interação térmica: corpo humano - meio 8 envolvente

Figura 2-2 Diagrama psicrométrico com a indicação da zona de conforto em 12 ambientes climatizados segundo a norma ASHRAE 55

Figura 2-3 Sitckman dentro do veículo e versão simplificada para medições 15 de velocidade de ar

Figura 2-4 Manequim térmico instalado em uma cabina para testes de aquecimento

Figura 2-5 Diagrama de um manequim com 16 segmentos

Figura 2-6 Diagrama para avaliação da teq em função da sensação térmica 18 estimada.

Figura 2-7 Diagrama para avaliação da $t_{\mathrm{eq}}$ em função da sensação térmica estimada.

Figura 3-1 Cabina do veículo e sistema de ar condicionado

Figura 3-2 Carta psicrométrica ilustrando o processo de resfriamento e mistura de ar externo

Figura 3-3 Estimativa da umidade relativa interna e entalpia interna

Figura 3-4 Lay-out de um túnel de vento típico

Figura 3-5 Célula de testes de um túnel de vento 28

Figura 3-6 Temperaturas internas durante ensaio em túnel de vento 30

$\begin{array}{lll}\text { Figura 3-7 Características do veículo } & 31\end{array}$

Figura 4-1 Esquema e diagrama T-s do ciclo de Carnot 42 
Figura 4-2 Esquema e diagrama T-s do ciclo ideal de refrigeração por compressão de vapor

Figura 4-3 Diagrama p-h de um ciclo padrão de refrigeração

Figura 4-4 Diagrama p-h de um ciclo real de refrigeração, ilustrando os efeitos do subresfriamento e superaquecimento, e das quedas de pressão

Figura 4-5 Diagrama T-s de um ciclo real de refrigeração por compressão de vapor

Figura 4-6 Ciclo de refrigeração com dispositivo de expansão tipo tubo de orifício

Figura 4-7 Ciclo de refrigeração com dispositivo de expansão tipo válvula termostática

Figura 4-8 Compressor alternativo de pistão

Figura 4-9 Diagrama teórico da pressão no cilindro ao longo da posição angular do eixo

Figura 4-10 Diagrama Pressão - Volume para um ciclo de compressão típico

Figura 4-11 Efeito da razão de compressão na eficiência volumétrica

Figura 4-12 Diagrama explodido ilustrativo de um compressor de prato oscilante de deslocamento fixo

Figura 4-13 Seção transversal de um modelo simplificado de compressor de prato oscilante

Figura 4-14 Eficiência volumétrica teórica e real de um compressor com refrigerante R22

Figura 4-15 Curva de capacidade de um compressor Sanden modelo SD5H14， 57 com cinco pistões acionados por prato oscilante, $138 \mathrm{~cm}^{3}$

Figura 4-16 Esquema típico de um condensador tipo tubo-aletas

Figura 4-17 Condensador de serpentina de tubos planos e aletas tipo "louver" 59 
Figura 4-18 Esquema de um condensador de tubos planos com microcanais e 59 aletas tipo "louver", com fluxo paralelo, dividido em seções de resfriamento do vapor superaquecido, condensação e subresfriamento

Figura 4-19 Distribuição de temperaturas em um condensador

Figura 4-20 Tipos de evaporadores $\quad 63$

$\begin{array}{lll}\text { Figura 4-21 Esquema de um tubo de orifício } & 65\end{array}$

$\begin{array}{lll}\text { Figura 4-22 Acumulador de líquido } & 66\end{array}$

Figura 4-23 Esquema de captação de vapor de refrigerante e óleo 67

$\begin{array}{lll}\text { Figura 5-1 Fluxograma de projeto do sistema de refrigeração } & 75\end{array}$

$\begin{array}{lll}\text { Figura 5-2 Curvas de eficiência volumétrica do compressor } & 77\end{array}$

Figura 5-3 Curva de eficiência isoentrópica do compressor 78

Figura 5-4 Curvas de vazão de refrigerante para $\mathrm{SC}=10^{\circ} \mathrm{C} \quad 79$

Figura 6-1 Ciclo real de refrigeração por compressão de vapor $\quad 84$

Figura 6-2 Relação UA_evap x Vazão de ar para o evaporador de placas 85

Figura 6-3 Relação UA_cond x Vazão de ar e Tcond-Tar_ext para o 89 condensador de tubos planos e aletas tipo louver

Figura 6-4 Fluxograma do processo de simulação do sistema 


\section{LISTA DE SÍMBOLOS}

\section{Letras Maiúsculas}

\begin{tabular}{|c|c|c|}
\hline A & Área & {$\left[\mathrm{m}^{2}\right]$} \\
\hline $\mathrm{C}$ & Troca de calor por conveção, Capacidade calorífica & {$[\mathrm{W}]$ ou $[\mathrm{W} / \mathrm{K}]$} \\
\hline CIL & Cilindrada (compressor) & {$\left[\mathrm{cm}^{3}\right]$} \\
\hline $\mathrm{COP}$ & Coeficiente de performance & {$[-]$} \\
\hline $\mathrm{Cp}$ & Calor específico à pressão costante & {$[\mathrm{J} / \mathrm{kg}-\mathrm{K}]$} \\
\hline $\mathrm{D}$ & Diâmetro & {$[\mathrm{m}]$} \\
\hline Dew & Temperatura do ponto de orvalho & {$\left[{ }^{\circ} \mathrm{C}\right]$} \\
\hline I & Incidência solar, Corrente elétrica & {$\left[\mathrm{W} / \mathrm{m}^{2}\right]$ ou $[\mathrm{A}]$} \\
\hline IR & Isolação da Roupa & {$\left[\mathrm{m}^{2}-\mathrm{K} / \mathrm{W}\right]$} \\
\hline $\mathrm{L}$ & Comprimento & {$[\mathrm{m}]$} \\
\hline $\mathrm{M}$ & Metabolismo & {$[\mathrm{W}]$} \\
\hline NUT & Número de unidades de transferência & {$[-]$} \\
\hline $\mathrm{P}$ & Pressão & {$[\mathrm{Pa}]$} \\
\hline PR & Razão de compressão & {$[-]$} \\
\hline Q & Vazão volumétrica & {$\left[\mathrm{m}^{3} / \mathrm{s}\right]$} \\
\hline$\dot{Q}$ & Taxa de transferência de calor & {$[\mathrm{W}]$} \\
\hline$\dot{Q}_{k}$ & Taxa de transferência de calor por condução & {$[\mathrm{W}]$} \\
\hline $\mathrm{R}$ & Troca de calor por radiação, Resistência térmica & {$[\mathrm{W}]$ ou $\left[\mathrm{m}^{2}-\mathrm{K} / \mathrm{W}\right]$} \\
\hline $\mathrm{SC}$ & Subresfriamento & {$\left[{ }^{\circ} \mathrm{C}\right]$} \\
\hline SH & Superaquecimento & {$\left[{ }^{\circ} \mathrm{C}\right]$} \\
\hline $\mathrm{T}$ & Temperatura & {$\left[{ }^{\circ} \mathrm{C}\right]$} \\
\hline $\mathrm{U}$ & Coeficiente global de transferência de calor & {$\left[\mathrm{W} / \mathrm{m}^{2}-\mathrm{K}\right]$} \\
\hline$\dot{V}$ & Deslocamento volumétrico & {$\left[\mathrm{m}^{3} / \mathrm{s}\right]$} \\
\hline $\mathrm{V}$ & Tensão elétrica & {$[\mathrm{V}]$} \\
\hline $\mathrm{V}$ & Velocidade & {$[\mathrm{m} / \mathrm{s}]$} \\
\hline $\mathrm{V}$ & Volume & {$\left[\mathrm{m}^{3}\right]$} \\
\hline $\mathrm{Va}$ & Volume de espaço morto & {$\left[\mathrm{m}^{3}\right]$} \\
\hline $\mathrm{Vb}$ & Volume de re-expansão & {$\left[\mathrm{m}^{3}\right]$} \\
\hline$\dot{W}$ & Fluxo de trabalho & {$[\mathrm{W}]$} \\
\hline $\mathrm{X}$ & Título & {$[-]$} \\
\hline
\end{tabular}




\section{Letras Minúsculas}

e Espessura

[m]

h Coeficiente de transferência de calor, entalpia

$\left[\mathrm{W} / \mathrm{m}^{2}-\mathrm{K}\right]$ ou $[\mathrm{kJ} / \mathrm{kg}]$

k Condutividade

$[\mathrm{W} / \mathrm{m}-\mathrm{K}]$

$\dot{m} \quad$ Vazão mássica

$[\mathrm{kg} / \mathrm{s}]$

n Número de revoluções

$\min ^{-1}$

s $\quad$ Entropia

$[\mathrm{kJ} / \mathrm{kg}-\mathrm{K}]$

w Umidade absoluta

$[\mathrm{kg} / \mathrm{kg}]$

\section{Letras gregas}

$[-]$

$\beta \quad$ Coeficiente de performance

[ - ]

$\varepsilon \quad$ Efetividade

$[-]$

$\phi \quad$ Umidade relativa

[ - ]

$\eta \quad$ Eficiência

[- ]

$\rho \quad$ Densidade

$\left[\mathrm{kg} / \mathrm{m}^{3}\right]$

$\tau \quad$ Transmissividade

[- ]

$\Delta \mathrm{t} \quad$ Diferença de temperatura

$\left[{ }^{\circ} \mathrm{C}\right.$ ]

\section{Subscritos}

$\begin{array}{cl}\text { ar } & \text { Ar } \\ \text { ar-sol } & \text { Ar-Sol } \\ \text { c } & \text { Condução, Compressor } \\ \text { comp } & \text { Compressor } \\ \text { cond } & \text { Condensador } \\ \text { D } & \text { Direto, Divisória } \\ \text { d, desc } & \text { Descarga } \\ \text { DIF } & \text { Difusão de vapor dágua pela pele } \\ \text { E } & \text { Entrada } \\ \text { e, ext } & \text { Externo } \\ \text { ES } & \text { Evaporação de suor } \\ \text { evap } & \text { Evaporador } \\ \text { H } & \text { Referente à alta temperatura } \\ \text { h } & \text { Relativo a condensação ou evaporação } \\ \text { I } & \text { Infiltração }\end{array}$




$\begin{array}{cl}\text { i, int } & \text { Interno } \\ \text { iso } & \text { Isoentrópico } \\ \text { L } & \text { Referente à baixa temperatura } \\ \text { r } & \text { Refrigerante } \\ \text { R } & \text { Respiração, Radiante } \\ \text { real } & \text { Real, efetivo } \\ \text { s } & \text { Solar, sucção, saída } \\ \text { sat } & \text { Saturação } \\ \text { t } & \text { total } \\ \text { v } & \text { Vidros, Ventilador } \\ \text { vol } & \text { Volumétrico } \\ \text { To } & \text { Tubo de orifício }\end{array}$




\section{RESUMO}

O ser humano consome grandes quantidades de energia para satisfazer as suas necessidades de conforto. Dentro do setor automotivo, depois da energia consumida com a mobilidade em si, o ar condicionado é o maior consumidor.

O sistema de climatização para aplicações automotivas tem características particulares, diferentes de sistemas de climatização para outros ambientes. Em uma aplicação automotiva a variação de condições é bastante significativa, como por exemplo a carga solar que é imposta, a velocidade do veículo, umidade do ar, as temperaturas interna e externa, variação do número e da posição dos ocupantes no interior do veículo, diferentes regimes de rotação e carga do motor, etc. O sistema deve, portanto, ser projetado para funcionar sob todas estas condições e propiciar condições de conforto térmico com o menor consumo de energia.

No presente trabalho o objetivo é o projeto e a simulação de um ciclo de refrigeração que atenda aos requerimentos de carga térmica para um automóvel compacto em um ensaio específico realizado em túnel de vento. A partir da carga térmica, o ciclo de refrigeração é dimensionado seguindo-se o procedimento de projeto, que engloba o dimensionamento dos componentes principais como compressor, condensador, evaporador e o dispositivo de expansão. Os resultados dos cálculos teóricos são comparados com o dimensionamento do veículo real, permitindo se chegar a conclusões sobre o projeto. A avaliação do desempenho do sistema projetado é realizada por meio de um procedimento de simulação proposto, e os resultados comparados com os do veículo testado.

O objeto de estudo é o sistema de refrigeração de um veículo compacto de quatro portas de fabricação nacional, submetido a um teste de desempenho do ciclo em um túnel de vento.

O procedimento de dimensionamento pode ser usado para o projeto básico do sistema de refrigeração. Os resultados obtidos com o modelo de simulação proposto são bastante razoáveis. O modelo pode ser utilizado para prever o resultado de modificações no ciclo de refrigeração, como a troca de componentes, ou mesmo para prever o funcionamento do sistema sob outras condições de operação. A utilização do modelo fica restrita aos limites da validade dos modelos semi-empíricos dos componentes, não sendo recomendada a utilização fora desses limites. Ainda assim, a faixa de aplicação é grande o suficiente para simular a maioria das condições de trabalho encontradas na climatização veicular. 


\begin{abstract}
Human being spends a large amount of energy to satisfy its comfort needs. In the automotive applications, air conditioning is the second larger energy consumption system, after the mobility system itself.

The refrigeration system for automotive application has peculiar characteristics, which are different from other refrigeration systems (e.g. buildings, food refrigeration, etc). In an automotive application, variation of several conditions are highly significant, such as the sun load, ambient temperature and humidity, the number and position of the occupants inside the vehicle, different engine loads and speeds and so on. The system must, therefore, be designed to operate satisfactorily under all these conditions and to provide thermal comfort with smallest possible energy consumption.

The objective of this work is to present the project and simulation of a refrigeration cycle for a compact size vehicle in order to meet thermal load requirements of a specific wind tunnel test. From the thermal load, the refrigeration cycle is designed according to a design procedure, which includes the sizing of main components such as compressor, condenser, evaporator and expansion device. The results of the calculations are compared with the actual vehicle design. The performance evaluation is achieved by using a proposed simulation procedure, and the simulation results are compared with the actual vehicle test results.

The study is conducted on the refrigerating system of a 4-door compact size vehicle locally manufactured, which was submitted to a refrigeration cycle performance test in a wind tunnel.

The design procedure can be used for sizing a baseline refrigeration cycle. The results achieved with the proposed simulation model are acceptable. The model can be used to predict the impact of a modification in refrigeration cycle such as a component change, or even to predict the system balance point under different operating conditions. The application of the model is restricted to the range of validation of the component semiempirical models, so that the use beyond these limits is not recommended. The range of application, however, is wide enough to accommodate most of the operating conditions found in the vehicular refrigeration applications.
\end{abstract}




\section{CAPÍTULO 1 INTRODUÇÃO}

A manutenção da vida depende de condições favoráveis. Por essa razão, determinadas espécies sobrevivem em certas regiões, ou condições ambientais, outras não. Determinados ambientes simplesmente não oferecem condições para o desenvolvimento da vida. O ser humano, contudo, tem a capacidade de mudar o ambiente para prover as condições necessárias à sua vida.

O conforto ambiental não está somente associado à manutenção da vida, mas também à sua qualidade. A condição de conforto ambiental está associada a questões sociais, culturais, econômicas, etc., sendo determinada pelos seguintes fatores:

- Conforto térmico

- Conforto lumínico

- Conforto acústico

- Qualidade do ar

- Ergonomia

A melhoria das condições ambientais nos espaços de trabalho está relacionada com a necessidade de aumento da produtividade do ser humano e do aproveitamento desses espaços, cada vez mais escassos. Observando-se por exemplo os espaços destinados ao comércio, como shopping centers, nota-se que as condições de conforto térmico, iluminação, nível de ruído, etc. são agradáveis, ao ponto de ser razoável deduzir que o bem-estar proporcionado por essas condições provavelmente induzem as pessoas ao consumo.

Como a obtenção dessas condições se dá à custa do uso de energia, reforça-se a tese do aumento da produtividade e de consumo como forma de retorno dos investimentos na melhoria das condições de conforto e dos gastos com energia. A questão do conforto em veículos, do ponto de vista econômico, se encaixa neste contexto.

Isnard (2004) afirma por exemplo que o conforto acústico é o terceiro critério de compra de um automóvel, depois do tamanho e do preço. Itens de conforto, como por exemplo o sistema de climatização, são um forte argumento de vendas de automóveis. As pessoas irão provavelmente preferir realizar os seus deslocamentos nos meios mais confortáveis dentro das suas condições econômicas. 
Atualmente existem à disposição tecnologias capazes de prover condições de conforto térmico em casas, edifícios, fábricas, veículos automotivos, enfim em qualquer ambiente onde se necessite, além das condições de conforto em si, aumentar a capacidade produtiva do ser humano.

Cada vez mais as pessoas passam várias horas se deslocando de um ponto a outro dentro de veículos automotivos. Algumas vezes trabalham enquanto se deslocam. Sem condições de conforto térmico (entre outras condições de conforto ambiental necessárias) isso não seria possível.

No caso particular dos automóveis, a produção em massa vem reduzindo custos e aumentando o acesso a veículos equipados com sistemas de aquecimento e refrigeração. A pressão por custos força a indústria a disponibilizar equipamentos cada vez menores e mais leves. Ao mesmo tempo, existe a necessidade de se reduzir o consumo de energia e as emissões de poluentes. Esses fatores impõem uma demanda de equipes de engenheiros preparados e de recursos de desenvolvimento, simulação e testes.

A melhoria das condições de conforto é o fator motivador da demanda por sistemas de climatização. Por essa razão, embora o estudo do conforto térmico em veículos automotivos não seja o objetivo principal deste trabalho, este tema merece atenção e lhe será dado uma abordagem geral mostrando as técnicas clássicas e os recentes avanços na área. As condições de conforto lumínico, acústico, de qualidade do ar e de ergonomia não são objeto de estudo neste trabalho.

O aumento de demanda por veículos mais confortáveis e consequentemente por projetos de sistemas de refrigeração para aplicação automotiva é um dos motivadores para a realização do presente trabalho.

Um segundo motivador partiu de uma percepção inicial deste autor de que este segmento da indústria automotiva tem carência de informações técnicas disponíveis na literatura aberta para os engenheiros que nele atuam. Especialmente pelo fato da maioria das informações serem de propriedade das empresas atuantes no setor. Esta percepção é também mencionada no trabalho de Ávila (2002).

Embora, no curso do desenvolvimento do trabalho, tenha sido verificada a existência de uma razoável quantidade de trabalhos técnicos publicados nesta área da engenharia, as informações encontram-se relativamente dispersas. Assim, um outro motivador passou a ser a reunião deste material em um único trabalho. 
O desenvolvimento de sistemas de refrigeração para automóveis surgiu no início dos anos de 1930 nos Estados Unidos. Um primeiro sistema foi adaptado em um Cadillac pela C\&C Kelvinator Co. no estado do Texas, EUA. Este sistema era independente, tinha capacidade de refrigeração de $0,37 \mathrm{~kW}$ e era alimentado por um motor a gasolina de 1,1kW. Em 1933 a General Motors iniciou os trabalhos com o sistema de refrigeração por compressão de vapor usando refrigerante R12. Em 1939 a Packard Motor Car lançou o primeiro sistema original de fábrica completo de refrigeração e aquecimento (Figura 1-1). A General Motors introduziu o sistema de ar condicionado na linha Cadillac em 1941 (Bhatti, 1999a).

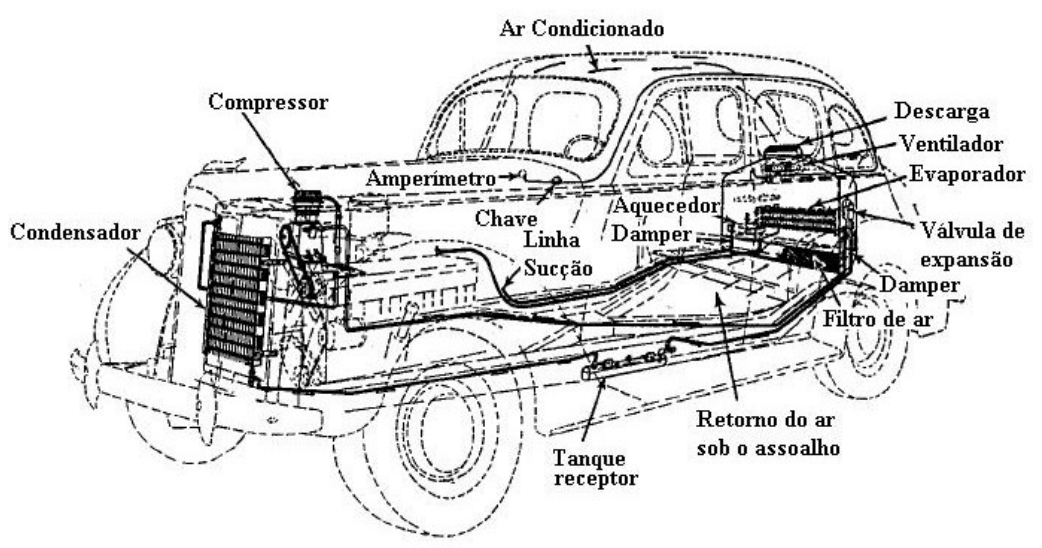

\section{Figura 1-1 Primeiro sistema de ar condicionado desenvolvido pela Packard Motor Car em 1939 (Bhatti, 1999a)}

O sistema evoluiu nos anos seguintes com diversas melhorias como ventilação frontal, compressor com embreagem eletromagnética e controles automáticos. Os anos de 1970 foram marcados pela associação entre os compostos de clorofluorcarbono (CFC), incluindo o R12, e a destruição da camada de ozônio, culminando com o protocolo de Montreal em 1981 que estabeleceu o banimento progressivo da produção de refrigerantes CFC (Bhatti, 1997).

Nos anos de 1990 iniciou-se a substituição do sistema de refrigeração com R12 pelo sistema com R134a utilizado atualmente. Devido à incompatibilidade de lubrificantes e vedações entre os sistemas R12 e R134a, diversas modificações foram feitas para evitar a contaminação dos sistemas devido ao uso do refrigerante incorreto, principalmente na área de serviços e conversão de sistemas, demandando diversas normas específicas para o setor como por exemplo a SAE-J639 (SAE, 1999a), SAEJ2210 (SAE, 1999b), SAE-J1732 (SAE, 1998) e SAE-J2197 (SAE, 1997).

Nos anos recentes os estudos sobre o efeito estufa e o potencial de aquecimento global reabriram a discussão sobre o fluido refrigerante utilizado nos 
sistemas de ar condicionado, já que o potencial de aquecimento global do R134a é bem maior do que por exemplo o gás carbônico. Muitos cientistas no mundo todo trabalham no momento estudando qual seria o melhor substituto para o R134a, se é que a substituição é realmente a melhor opção para a questão do aquecimento global.

\subsection{OBJETIVOS E OBJETO DE ESTUDO}

O sistema de climatização para aplicações automotivas tem características particulares, diferentes de sistemas de climatização para outros ambientes. A obtenção de uma condição de conforto térmico em um automóvel é uma tarefa algo mais complexa do que em uma edificação. Em uma aplicação automotiva a variação das condições de operação é bastante significativa, como por exemplo a carga solar (insolação) que é imposta, a velocidade do veículo, umidade do ar, as temperaturas interna e externa, variação do número e da posição dos ocupantes no interior do veículo, diferentes regimes de rotação e carga do motor, etc. O sistema de climatização deve, portanto, ser projetado para funcionar sob todas estas condições, que implicam em variações significativas de carga térmica e, conseqüentemente, de capacidades de refrigeração.

O projeto adequado de um sistema de climatização que atenda aos requerimentos de carga térmica começa com o dimensionamento do ciclo de refrigeração e é complementado com o sistema de distribuição de ar, sistemas de controle, etc.

No presente trabalho o objetivo é o projeto e a simulação de um ciclo de refrigeração que atenda aos requerimentos de carga térmica para um automóvel compacto em um ensaio específico realizado em túnel de vento. A partir da carga térmica, o ciclo de refrigeração é dimensionado seguindo-se o procedimento de projeto, que engloba o dimensionamento dos componentes principais como compressor, condensador, evaporador e o dispositivo de expansão. Os resultados dos cálculos teóricos são comparados com o dimensionamento do veículo real, permitindo se chegar a conclusões sobre o projeto. A avaliação do desempenho do sistema projetado é realizada por meio de um procedimento de simulação proposto, e os resultados comparados com os do veículo testado.

O objeto de estudo é o sistema de refrigeração de um veículo compacto de quatro portas de fabricação nacional, submetido a um teste de desempenho do sistema em um túnel de vento. 


\subsection{ORGANIZAÇÃO DO TRABALHO}

Inicialmente, no capítulo 2 são apresentadas algumas relações entre conforto térmico e segurança veicular. Alguns "requerimentos" do sistema de climatização e conforto térmico são objeto de regulamentação. É apresentada uma revisão sobre a teoria de conforto térmico em ambientes climatizados e a determinação de condições de conforto térmico pelas normas ISO 7730 (ISO, 1994) e ASHRAE 55 (ASHRAE, 2004). Em seguida são apresentados os avanços na avaliação do conforto térmico em veículos automotivos, como o uso de modelos matemáticos mais sofisticados, operação em regime transitório e uso de manequins térmicos.

O capítulo 3 trata da carga térmica e dos ganhos de calor para o projeto do sistema de refrigeração na condição de ensaio em túnel de vento. São analisados os ganhos de calor através da envoltória do veículo e a variação da energia interna (fontes internas de calor). Os resultados dos cálculos dos ganhos de calor são comparados com a carga térmica real do veículo, permitindo-se chegar a conclusões sobre a hipótese de regime permanente e sobre a diferença entre ganho de calor e carga térmica em um veículo automotivo.

O capítulo 4 apresenta a teoria do sistema de refrigeração por compressão de vapor com considerações quanto aos balanços de energia, o coeficiente de performance e a escolha do refrigerante. Também apresenta uma descrição dos componentes do sistema: a sua construção mecânica, funcionamento e características.

Em seguida o capítulo 5 trata do procedimento de projeto do sistema de refrigeração de modo que o mesmo seja capaz de atender à carga térmica para a condição de ensaio, calculada no capítulo 3. O procedimento de projeto é apresentado na forma de um fluxograma e os resultados são comparados com o dimensionamento do veículo real para verificar a sua validade.

Por fim, no capítulo 6 é apresentado um procedimento para a simulação do desempenho do sistema trabalhando sob diferentes condições de operação. Este capítulo apresenta um fluxograma para o cálculo iterativo do ponto de equilíbrio e os resultados da análise de desempenho são comparados com os do veículo real permitindo-se chegar a conclusões sobre o modelo utilizado. 


\section{CAPÍTULO 2 CONFORTO TÉRMICO E SEGURANÇA}

Diversos aspectos de conforto térmico em automóveis estão relacionados com questões da segurança veicular, de tal forma que há regulamentações específicas sobre o assunto estabelecidas pelas autoridades de transporte de cada país ou região, como a EEC 78/317 na Comunidade Européia e a FMVSS-103 nos Estados Unidos (Bosch, 2000).

Sobre os primeiros automóveis, em Ávila (2002) é lembrado que “... dirigir carros abertos em dias ensolarados, era marcante prazer que os carros proporcionavam a $15 \mathrm{~km} / \mathrm{h}$, apresentando, como único item de conforto, um pára-brisa, para proteger o motorista contra eventuais insetos ou elementos estranhos que pudessem vir com o vento". Estabelecendo assim uma relação básica entre segurança dos ocupantes e conforto. O autor ainda descreve que à medida que os automóveis ganharam cabinas fechadas, outros métodos de prover conforto térmico foram sendo desenvolvidos, como janelas basculantes, quebra-ventos e entradas de ar. Nos dias de hoje os veículos são equipados com sistemas de ventilação forçada, aquecimento e refrigeração.

Um aspecto importante da segurança veicular relacionado com o conforto térmico é o desembaçamento e descongelamento dos vidros. Atualmente a maioria dos países têm legislações específicas que exigem sistemas capazes de garantir a transparência dos vidros. A solução geralmente adotada nos veículos atuais é utilizar os sistemas de aquecimento do ar da cabina para descongelar e desembaçar o pára-brisas e os vidros laterais, e um sistema de aquecimento elétrico para o vidro traseiro. Os fenômenos de embaçamento e formação de gelo nos vidros ocorrem com freqüência nos dias frios, quando a temperatura dos vidros está abaixo da temperatura de orvalho ou abaixo da temperatura de congelamento da água. Desta forma, o uso de ar aquecido mantém a transparência dos vidros ao mesmo tempo em que eleva a temperatura da cabina a níveis confortáveis. As normas SAE-J902 (SAE, 1999c) e SAE-J953 (SAE, 1999d) tratam dos sistemas de descongelamento e desembaçamento do pára-brisas e do vidro traseiro respectivamente. O embaçamento também ocorre em dias quentes e úmidos, e neste caso o uso do sistema de refrigeração e desumidificação provém conforto enquanto mantém a transparência dos vidros.

Outro aspecto correlaciona o conforto térmico com o nível de atenção dos motoristas. Uma pesquisa financiada pela Nissan Motor Netherland BV e realizada pelo Departamento de Psicologia da Universidade de Amsterdam afirma que as melhores 
temperaturas para quem está dirigindo um automóvel estão entre $18,5^{\circ} \mathrm{C}$ e $21,5^{\circ} \mathrm{C}$, ligeiramente abaixo da condição de conforto, pois o motorista fica mais atento por estar sentindo um pouco de frio.

As condições de segurança ficam ameaçadas sob temperaturas extremas. A exposição excessiva a um ambiente quente ou frio pode levar ao "stress térmico" (ISO 7243, 1989; ISO 7933, 1989), resultado de condições microclimáticas desfavoráveis que requerem a intervenção excessiva do sistema termorregulador. A exposição ao calor excessivo causa elevação da temperatura do corpo e sonolência, podendo levar ao colapso físico.

A exposição ao frio excessivo pode causar redução da temperatura corporal (hipotermia). Steen (2001) destaca como sinais de hipotermia: a perda de memória, desorientação, incoerência, fala embaralhada, tontura, exaustão e tremor descontrolado. No mesmo artigo, Steen (2001) afirma que 70\% dos acidentes de automóvel resultando em morte nos Estados Unidos são relacionados com gelo ou neve. Desses, 25\% são atribuídos a pessoas que ficam presas em seus veículos em tempestades de neve. Entre outras orientações, a Cruz Vermelha americana recomenda nesses casos que os ocupantes fiquem dentro do veículo e liguem o motor e o sistema de aquecimento por 10 minutos a cada hora. Essa é uma situação de risco bastante improvável em regiões de clima quente como o Brasil, mas que justifica a obrigatoriedade de os veículos estarem equipados com sistema de aquecimento na maioria dos países.

A qualidade do ar no interior de um veículo também é um aspecto do conforto térmico associado à segurança. A norma ASHRAE 62 (ASHRAE, 1989) estabelece que a quantidade de ar externo de renovação deve ser de 7 1/s por pessoa. A renovação de ar é necessária para que haja eliminação de odores e para manter a concentração de gás carbônico em níveis aceitáveis $\left(<700\right.$ ppm). O excesso de $\mathrm{CO}_{2}$ causa sonolência. Os sistemas de filtragem, por sua vez, removem partículas de poeira a fim de garantir a qualidade do ar.

\subsection{CONFORTO TÉRMICO}

Conforto térmico é definido pela norma ASHRAE 55 (ASHRAE, 2004) como sendo "um estado de espírito que reflete satisfação com o ambiente térmico que envolve a pessoa”. O metabolismo do corpo humano converte continuamente a energia dos alimentos em trabalho e calor, e o calor deve ser dissipado pelo corpo para que a sua temperatura interna permaneça dentro de limites estreitos para evitar o desconforto e o stress térmico. 
Para o propósito da engenharia a sensação de conforto deve ser convertida e expressa em quantidades físicas mensuráveis (Nilsson, 2004). Esta correlação tem sido obtida com sucesso por meio de métodos como o de Fanger (Fanger, 1972) para ambientes relativamente homogêneos e em regime permanente.

O modelo desenvolvido por Fanger (1972) é um dos mais utilizados para a avaliação de conforto térmico. O modelo de Fanger é baseado no balanço de energia do corpo humano (Figura 2-1). Na Figura 2.1 é utilizado o termo "calor gerado" (ao invés de variação de energia interna), por ser termo normalmente utilizado para se referir à diferença entre o metabolismo e o trabalho gerado pelos músculos (M-W).

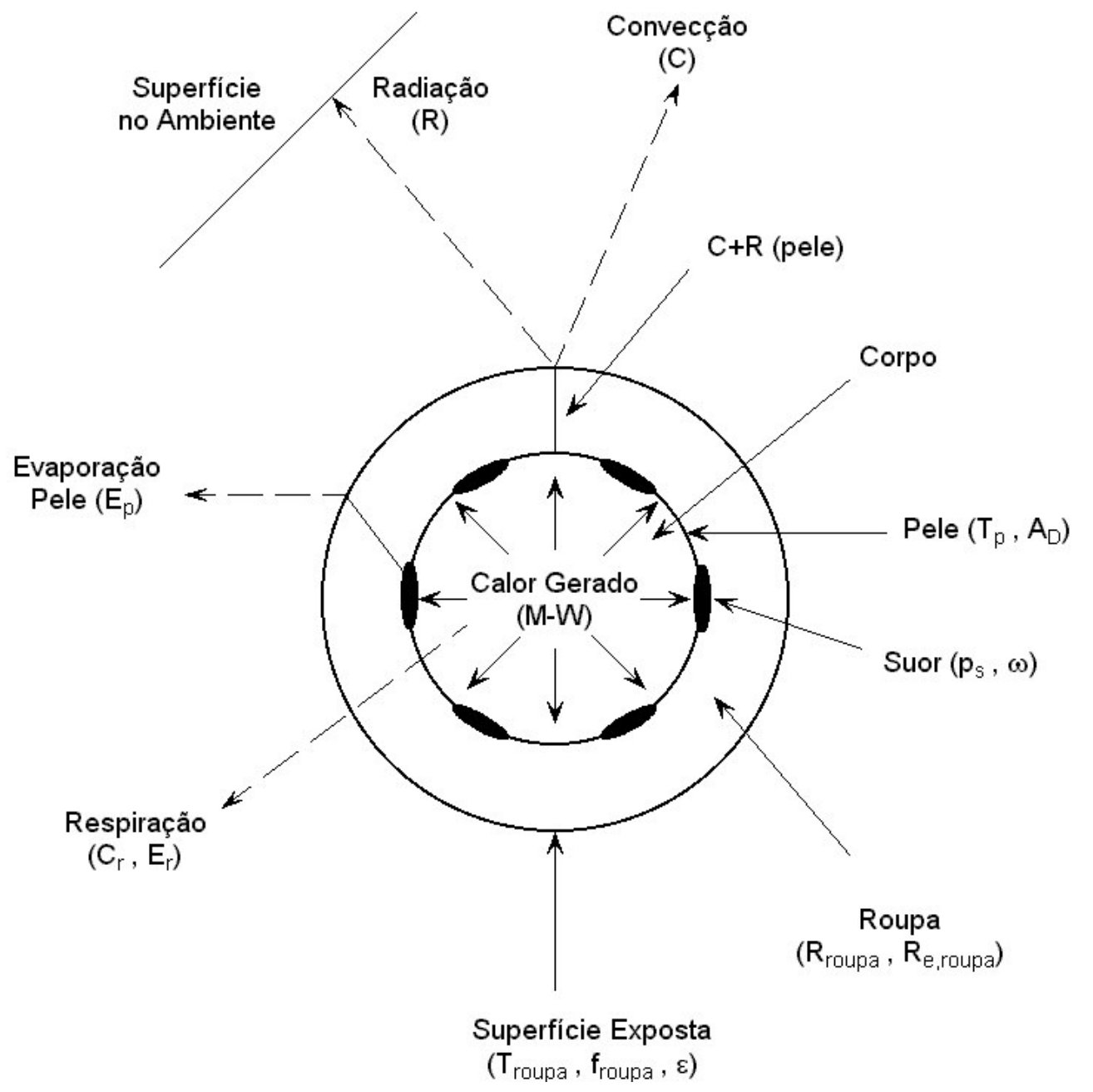

Figura 2-1 Modelo cilíndrico da interação térmica: corpo humano - meio envolvente (ASHRAE, 2001)

Da $1^{\text {a }}$ Lei da Termodinâmica, em regime permanente, o balanço de energia para o corpo humano, é dado pela equação 2.1: 


$$
M-\dot{W}=\left(C+R+C_{R}\right)+\left(E_{E S}+E_{D I F}+E_{R}\right) \quad\left[\mathrm{W} / \mathrm{m}^{2}\right]
$$

Verifica-se na Eq. (2.1) que o calor "produzido pelo corpo" (descontado-se o trabalho $\dot{W}$ realizado pelo corpo), $\mathrm{M}-\mathrm{W}$, deve ser igual às trocas de calor com o ambiente para que se possa obter condições de conforto térmico $\left(1^{\mathrm{a}}\right.$. condição de conforto térmico: condição de neutralidade térmica).

Essas trocas de calor ocorrem devido à diferença de temperaturas entre a pele e o meio onde se encontra a pessoa, por meio dos mecanismos de convecção e radiação $(\mathrm{C}+\mathrm{R})$, e pela perda de calor convectivo por meio da respiração $\left(C_{R}\right)$. Também ocorrem pelo transporte de massa por meio da evaporação de suor pela pele $\left(\mathrm{E}_{\mathrm{ES}}\right)$, da difusão de vapor d'água pela pele $\left(\mathrm{E}_{\mathrm{DIF}}\right)$ e pela evaporação por meio da respiração $\left(\mathrm{E}_{\mathrm{R}}\right)$.

Do balanço de energia do corpo humano e aplicando-se as equações que descrevem os mecanismos de transferência de calor, são obtidas as variáveis de conforto térmico:

a) Parâmetros individuais: o tipo de atividade (M, W) e a isolação da vestimenta $\left(I_{R}\right)$;

b) Parâmetros do ambiente: a temperatura do ar ambiente $\left(\mathrm{T}_{\mathrm{AR}}\right)$; a temperatura radiante média $\left(\bar{T}_{r}\right)$; a velocidade do ar $\left(\mathrm{V}_{\mathrm{AR}}\right)$ e a umidade relativa do ar $(\phi)$.

$\mathrm{O}$ metabolismo, função da atividade, normalmente é expresso em termos de unidades de metabolismo $\mathrm{MET}^{1}$. A vestimenta representa uma resistência à troca de calor entre o corpo e o meio, e portanto afeta o equilíbrio térmico. A resistência térmica da roupa $\left(\mathrm{I}_{\mathrm{R}}\right)$ é normalmente representada pela unidade $\mathrm{CLO}^{2}$.

Uma vez realizado o balanço térmico do corpo humano, Fanger (1972) realizou ensaios com pessoas para a determinação das outras duas variáveis de conforto térmico: a temperatura da pele, $\mathrm{T}_{\mathrm{p}}\left(2^{\mathrm{a}}\right.$. condição de conforto térmico) e o nível de suor, $\mathrm{E}_{\mathrm{ES}}\left(3^{\mathrm{a}}\right.$. condição de conforto térmico), função da atividade (metabolismo). Estas condições de conforto térmico são apresentadas nas eqs. 2.2 e 2.3 .

$$
\begin{array}{ll}
\mathrm{T}_{\mathrm{p}}=35,7-0,0275(\mathrm{M}-\mathrm{W}) & {\left[{ }^{\circ} \mathrm{C}\right]} \\
\mathrm{E}_{\mathrm{ES}}=0,42(\mathrm{M}-\mathrm{W}-58,2) & {\left[\mathrm{W} / \mathrm{m}^{2}\right]}
\end{array}
$$

Inserindo as Eqs. 2.2 e 2.3 na Eq. (2.1), juntamente com as equações de transferência de

\footnotetext{
${ }^{1} 1 \mathrm{MET}=58,2 \mathrm{~W} / \mathrm{m}^{2}$ (atividade sedentária)

$21 \mathrm{CLO}=0,155 \mathrm{~m}^{2} \mathrm{C} / \mathrm{W}$ (vestimenta típica de inverno, pesada)
} 
calor, obtém-se a equação de conforto de Fanger (Fanger, 1972). Uma vez obtida a equação de conforto térmico, Fanger continuou os seus ensaios e obteve um modelo baseado no voto das pessoas com relação ao ambiente térmico em que se encontravam, o voto médio estimado (PMV- Predicted Mean Vote), que variava de muito frio (-3) ao muito quente $(+3)$.

A Tab. 2.1 apresenta o PMV com o respectivo nível de insatisfação das pessoas (PPD - Predicted Percentage of Dissatisfied), onde se verifica que mesmo com PMV igual a zero (condição de neutralidade térmica) existem 5\% de insatisfeitos.

Tabela 2-1 Escala de sensação térmica

\begin{tabular}{|lccccccc|}
\hline \multicolumn{7}{|c|}{ Escala de sensação térmica } \\
\hline PMV & muito frio & frio & $\begin{array}{c}\text { leve sensação } \\
\text { de frio }\end{array}$ & neutro & $\begin{array}{c}\text { leve sensação } \\
\text { de calor }\end{array}$ & quente & muito quente \\
\hline PPD & $100 \%$ & $78 \%$ & $26 \%$ & $5 \%$ & $26 \%$ & $78 \%$ & $100 \%$ \\
\hline
\end{tabular}

O trabalho de Fanger (Fanger, 1972) é a base da norma ISO 7730 (ISO, 1994) de conforto térmico. Uma vez que o cálculo do voto médio estimado é um pouco trabalhoso, Fanger (1972) e a ISO 7730 (ISO, 1994) apresentam tabelas, como aquela apresentada na Tab. 2.2, e uma rotina para utilização em microcomputador, que permitem determinar o PMV para diferentes atividades, tipos de vestimenta e condições ambientais.

A ASHRAE 55 (ASHRAE, 2004) também apresenta gráficos para a determinação das condições de conforto térmico em ambientes condicionados - as Cartas de Conforto da ASHRAE. A Fig. 2.2 apresenta uma carta psicrométrica com a zona de conforto representada pela área hachurada.

Verifica-se na Tab. 2.2 e na Fig. 2.2 que os resultados são apresentados em função da temperatura operativa, $\mathrm{T}_{\mathrm{o}}{ }^{3}$, que é uma função da temperatura média radiante, $\bar{T}_{r}$, e da temperatura do ar, $\mathrm{T}_{\mathrm{AR}}$, dado pela equação $2.4^{4}$ :

$$
T_{o}=a \cdot T_{a}+(1-a) \cdot \bar{T}_{r}
$$

\footnotetext{
${ }^{3} \mathrm{~T}_{\mathrm{o}}=$ temperatura operativa $\left({ }^{\circ} \mathrm{C}\right)$ : a temperatura de um meio imaginário (envolvendo ar e superfícies) com o qual a pessoa troca a mesma quantidade de calor por convecção e radiação que aquela trocada com o meio real.

${ }^{4}$ ANSI/ASHRAE 55 (ASHRAE,2004) e ISO 7730 (ISO,1994).
} 
Tabela 2-2 Determinação do voto médio estimado - PMV (ISO 7730, 1994) Atividade sedentária $(\mathrm{MET}=1.0)$ e umidade relativa do ar de $50 \%$

\begin{tabular}{|c|c|c|c|c|c|c|c|c|c|c|}
\hline \multicolumn{2}{|c|}{ Vestimenta } & \multirow{2}{*}{$\begin{array}{c}\text { Temperatura } \\
\text { Operativa } \\
{ }^{\circ} \mathrm{C}\end{array}$} & \multicolumn{8}{|c|}{ Velocidade Relativa do ar $-\mathrm{m} / \mathrm{s}$} \\
\hline CLO & $\frac{\mathbf{m}^{2_{0}} \mathrm{C}}{W}$ & & $<0.10$ & 0.10 & 0.15 & 0.20 & 0.30 & 0.40 & 0.50 & 1.00 \\
\hline 0 & 0 & $\begin{array}{l}26 \\
27 \\
28 \\
29 \\
30 \\
31 \\
32 \\
33\end{array}$ & $\begin{array}{r}-1.62 \\
-1.00 \\
-0.39 \\
0.21 \\
0.80 \\
1.39 \\
1.96 \\
2.50\end{array}$ & $\begin{array}{r}-1.62 \\
-1.00 \\
-0.42 \\
0.13 \\
0.68 \\
1.25 \\
1.83 \\
2.41\end{array}$ & $\begin{array}{r}-1.96 \\
-1.36 \\
-0.76 \\
-0.15 \\
0.45 \\
1.08 \\
1.71 \\
2.34\end{array}$ & $\begin{array}{r}-2.34 \\
-1.69 \\
-1.05 \\
-0.39 \\
0.26 \\
0.94 \\
1.61 \\
2.29\end{array}$ & & & & \\
\hline 0.25 & 0.039 & $\begin{array}{l}24 \\
25 \\
26 \\
27 \\
28 \\
29 \\
30 \\
31\end{array}$ & $\begin{array}{r}-1.52 \\
-1.05 \\
-0.58 \\
-0.12 \\
0.34 \\
0.80 \\
1.25 \\
1.71\end{array}$ & $\begin{array}{r}-1.52 \\
-1.05 \\
-0.61 \\
-0.17 \\
0.27 \\
0.71 \\
1.15 \\
1.61\end{array}$ & $\begin{array}{r}-1.80 \\
-1.33 \\
-0.87 \\
-0.40 \\
0.07 \\
0.54 \\
1.02 \\
1.51\end{array}$ & $\begin{array}{r}-2.06 \\
-1.57 \\
-1.08 \\
-0.58 \\
-0.09 \\
0.41 \\
0.91 \\
1.43\end{array}$ & $\begin{array}{r}-2.47 \\
-1.94 \\
-1.41 \\
-0.87 \\
-0.34 \\
0.20 \\
0.74 \\
1.30\end{array}$ & $\begin{array}{r}-2.24 \\
-1.67 \\
-1.10 \\
-0.53 \\
0.04 \\
0.61 \\
1.20\end{array}$ & $\begin{array}{r}-2.48 \\
-1.89 \\
-1.29 \\
-0.70 \\
-0.10 \\
0.50 \\
1.12\end{array}$ & $\begin{array}{r}-2.66 \\
-1.97 \\
-1.28 \\
-0.58 \\
0.11 \\
0.83\end{array}$ \\
\hline 0.50 & 0.078 & $\begin{array}{l}23 \\
24 \\
25 \\
26 \\
27 \\
28 \\
29 \\
30\end{array}$ & $\begin{array}{r}-1.10 \\
-0.72 \\
-0.34 \\
0.04 \\
0.42 \\
0.80 \\
1.17 \\
1.54\end{array}$ & $\begin{array}{r}-1.10 \\
-0.74 \\
-0.38 \\
-0.01 \\
0.35 \\
0.72 \\
1.08 \\
1.45\end{array}$ & $\begin{array}{r}-1.33 \\
-0.95 \\
-0.56 \\
-0.18 \\
0.20 \\
0.59 \\
0.98 \\
1.37\end{array}$ & $\begin{array}{r}-1.51 \\
-1.11 \\
-0.71 \\
-0.31 \\
0.09 \\
0.49 \\
0.90 \\
1.30\end{array}$ & $\begin{array}{r}-1.78 \\
-1.36 \\
-0.94 \\
-0.51 \\
-0.08 \\
0.34 \\
0.77 \\
1.20\end{array}$ & $\begin{array}{r}-1.99 \\
-1.55 \\
-1.11 \\
-0.66 \\
-0.22 \\
0.23 \\
0.68 \\
1.13\end{array}$ & $\begin{array}{r}-2.16 \\
-1.70 \\
-1.25 \\
-0.79 \\
-0.33 \\
0.14 \\
0.60 \\
1.06\end{array}$ & $\begin{array}{r}-2.22 \\
-1.71 \\
-1.19 \\
-0.68 \\
-0.17 \\
0.34 \\
0.86\end{array}$ \\
\hline 0.75 & 0.118 & $\begin{array}{l}21 \\
22 \\
23 \\
24 \\
25 \\
26 \\
27 \\
28\end{array}$ & $\begin{array}{r}-1.11 \\
-0.79 \\
-0.47 \\
-0.15 \\
0.17 \\
0.49 \\
0.81 \\
1.12\end{array}$ & $\begin{array}{r}-1.11 \\
-0.81 \\
-0.50 \\
-0.19 \\
0.12 \\
0.43 \\
0.74 \\
1.05\end{array}$ & $\begin{array}{r}-1.30 \\
-0.96 \\
-0.66 \\
-0.33 \\
-0.01 \\
0.31 \\
0.64 \\
0.96\end{array}$ & $\begin{array}{r}-1.44 \\
-1.11 \\
-0.78 \\
-0.44 \\
-0.11 \\
0.23 \\
0.56 \\
0.90\end{array}$ & $\begin{array}{r}-1.66 \\
-1.31 \\
-0.96 \\
-0.61 \\
-0.28 \\
0.09 \\
0.45 \\
0.80\end{array}$ & $\begin{array}{r}-1.82 \\
-1.46 \\
-1.09 \\
-0.73 \\
-0.37 \\
0.00 \\
0.36 \\
0.73\end{array}$ & $\begin{array}{r}-1.95 \\
-1.58 \\
-1.20 \\
-0.83 \\
-0.46 \\
-0.08 \\
0.29 \\
0.67\end{array}$ & $\begin{array}{r}-2.36 \\
-1.95 \\
-1.55 \\
-1.14 \\
-0.74 \\
-0.33 \\
0.08 \\
0.48\end{array}$ \\
\hline 1.00 & 0.155 & $\begin{array}{l}20 \\
21 \\
22 \\
23 \\
24 \\
25 \\
26 \\
27\end{array}$ & $\begin{array}{r}-0.85 \\
-0.57 \\
-0.30 \\
-0.02 \\
0.26 \\
0.53 \\
0.81 \\
1.08\end{array}$ & $\begin{array}{r}-0.87 \\
-0.60 \\
-0.33 \\
-0.07 \\
0.20 \\
0.48 \\
0.75 \\
1.02\end{array}$ & $\begin{array}{r}-1.02 \\
-0.74 \\
-0.46 \\
-0.18 \\
0.10 \\
0.38 \\
0.66 \\
0.95\end{array}$ & $\begin{array}{r}-1.13 \\
-0.84 \\
-0.55 \\
-0.27 \\
0.02 \\
0.31 \\
0.60 \\
0.89\end{array}$ & $\begin{array}{r}-1.29 \\
-0.99 \\
-0.69 \\
-0.39 \\
-0.09 \\
0.21 \\
0.51 \\
0.81\end{array}$ & $\begin{array}{r}-1.41 \\
-1.11 \\
-0.80 \\
-0.49 \\
-0.18 \\
0.13 \\
0.44 \\
0.75\end{array}$ & $\begin{array}{r}-1.51 \\
-1.19 \\
-0.88 \\
-0.56 \\
-0.25 \\
0.07 \\
0.39 \\
0.71\end{array}$ & $\begin{array}{r}-1.81 \\
-1.47 \\
-1.13 \\
-0.79 \\
-0.46 \\
-0.12 \\
0.22 \\
0.56\end{array}$ \\
\hline 1.50 & 0.233 & $\begin{array}{l}14 \\
16 \\
18 \\
20 \\
22 \\
24 \\
26 \\
28\end{array}$ & $\begin{array}{r}-1.36 \\
-0.94 \\
-0.52 \\
-0.09 \\
0.35 \\
0.79 \\
1.23 \\
1.67\end{array}$ & $\begin{array}{r}-1.36 \\
-0.95 \\
-0.54 \\
-0.13 \\
0.30 \\
0.74 \\
1.18 \\
1.62\end{array}$ & $\begin{array}{r}-1.48 \\
-1.07 \\
-0.64 \\
-0.22 \\
0.23 \\
0.68 \\
1.13 \\
1.56\end{array}$ & $\begin{array}{r}-1.58 \\
-1.15 \\
-0.72 \\
-0.28 \\
0.18 \\
0.63 \\
1.09 \\
1.56\end{array}$ & $\begin{array}{r}-1.72 \\
-1.27 \\
-0.82 \\
-0.37 \\
0.10 \\
0.57 \\
1.04 \\
1.52\end{array}$ & $\begin{array}{r}-1.82 \\
-1.36 \\
-0.90 \\
-0.44 \\
0.04 \\
0.52 \\
1.01 \\
1.48\end{array}$ & $\begin{array}{r}-1.89 \\
-1.43 \\
-0.96 \\
-0.49 \\
0.00 \\
0.49 \\
0.98 \\
1.47\end{array}$ & $\begin{array}{r}-2.12 \\
-1.63 \\
-1.14 \\
-0.65 \\
-0.14 \\
0.37 \\
0.89 \\
1.40\end{array}$ \\
\hline 2.00 & 0.310 & $\begin{array}{l}10 \\
12 \\
14 \\
16 \\
18 \\
20 \\
22 \\
24\end{array}$ & $\begin{array}{r}-1.38 \\
-1.03 \\
-0.68 \\
-0.32 \\
0.03 \\
0.40 \\
0.76 \\
1.13\end{array}$ & $\begin{array}{r}-1.39 \\
-1.05 \\
-0.70 \\
-0.35 \\
-0.00 \\
0.36 \\
0.72 \\
1.09\end{array}$ & $\begin{array}{r}-1.49 \\
-1.14 \\
-0.79 \\
-0.43 \\
-0.07 \\
0.30 \\
0.67 \\
1.05\end{array}$ & $\begin{array}{r}-1.56 \\
-1.21 \\
-0.85 \\
-0.48 \\
-0.11 \\
0.26 \\
0.54 \\
1.02\end{array}$ & $\begin{array}{r}-1.67 \\
-1.30 \\
-0.93 \\
-0.56 \\
-0.18 \\
0.20 \\
0.59 \\
0.98\end{array}$ & $\begin{array}{r}-1.74 \\
-1.37 \\
-0.99 \\
-0.61 \\
-0.23 \\
0.16 \\
0.55 \\
0.95\end{array}$ & $\begin{array}{r}-1.80 \\
-1.42 \\
-1.04 \\
-0.65 \\
-0.26 \\
0.13 \\
0.53 \\
0.93\end{array}$ & $\begin{array}{r}-1.96 \\
-1.57 \\
-1.17 \\
-0.77 \\
-0.37 \\
0.04 \\
0.45 \\
0.87\end{array}$ \\
\hline
\end{tabular}

OBS: 1) Valores de PMV em torno de zero indicam condições de conforto térmico.

2) Valores de CLO igual a 0,5 representam uma vestimenta leve de verão (calça comprida com camisa de mangas curtas), enquanto valores de CLO igual a 1,0 representam uma vestimenta pesada de inverno. 
onde a constante $\boldsymbol{a}$ varia de acordo com a velocidade do ar $\left(V_{A R}\right)$ :

$\begin{array}{cccc}V_{A R}(\mathrm{~m} / \mathrm{s}) & 0-0,2 & 0,2-0,6 & 0,6-1,0 \\ a & 0,5 & 0,6 & 0,7\end{array}$

A norma ISO 7726 (ISO, 1998) apresenta procedimentos de medição e métodos para a obtenção das variáveis ambientais: velocidade média do ar, $\mathrm{V}_{\mathrm{AR}}$, temperatura média radiante, $\bar{T}_{r}$, da temperatura do ar, $\mathrm{T}_{\mathrm{AR}}$ e umidade do ar: umidade absoluta, $\omega$, e umidade relativa, $\phi$.

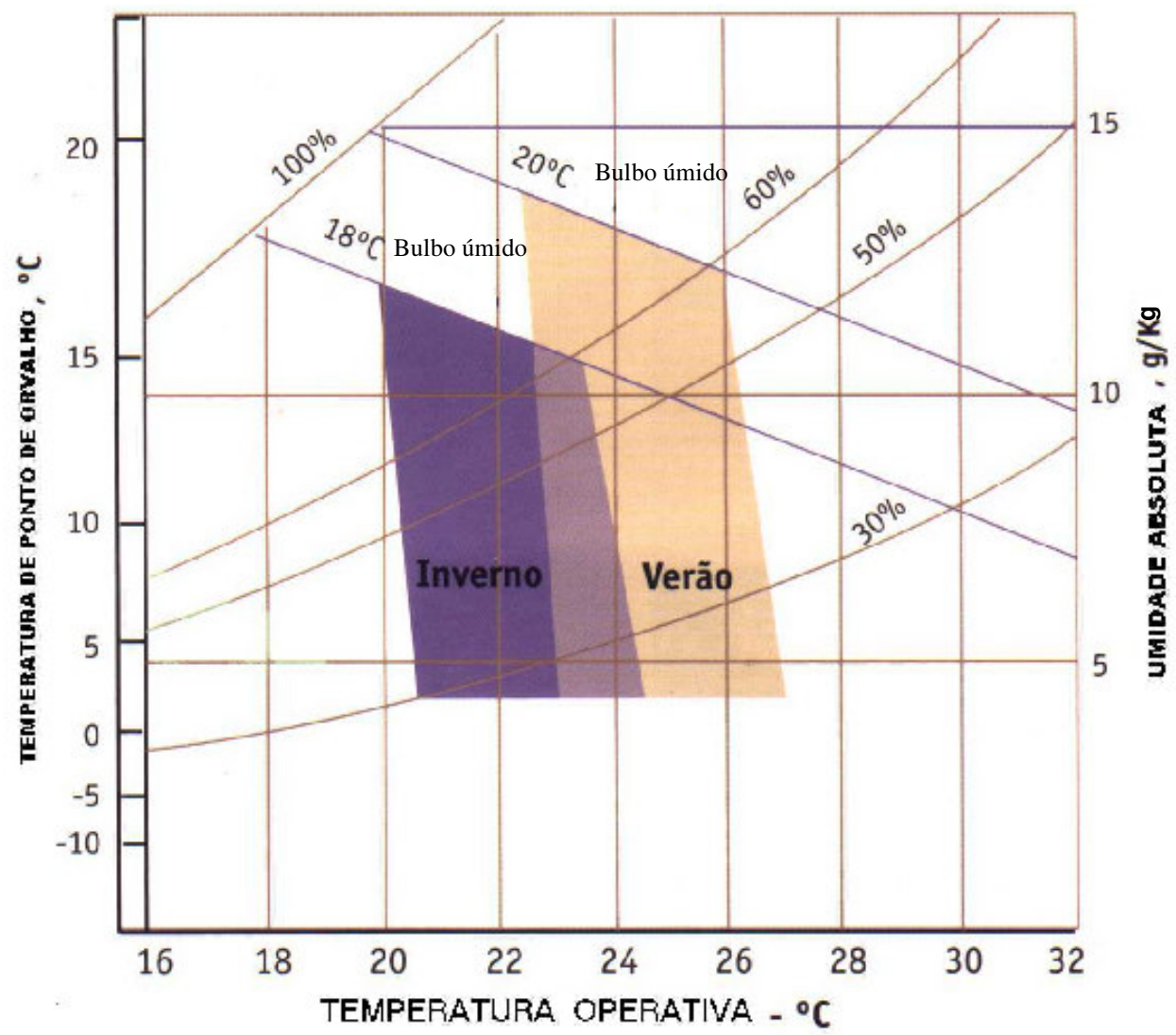

Figura 2-2 Diagrama psicrométrico com a indicação da zona de conforto em ambientes climatizados segundo a norma ASHRAE 55 (ASHRAE, 2004).

Os métodos da ISO 7730 (ISO, 1994) e ASHRAE 55 (ASHRAE, 2004) permitem a determinação de condições gerais de conforto térmico utilizadas como diretrizes em projetos de sistemas de climatização (veicular ou de outro ambiente climatizado qualquer) na determinação da carga térmica. 


\subsection{DESCONFORTO TÉRMICO LOCAL}

As condições de conforto térmico de Fanger (ISO 7730) e da ASHRAE 55 foram obtidas para o corpo como um todo. Contudo, uma pessoa pode sentir neutralidade térmica (PMV=0), mas pode não estar confortável se uma parte do corpo está "quente" e uma outra "fria". Portanto, para se ter condições de conforto é necessário também que não haja desconforto local (quente ou frio) para qualquer parte do corpo.

Este desconforto térmico local pode ser causado por:

$>$ Correntes de ar ('draft" ou "draught");

$>$ Assimetria de radiação;

$>$ Diferença de temperatura vertical do ar entre os pés e a cabeça;

$>$ Diferença de temperatura entre os pés e o piso.

Limites máximos previstos para cada uma das causas de desconforto térmico local também são apresentados nas normas ASHRAE 55 (ASHRAE, 2004) e ISO 7730 (ISO,1994).

\subsection{AVALIAÇÃO DE CONFORTO TÉRMICO EM VEÍCULOS AUTOMOTIVOS}

Nos veículos automotivos o estudo do conforto térmico é significativamente mais complexo do que em ambientes que podem ser considerados homogêneos, como em edificações.

Dentro de um automóvel, por exemplo, ocorrem gradientes de temperatura e velocidade do ar significativos, com grandes assimetrias de temperatura e transientes durante o processo de resfriamento e aquecimento. Em um automóvel as saídas de ar geralmente são pequenas e o espaço confinado prejudica a circulação do ar. Além disso, há uma grande incidência solar e uma isolação adicional devido aos bancos. Por esses motivos, o uso dos índices PMV (ISO 7730) ou de cartas da ASHRAE não são os mais apropriados (Madsen et al, 1986; Hosni et al, 2003a; Nilsson, 2004).

Em contrapartida, o automóvel oferece aos ocupantes controles de velocidade, direcionamento e temperatura do ar, permitindo ajustes localizados; o que é menos comum em edificações (Hosni et al, 2003a).

Alguns pesquisadores têm associado o controle das condições de conforto térmico com a temperatura da pele (uma das condições de conforto térmico de Fanger). Wei e Dage 
(1995) apresentaram um controlador automático para aplicação em veículos automotivos baseado na leitura da temperatura da pele dos ocupantes através de um sensor infravermelho. Os resultados experimentais mostraram que a resposta do sistema é mais rápida ao incluir no controlador a informação da temperatura da pele do que simplesmente controlar a temperatura do ar. Os resultados obtidos também mostraram correlação entre a temperatura medida na pele dos ocupantes com o voto relativo à sensação térmica dos mesmos.

Furuse e Komoriya (1997) realizaram um experimento simulando a cabina de um automóvel e apresentaram um modelo de redes neurais para calcular a sensação de conforto e a sensação térmica total e parcial. O modelo de redes neurais apresentado usa informações da temperatura da pele medidas em 15 pontos diferentes do corpo. Os autores concluíram que o modelo de redes neurais pode ser adequado para presumir a sensação térmica dos passageiros. O estudo não considerou radiação solar e alta umidade do ar.

$\mathrm{Na}$ busca de uma melhor avaliação do conforto térmico em ambientes não homogêneos, como o automóvel, outros modelos mais complexos para representar o sistema de regulação térmica do corpo humano têm sido elaborados.

Com o intuito de avaliar a condição de conforto em regime transitório, Brown e Jones (1997) utilizaram um modelo de conforto térmico para regime transitório desenvolvido na Universidade do Estado de Kansas (EUA). Estes pesquisadores desenvolveram experimentos em veículos para demonstrar a correlação do modelo com o voto de indivíduos submetidos a diversas condições de transientes térmicos durante 45 minutos (típicos de aquecimento no inverno e de resfriamento no verão). O modelo foi alimentado com informações coletadas por vários sensores de temperatura, umidade relativa e velocidade do ar, instalados em um painel de madeira chamado de stickman (Figura 2-3) colocado nos assentos dianteiros e também com a temperatura da pele dos indivíduos submetidos aos testes. Os resultados mostraram que o modelo apresenta boa correlação com o voto médio dos indivíduos durante os 10 a 15 minutos iniciais, porém tendem a divergir do voto subjetivo após este intervalo.

Hosni et al (2003a; 2003b) investigaram o conforto térmico sob condições fortemente transientes, propondo avanços ao modelo de Brown e Jones (1997). Um veículo foi instalado em uma câmara climatizada a fim de simular condições de inverno e verão. A câmara foi provida de lâmpadas para simular uma carga solar de $1000 \mathrm{~W} / \mathrm{m}^{2}$ (condição de verão). Dispositivos dotados de globos para medição da temperatura radiante, temperatura e umidade do ar e velocidade do ar foram utilizados para coletar dados de cada ensaio. 
Estes dispositivos simulam a posição dos ocupantes dentro do veículo e as informações foram coletadas em diversos segmentos do corpo. Outros sensores de temperatura foram instalados no veículo no nível da respiração dos ocupantes e nas saídas de ar. Foram conduzidos no mesmo veículo, sob as mesmas condições, ensaios subjetivos onde os indivíduos registraram a sensação térmica usando uma escala de 9 pontos (Hosni et al, 2003a).

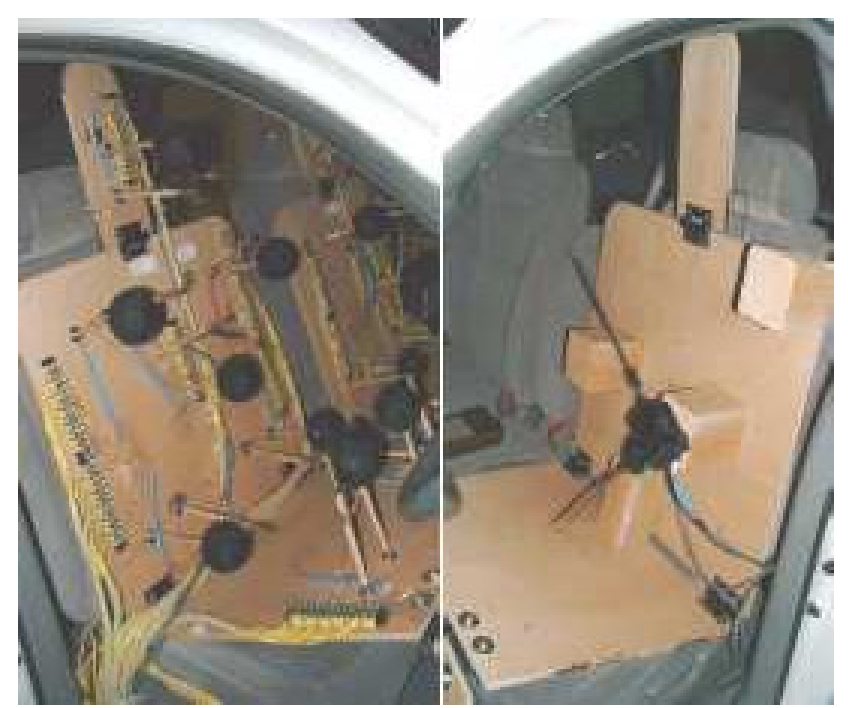

Figura 2-3 Sitckman dentro do veículo (esquerda) e versão simplificada para medições de velocidade de ar (direita) (Hosni et al, 2003c)

Os dados obtidos com os sensores foram alimentados em um modelo térmico humano para determinar a resposta fisiológica para cada condição do ambiente. Os resultados do modelo térmico foram comparados com os votos subjetivos para verificar a sua validade. Após cinco fases de modelamento, chegou-se a uma correlação entre a resposta fisiológica do modelo e o voto subjetivo dos indivíduos, tanto durante a parte transiente como em regime permanente (Hosni et al, 2003b). Este modelo considera o fluxo instantâneo de calor através da pele e a sua direção, assim como também a taxa de variação deste fluxo. Além disso, o trabalho conclui que a resposta térmica de um indivíduo depende da condição térmica prévia à qual ele foi submetido, de tal forma que a experiência anterior afeta a resposta atual. Esses fatores foram incluídos neste modelo de conforto térmico.

Até o momento, contudo, um método que tem sido bastante utilizado para a avaliação de condições de conforto térmico em automóveis é o da utilização de manequins térmicos. O manequim térmico foi concebido inicialmente para avaliar a resistência térmica de vestimentas para o inverno. Atualmente os manequins térmicos possuem vários 
segmentos com controle do fluxo de calor e sensores de temperatura individuais. Cada segmento do manequim é aquecido por filamentos, e o controle pode ser feito por fluxo de calor constante ou temperatura de superfície constante (Nilsson, 2004).

A norma ISO 14505-2 (ISO, 2004) trata da determinação de temperaturas equivalentes ${ }^{5}, \mathrm{t}_{\mathrm{eq}}$, na avaliação de conforto térmico em automóveis. Esta norma prevê a utilização dos métodos de medição da temperatura equivalente usando sensores aquecidos e também manequins térmicos (Figura 2-4).

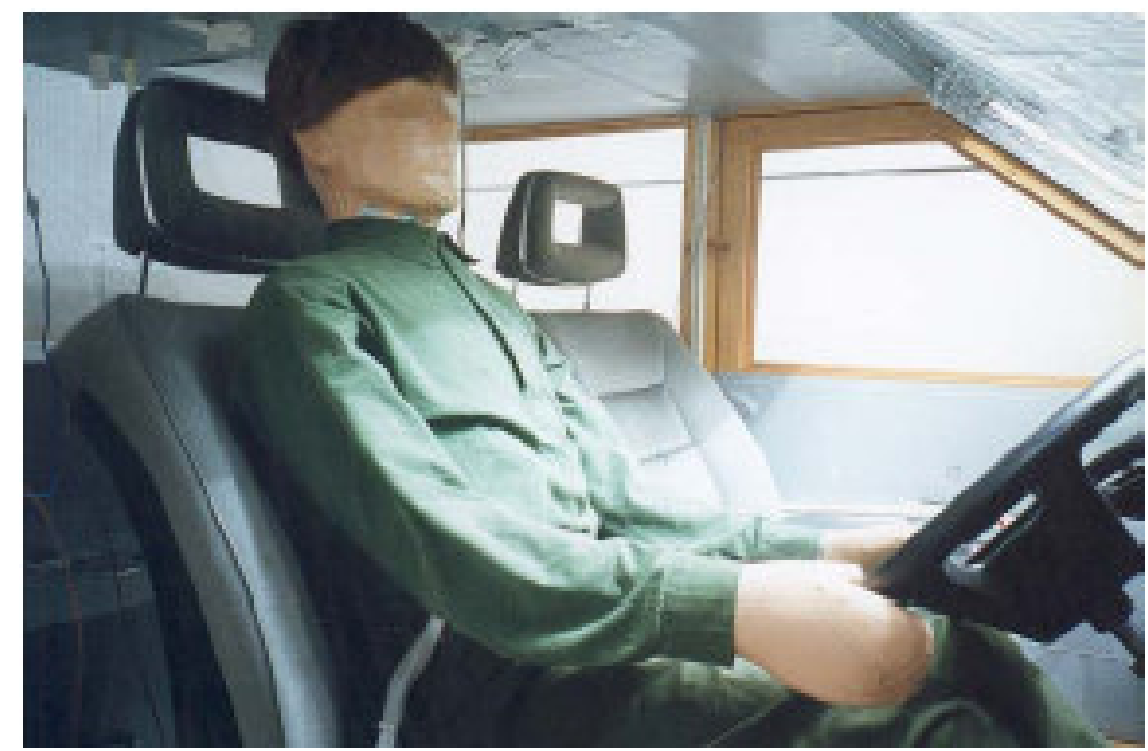

\section{Figura 2-4 Manequim térmico instalado em uma cabina para testes de aquecimento (Nilsson, 2004)}

A determinação de $t_{\text {eq }}$ é baseada na transferência de calor por convecção e radiação para pessoas com vestimentas. A transferência de calor por condução é assumida como sendo pequena e a perda de calor por evaporação de suor não é considerada já que em condições normais de uso do veículo a quantidade de suor é pequena. As perdas de calor por radiação $\mathrm{R}$ e condução $\mathrm{C}$ são dadas pelas eqs. 2.5 e 2.6:

$$
\begin{array}{ll}
R=h_{r}\left(t_{s k}-\bar{t}_{r}\right) & {\left[\mathrm{W} / \mathrm{m}^{2}\right]} \\
C=h_{c}\left(t_{s k}-t_{a}\right) & {\left[\mathrm{W} / \mathrm{m}^{2}\right]}
\end{array}
$$

onde:

\footnotetext{
5 A norma ISO 14505-2 define a temperatura equivalente $t_{\mathrm{eq}}$ como “a temperatura uniforme de um ambiente imaginário com velocidade do ar igual a zero no qual uma pessoa troca a mesma quantidade de calor por radiação e convecção do que no ambiente não uniforme real no qual ela se encontra".
} 
$\mathrm{C}=$ troca de calor por condução

$\left[\mathrm{W} / \mathrm{m}^{2}\right]$

$\mathrm{R}=$ troca de calor por radiação

$\left[\mathrm{W} / \mathrm{m}^{2}\right]$

$\mathrm{h}_{\mathrm{r}}=$ coeficiente de transferência de calor por radiação

$\left[\mathrm{W} / \mathrm{m}^{2 \mathrm{o}} \mathrm{C}\right]$

$\mathrm{h}_{\mathrm{c}}=$ coeficiente de transferência de calor por condução

$\left[\mathrm{W} / \mathrm{m}^{2 \mathrm{o}} \mathrm{C}\right]$

$\mathrm{sk}=$ temperatura da pele

$\bar{t}_{r}=$ temperatura radiante média

$\mathrm{t}_{\mathrm{a}}=$ temperatura ambiente

A temperatura equivalente é dada pela equação 2.7:

$$
t_{e q}=t_{s}-\frac{\dot{Q}}{h_{c a l}}
$$

onde:

$$
\begin{array}{ll}
\dot{Q}=\mathrm{R}+\mathrm{C}=\text { perda de calor por radiação e convecção medida } & {\left[\mathrm{W} / \mathrm{m}^{2}\right]} \\
\mathrm{t}_{\mathrm{eq}}=\text { temperatura do ambiente padrão } & {\left[{ }^{\circ} \mathrm{C}\right]} \\
\mathrm{t}_{\mathrm{s}}=\text { temperatura da superfície medida } & {\left[{ }^{\circ} \mathrm{C}\right]} \\
\mathrm{h}_{\mathrm{cal}}=\text { coeficiente de transferência de calor combinado } & {\left[\mathrm{W} / \mathrm{m}^{20} \mathrm{C}\right]}
\end{array}
$$

O ambiente padrão é um ambiente homogêneo com temperatura de bulbo seco de $24^{\circ} \mathrm{C}, \bar{t}_{r}=t_{a}$, e com velocidade do ar $<0,1 \mathrm{~m} / \mathrm{s}$. O valor de $\mathrm{h}_{\text {cal }}$ é calibrado colocando-se o manequim no ambiente padrão e medindo-se os valores de $\dot{Q}$ e $\mathrm{t}_{\mathrm{s}}$, usando a expressão 2.7 modificada conforme abaixo:

$$
h_{c a l}=\frac{\dot{Q}}{t_{s}-t_{e q}} \quad\left[\mathrm{~W} / \mathrm{m} 2^{\circ} \mathrm{C}\right]
$$

O método de avaliação consiste em posicionar o manequim no ambiente real como por exemplo na Figura 2-4 e medir os fluxos de calor e as temperaturas de superfície de cada segmento. Através da equação 2.7 é possível determinar a teq para cada segmento ou para todo o corpo utilizando os valores de $\mathrm{h}_{\text {cal }}$ calibrados e os novos valores de $\dot{Q}$ e $\mathrm{t}_{\mathrm{s}}$.

A temperatura equivalente é um indicador do nível de afastamento entre a temperatura do ambiente e a temperatura correspondente a uma sensação térmica de neutralidade. A norma ISO 14505-2 apresenta dois gráficos mostrando a sensação térmica para cada segmento do corpo (Figura 2-5) em uma escala de 1 a 5 em função da temperatura equivalente correspondente (Tabela 2-3), sendo um gráfico para a condição de 
verão e outro para condição de inverno (Figura 2-6 e Figura 2-7).

O método de medição de temperaturas equivalentes é útil para se fazer uma avaliação objetiva de um ambiente altamente não homogêneo como um veículo. Entretanto este método é considerado inadequado nos casos em que o ambiente apresenta grandes variações no tempo (regime transiente), devido ao tempo de resposta do manequim aquecido (Hosni et al, 2003b).
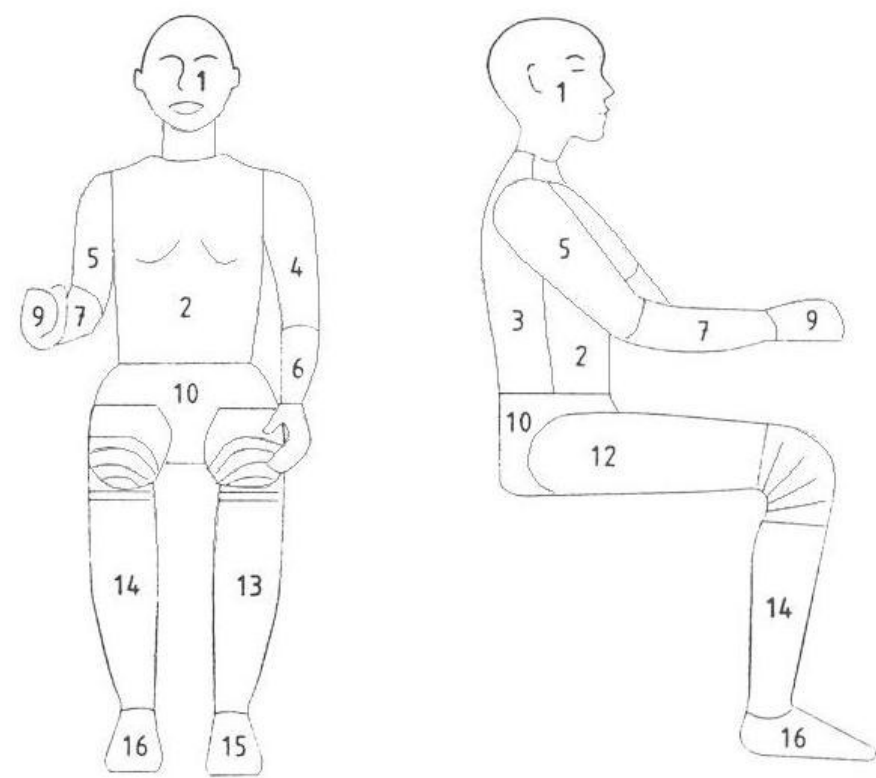

Figura 2-5 Diagrama de um manequim com 16 segmentos (ISO 14505-2)

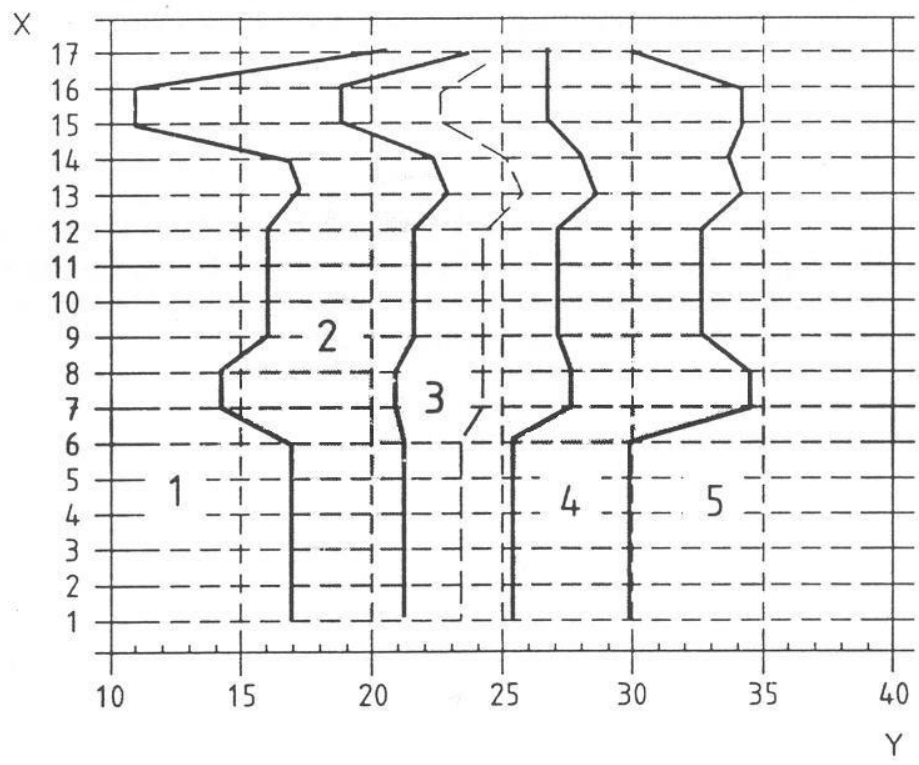

Figura 2-6 Diagrama para avaliação da $t_{\text {eq }}$ em função da sensação térmica estimada. Os valores se referem a uma condição de verão, com o sistema operando na condição de resfriamento e pessoas usando roupas leves $(0,6$ CLO) (ISO 14505-2) 


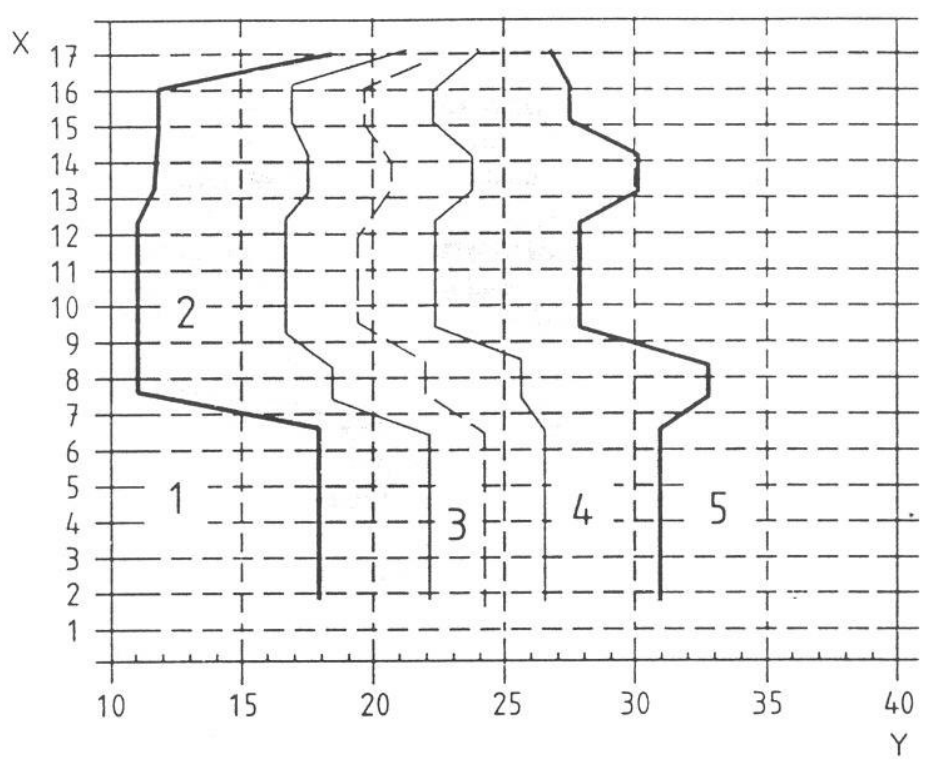

Figura 2-7 Diagrama para avaliação da $t_{\text {eq }}$ em função da sensação térmica estimada. Os valores se referem a uma condição de inverno, com o sistema operando em aquecimento e pessoas usando roupas de inverno (1,0 CLO) (ISO 14505-2)

Tabela 2-3 Escala de sensação de conforto térmico

Escala de sensação de conforto térmico (ISO 14505-2)

\begin{tabular}{|c|c|c|c|c|}
\hline $\mathbf{1}$ & $\mathbf{2}$ & $\mathbf{3}$ & $\mathbf{4}$ & $\mathbf{5}$ \\
\hline Muito frio & Frio / confortável & Confortável & Quente / confortável & Muito quente \\
\hline
\end{tabular}

O uso de ensaios subjetivos em automóveis tem sido reduzido, devido ao seu alto custo, da necessidade de protótipos representativos para a sua realização e de equipamentos com disponibilidade escassa como as câmaras climatizadas.

Cada vez mais a tendência é investir para que se possa avaliar os projetos ainda na fase de conceito, usando ferramentas de modelamento matemático para análise das trocas de calor, dentre elas a dinâmica dos fluidos computacional (CFD) e manequins virtuais têm sido amplamente empregadas na análise de interiores dos veículos. A disponibilidade de modelos de conforto térmico humano confiáveis permite que se possa calcular a estimativa de voto da sensação térmica. Os testes subjetivos ainda são empregados nas fases posteriores quando os protótipos estão disponíveis, porém a quantidade de ensaios necessários é menor.

Em um artigo recente, Ambs (2002) reporta o uso de um método de análise virtual de conforto térmico baseado em um modelo simplificado do interior de um veículo, a partir 
do qual se cria uma malha de elementos finitos, calcula-se a carga solar no interior do veículo, as condições de trocas de calor através das superfícies, as massas das partes interiores (bancos, painel, etc.) e simulam-se as condições padrão de testes de aquecimento e refrigeração, fortemente transitórias. $\mathrm{O}$ autor incluiu em seu estudo o modelo de conforto térmico de Brown e Jones (1997) utilizando manequins numéricos. Apesar de demonstrar o avanço na direção da análise de conforto térmico em ambiente virtual, o trabalho não chega a apresentar resultados de teste no veículo real para que se possa verificar a validade dos modelos. Verifica-se a presença de desconforto local na região das costas, pernas e pés, mas não são apresentadas propostas de solução/melhoria.

O estudo do conforto térmico tem tido grandes avanços nas últimas décadas, pois a disponibilidade de computadores permite o uso de modelamentos cada vez mais complexos, ao mesmo tempo que permite o estudo detalhado do ambiente condicionado. 


\section{CAPÍTULO 3 CARGA TÉRMICA}

Para se atingir as condições de conforto térmico em ambientes condicionados o primeiro passo no processo de dimensionamento do ciclo de refrigeração é a determinação da carga térmica, que pode ser classificada em carga térmica do ambiente e carga térmica do equipamento (Yamane e Saito, 1986).

Antes de se começar a detalhar como serão avaliadas as diversas cargas térmicas, é necessário fazer uma distinção entre carga térmica e ganho de calor. A ASHRAE (2001) apresenta esta distinção claramente, definindo:

a) Carga térmica como sendo a taxa de calor que deve ser removida de um determinado local para se manter a temperatura do ar interior em um valor constante.

b) Ganho de calor como sendo a taxa instantânea em que o calor é transferido para um ambiente ou convertido internamente.

Esta distinção é necessária pois nas aplicações reais, em regime transitório, a carga térmica não corresponde necessariamente ao ganho de calor. Imagina-se um ambiente (sistema) definido por paredes, cuja fronteira é o lado externo das mesmas. Em um período de aquecimento, o calor transferido para o ar no interior deste ambiente equivale ao calor que atravessa a fronteira do sistema (ganho de calor) menos o aumento da energia interna das paredes.

Devido a este fator, em edificações com sistema de ar condicionado central, cálculos de capacidade de refrigeração realizados como se fossem ganhos de calor resultariam em valores maiores do que a carga térmica real do ambiente. Assim, o dimensionamento do sistema de refrigeração para o ganho de calor resultaria em um equipamento superdimensionado.

Nos automóveis ocorre um processo um pouco diferente. A transferência de calor para o ar interior pode ser considerada como um ganho de calor (estruturas com isolamento térmico relativamente baixo sofrem pequena variação de energia interna). A grande diferença, contudo, está na forma de se considerar a carga térmica para o dimensionamento do ciclo de refrigeração em sistemas de climatização veicular. Neste caso o sistema de refrigeração deve retirar cargas maiores do que aquelas calculadas mesmo considerando a carga térmica como sendo aquela relativa aos ganhos de calor. O que ocorre no caso dos automóveis é que há a necessidade de se remover o calor equivalente aos ganhos através da 
envoltória mais o equivalente ao aumento da energia interna do veículo, (estacionado ao sol, por exemplo) em tempo curto de 20 a 30 minutos no máximo (o período de resfriamento do ar: cool down).

O objetivo deste capítulo é calcular a carga térmica total em regime permanente de um veículo de fabricação nacional do tipo compacto com quatro portas durante um ensaio de desempenho do ar condicionado realizado em túnel de vento.

\subsection{GANHOS DE CALOR}

Em um veículo automotivo, há diversos "ganhos de calor” que contribuem para a carga térmica total, como segue:

- Condução de calor através da carroçaria e vidros;

- Irradiação solar pelos vidros;

- Condução de calor do compartimento do motor;

- Pessoas no interior do veículo;

- Equipamentos internos (motores, ventiladores e iluminação).

- Infiltração / Renovação de ar

No presente trabalho será usada a mesma metodologia utilizada por Stancato (1992) para a determinação de cada um dos ganhos de calor, com algumas adaptações devido à condição de operação, que no caso será o ensaio de desempenho do ar condicionado em túnel de vento.

\subsubsection{Condução através de paredes e vidros}

O cálculo de ganho de calor por condução $\left(\dot{Q}_{k}\right)$ é feito com base na temperatura ar-sol. A Temperatura ar-sol é determinada por um balanço dos fluxos de calor na superfície, e depende do coeficiente de convecção externa $h_{e}$. Os valores de $h_{e}$ e $T_{\text {ar-sol }}{ }^{6}$ foram calculados de acordo com as correlações apresentadas em Stancato (1992).

$$
\dot{Q}_{k}=\frac{\left(T_{a r-s o l}-T i\right) \times A}{R t}
$$

com:

$$
T_{A r-S o l}=T_{e x t}+\frac{\alpha \cdot I_{D}}{h_{e}}
$$

\footnotetext{
${ }^{6}$ Stancato (1992) utiliza o termo Temperatura de superfície externa (TSE) para designar a $\mathrm{T}_{\text {ar-sol }}$
} 


$$
\begin{gathered}
R t=R c+1 / h_{i} \\
R c=\sum_{i=1}^{n} \frac{e_{i}}{k_{i}}
\end{gathered}
$$

onde:

Tar-sol $=$ temperatura da superfície exterior (paredes e vidros) $\quad{ }^{\circ} \mathrm{C}$

$\mathrm{Ti}=$ temperatura do ar interior da cabina

${ }^{\circ} \mathrm{C}$

$\mathrm{Rt}=$ resistência total (condução + convecção)

$\mathrm{m}^{2}-\mathrm{K} / \mathrm{W}$

$\mathrm{Rc}=$ resistência de condução $\mathrm{m}^{2}-\mathrm{K} / \mathrm{W}$

$\mathrm{h}_{\mathrm{i}}=$ coeficiente de convecção interna $\mathrm{W} / \mathrm{m}^{2}-\mathrm{K}$

$h_{e}=$ coeficiente de convecção externa $\mathrm{W} / \mathrm{m}^{2}-\mathrm{K}$

$\mathrm{A}=$ área da superfície

$\mathrm{m}^{2}$

$\mathrm{e}=$ espessura da camada de material

$\mathrm{m}$

$\mathrm{k}=$ coeficiente de condução do material

$\mathrm{W} / \mathrm{m}-\mathrm{K}$

$\mathrm{T}_{\mathrm{ext}}=$ temperatura de bulbo seco externa

${ }^{\circ} \mathrm{C}$

$\mathrm{I}_{\mathrm{D}}=$ incidência solar direta

$\mathrm{W} / \mathrm{m}^{2}$

$\alpha=$ absortividade da superfície

Adimensional

\subsubsection{Radiação solar através de janelas}

No interior do túnel de vento considera-se somente a radiação direta incidente, ignorando-se a influência da radiação difusa do céu. Assim, a carga térmica de radiação solar $\dot{Q}_{s}$ fica:

$$
\dot{Q}_{s}=I_{D} \times \tau_{D} \times A_{v}
$$

onde:

$\mathrm{I}_{\mathrm{D}}=$ Incidência solar direta

$\left(\mathrm{W} / \mathrm{m}^{2}\right)$

$\tau_{\mathrm{D}}=$ transmissividade relativa à radiação incidente

(adimensional)

$\mathrm{A}_{\mathrm{v}}=$ área envidraçada

$\left(\mathrm{m}^{2}\right)$

\subsubsection{Condução de calor do compartimento do motor}

Stancato (1992) considerou uma temperatura de superfície externa da divisória do compartimento do motor, calculada a partir do conhecimento da radiação de calor do motor. Quando esta informação não está disponível, como no presente trabalho, adota-se 
uma temperatura do compartimento do motor $\mathrm{T}_{\text {motor }}$ para o cálculo de $\dot{Q}_{\text {motor }}$ :

$$
\dot{Q}_{\text {MOTOR }}=\frac{\left(T_{\text {МОтОR }}-T i\right)}{R t_{\text {MOTOR }}} \times A_{D}
$$

onde:

$\mathrm{T}_{\text {MOTOR }}=$ temperatura do ar do compartimento do motor ${ }^{\mathrm{o}} \mathrm{C}$

$\mathrm{Rt}_{\mathrm{MOTOR}}=$ resistência total (condução + conveção) da divisória $\mathrm{m}^{2}-\mathrm{K} / \mathrm{W}$ $\mathrm{A}_{\mathrm{D}}=$ área da divisória $\mathrm{m}^{2}$

\subsubsection{Pessoas no interior do veículo}

Durante o ensaio no túnel de vento não há pessoas no interior do veículo, já que a velocidade do veículo é controlada pelo dinamômetro por meio de um sistema de acelerador automático instalado no assoalho do motorista. Dessa forma, $Q_{P E S S O A S}=0 \mathrm{~W}$.

\subsubsection{Equipamentos internos (motores, ventiladores e iluminação).}

A única fonte de calor considerada foi o próprio motor do sistema de ventilação. Parte da energia elétrica entregue ao motor é convertida em calor devido à resistência elétrica e ao atrito entre o eixo e os mancais. Outra parte é transferida para o fluido, que ganha energia cinética e posteriormente se converte em variação de energia interna, à medida que o fluido perde velocidade no interior da cabina. Desta maneira, a energia elétrica (trabalho) que atravessa a fronteira do sistema, dada pela Eq. 3.4, equivale ao ganho de calor $\dot{Q}$.

$$
\dot{Q}=V \times I \quad[\mathrm{~W}]
$$

onde:

$\mathrm{V}=$ Tensão aplicada aos terminais do motor

$\mathrm{I}=$ Corrente consumida pelo motor

\subsubsection{Infiltração e renovação de ar}

No ensaio de túnel de vento o sistema trabalhou todo o tempo em recirculação, de maneira que não houve renovação de ar. O movimento do ar no túnel causa diferença de pressão entre o interior e o ambiente externo, e essa diferença de pressão provoca infiltração do ar externo através de qualquer fenda existente na carroçaria. Ruth (1975) avalia a infiltração através do comprimento e largura das fendas, mas não é possível 
conhecer cada uma dessas fendas e as suas dimensões, dadas as variações dos processos de produção. A tarefa de determinar esta infiltração é portanto complexa. Forrest e Bhatti (2002) avaliaram a infiltração entre $10 \%$ e $25 \%$ do ar insuflado. Para este trabalho estimou-se uma vazão total de infiltração entre $10 \%$ e $15 \%$ da vazão total do sistema de ventilação, desde que o vazamento da carroçaria atenda as especificações. O vazamento da carroçaria é medido antes da execução do ensaio no túnel de vento, por meio de um equipamento que mede a vazão de ar insuflado no veículo necessária para manter uma pressão interna constante e conhecida.

O ganho de calor por infiltração $\dot{Q}_{I}$ é calculado por:

$$
\dot{Q}_{I}=\dot{m}_{I} \times\left(h_{e x t}-h_{\text {int }}\right) \quad[\mathrm{W}]
$$

onde:

$$
\begin{array}{ll}
\dot{m}_{I}=\text { Vazão de ar de infiltração } & \mathrm{kg} / \mathrm{s} \\
\mathrm{h}_{\text {ext }}=\text { Entalpia do ar externo } & \mathrm{J} / \mathrm{kg} \\
\mathrm{h}_{\text {int }}=\text { Entalpia do ar interno da cabina } & \mathrm{J} / \mathrm{kg}
\end{array}
$$

A entalpia do ar interno depende da umidade relativa do ar interno, que não foi medida no experimento do túnel de vento, portanto será necessário estimá-la. Stancato (1992) avaliou a entalpia do ar interno da cabina de um ônibus medindo diretamente o valor da umidade relativa usando três psicrômetros. Ruth (1975) também avalia a carga térmica de infiltração pela diferença de entalpias externa e interna, porém não fornece detalhes de como obteve os valores. Em um estudo sobre um sistema de ar condicionado energeticamente eficiente, Forrest e Bhatti (2002) avaliam a influência das infiltrações na carga térmica do equipamento de ar condicionado através de uma análise de mistura adiabática do ar recirculado com o ar externo, fixando o valor da umidade relativa interna para uma condição de conforto.

A Figura 3-1 apresenta a cabina do veículo recebendo ar externo por infiltração à temperatura $\mathrm{T}_{\text {ext }}$ com umidade $\phi_{\text {ext }}$, que se mistura com o ar de descarga do sistema de ar condicionado à temperatura $\mathrm{T}_{\mathrm{D}} \mathrm{e}$ umidade $\phi_{\mathrm{D}}$ e resulta no ar interno com temperatura $\mathrm{T}_{\text {int }} \mathrm{e}$ umidade $\phi_{\text {int }}$. 


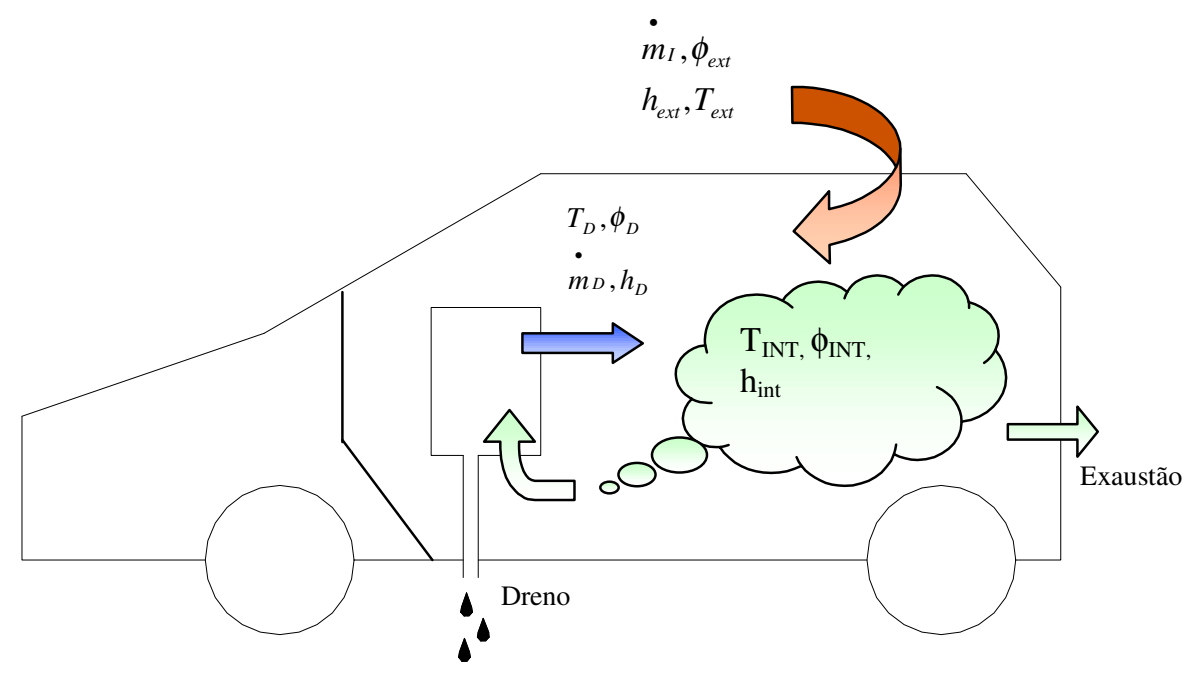

Figura 3-1 Cabina do veículo e sistema de ar condicionado

Parte da quantidade de ar admitido por infiltração sai para o ambiente pelo exaustor na parte traseira, e a água condensada no processo de resfriamento sai pelo dreno. O processo pode ser visto no diagrama da Figura 3-2.

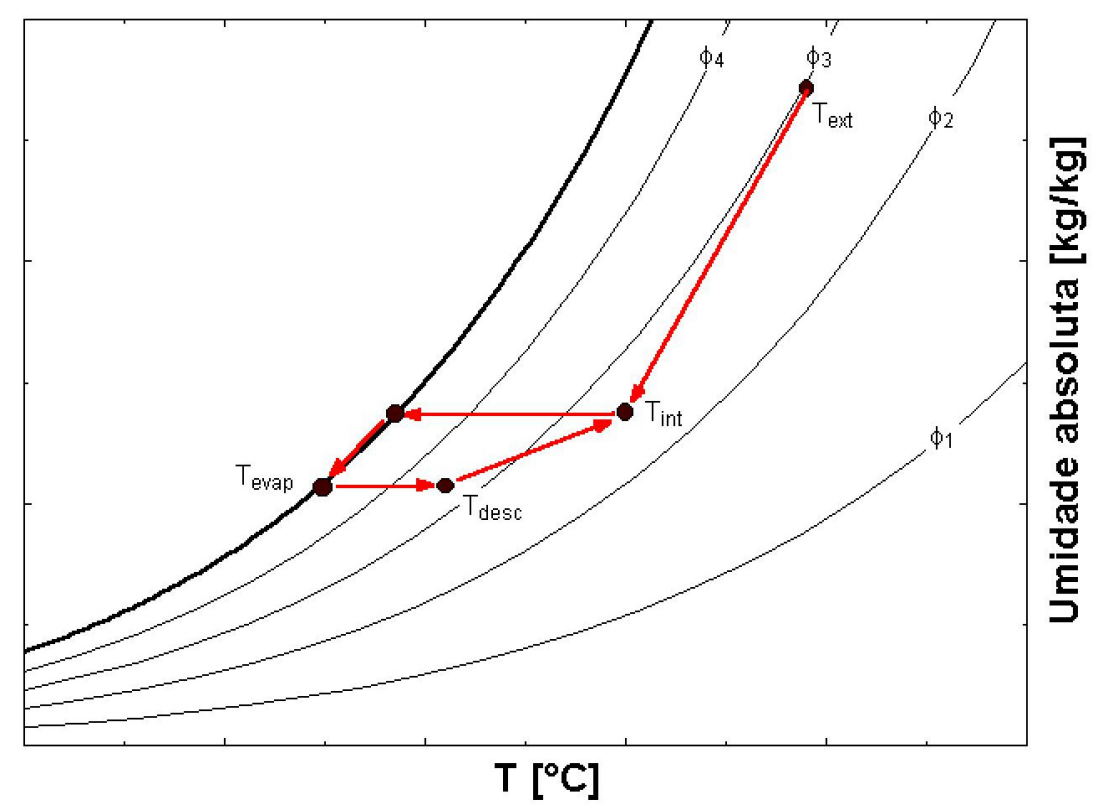

Figura 3-2 Carta psicrométrica ilustrando o processo de resfriamento e mistura de ar externo.

Para estimar a umidade relativa interna da cabina, e por consequência a entalpia interna, será usada uma mistura adiabática do ar de descarga dos difusores com o ar de infiltração, obtendo-se uma temperatura fictícia de mistura $\mathrm{T}_{\mathrm{m}}$ com umidade absoluta $\mathrm{w}_{\mathrm{m}}$. Em seguida aplica-se o aquecimento da mistura desde a temperatura $T_{m}$ até a temperatura interna $\mathrm{T}_{\text {int }}$ (que é conhecida), mantendo-se a umidade absoluta constante. A partir daí determina-se a umidade relativa interna $\phi_{\text {int }} \mathrm{e}$ a entalpia interna $\mathrm{h}_{\text {int }}$. $\mathrm{O}$ procedimento é 
ilustrado na Figura 3-3.

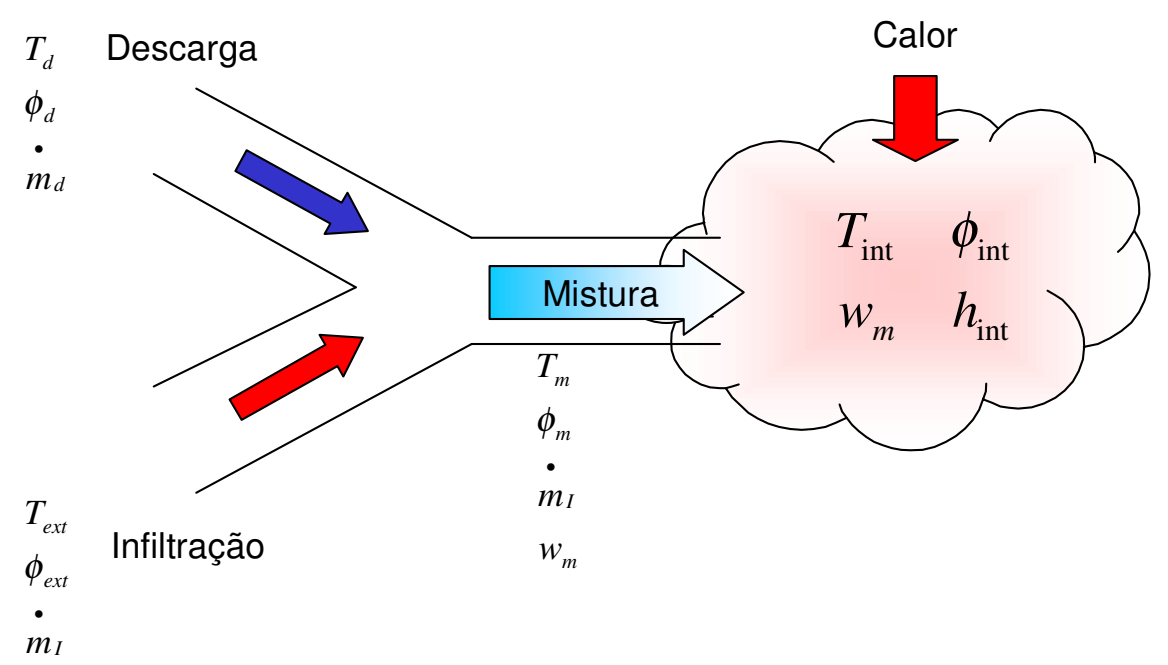

Figura 3-3 Estimativa da umidade relativa interna e entalpia interna

\subsection{CONDIÇÕES DE OPERAÇÃO}

Para a determinação dos ganhos de calor (carga térmica) é necessário que se conheça as condições para as quais estes ganhos de calor serão calculados. Assim, nesta parte será apresentada uma breve descrição de um túnel de vento e as condições de operação para um teste de desempenho de ar condicionado veicular. O túnel de vento é utilizado para os ensaios de desempenho do sistema por diversos fatores. Os mais importantes são a repetitividade dos resultados, a possibilidade de executar os ensaios independentemente das condições climáticas, o fato de o túnel simular diversas condições de condução em estrada e com o veículo parado, e a possibilidade de obter vários dados com boa precisão.

O túnel de vento para testes de climatização em automóveis deve ser capaz de reproduzir condições de estrada para efetuar testes em escala 1:1. Deve proporcionar o controle da temperatura e umidade do ar, a velocidade do ar, simular a carga solar. Precisa de um dinamômetro para submeter o veículo às condições de velocidade e carga em que se pretende testar o sistema, e ter capacidade de fazer a aquisição de dados do veículo. A Figura 3-4 apresenta um lay-out de um túnel de vento típico para testes climáticos em automóveis, enquanto a Figura 3-5 apresenta a célula de testes de um túnel de vento. 


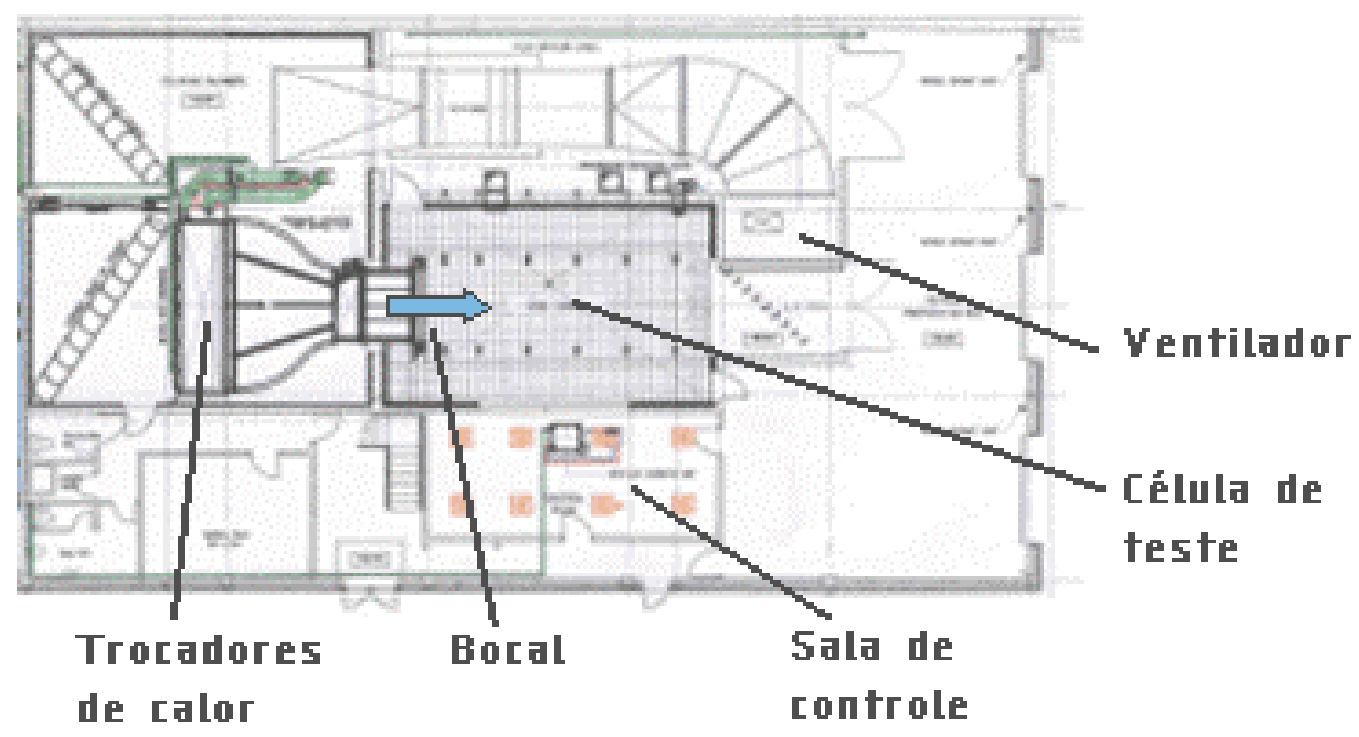

Figura 3-4 Lay-out de um túnel de vento típico (Calsonic Kansei Europe, 2002).

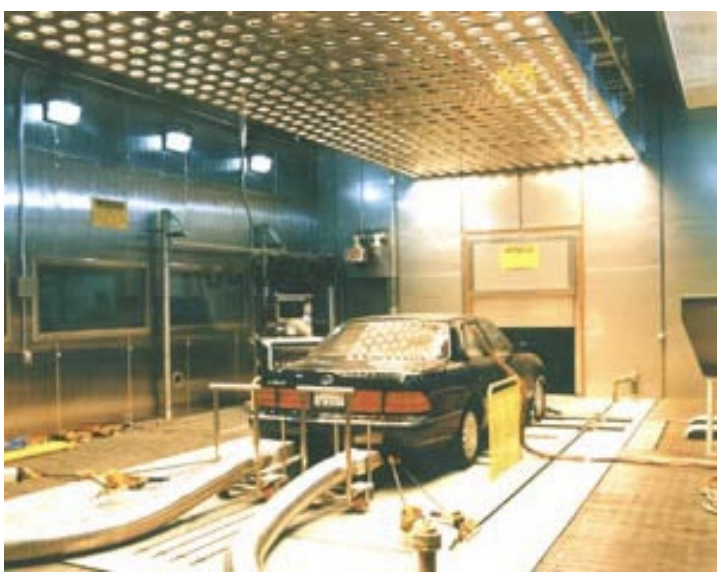

Figura 3-5 Célula de testes de um túnel de vento (Ransco Industries, 1999).

As especificações de um túnel de vento típico são as seguintes:

$\begin{array}{ll}\text { Velocidade do ar/dinamômetro: } & 0 \text { a } 200 \mathrm{~km} / \mathrm{h} \\ \text { Faixa de temperatura: } & -20^{\circ} \mathrm{C} \text { a } 60^{\circ} \mathrm{C} \\ \text { Controle de umidade relativa } & 30 \% \text { a } 90 \% \\ \text { Carga solar: } & 0 \text { a } 1000 \mathrm{~W} / \mathrm{m} 2 \\ \text { Dinamômetro: } & 300 \mathrm{Hp}\end{array}$

As condições de operação em que se pretende determinar a carga térmica são as seguintes:

a) Condições impostas pelo túnel de vento:

Temperatura de bulbo seco ambiente: $\quad 43^{\circ} \mathrm{C}$ 
Umidade relativa do ar:

$40 \%$

Carga solar:

$1000 \mathrm{~W} / \mathrm{m} 2$

Velocidadade do ar/dinamômetro:

$50 \mathrm{~km} / \mathrm{h}, 100 \mathrm{~km} / \mathrm{h}$ e zero

Carga do dinamômetro (força trativa): calculada para cada velocidade em função de parâmetros do veículo (peso, área frontal, coeficiente aerodinâmico, etc).

\section{b) Condições do veículo:}

Ventilação:

Recirculação de ar:

Temperatura:

Modo de ventilação:
Ligada à máxima velocidade

Fechada (100\% recirculação)

Frio máximo

Painel (frontal)

Marchas: 4a, 5a e ponto morto (para as velocidades de $50 \mathrm{~km} / \mathrm{h}, 100 \mathrm{~km} / \mathrm{h}$ e zero, respectivamente)

Temperatura interna inicial: $\quad 60^{\circ} \mathrm{C}$

Os dados são obtidos por meio de varreduras de todos os sensores em períodos estabelecidos. Inicialmente o veículo é colocado com os vidros fechados e o motor desligado sob as condições de temperatura, umidade e carga solar, até que a temperatura interna da cabina atinja os $60^{\circ} \mathrm{C}$.

Quando a temperatura interna é atingida, inicia-se o ensaio com velocidade de $50 \mathrm{~km} / \mathrm{h}$ durante 30 minutos, passa-se a $100 \mathrm{~km} / \mathrm{h}$ por mais 30 minutos, e finalmente velocidade zero, com motor funcionando em marcha lenta com ponto morto por mais 30 minutos. Durante o ensaio são obtidas as leituras de temperatura média interna (média das leituras de temperatura na altura da cabeça, da cintura e dos pés para cada um dos quatro assentos), das pressões e temperaturas do ciclo de refrigeração e dados sobre as condições ambientes no túnel.

A temperatura interna média da cabina do veículo se comporta tipicamente conforme o gráfico da Figura 3-6. Para o cálculo dos ganhos de calor foram consideradas as condições de operação ao final dos 30 minutos de cada velocidade, onde se considera a operação do sistema em regime permanente. 


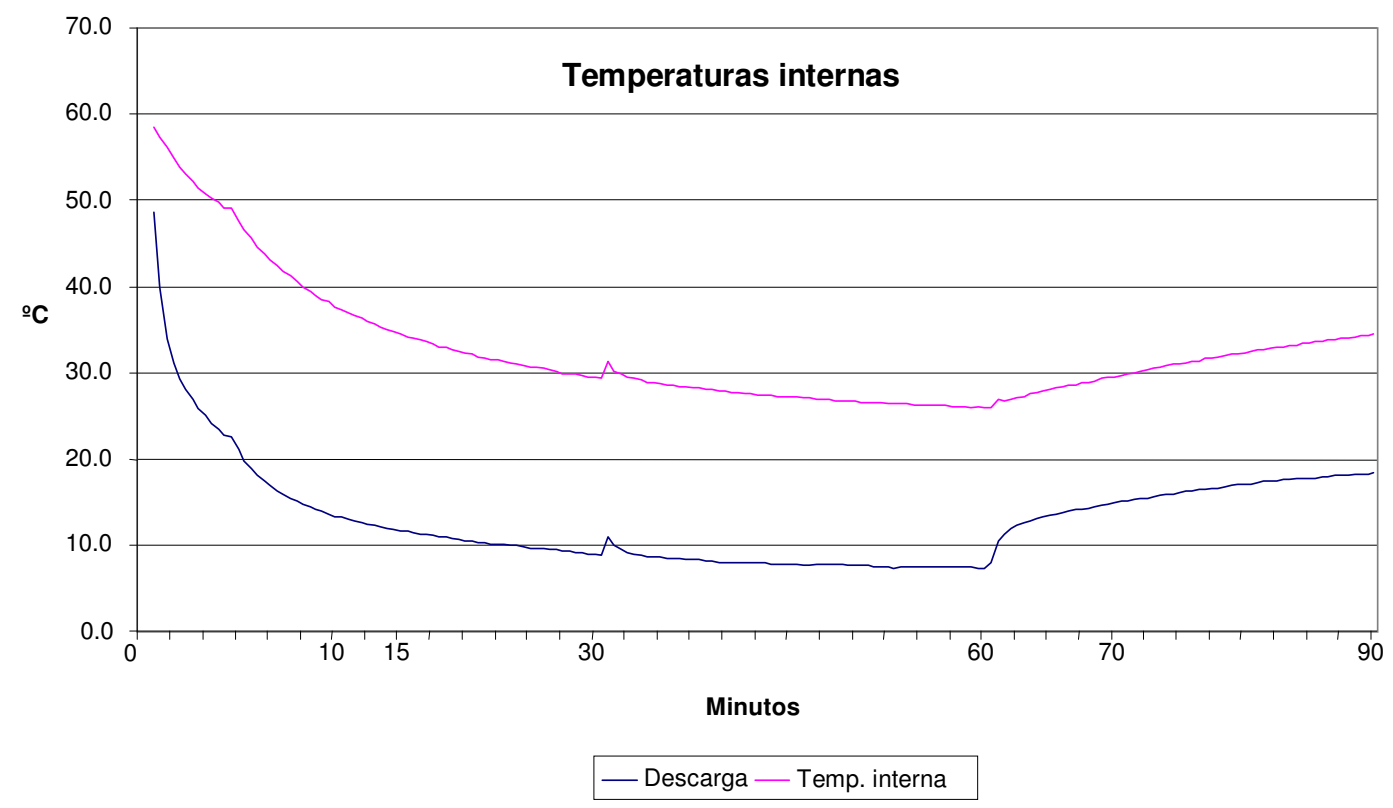

Figura 3-6 Temperaturas internas durante ensaio em túnel de vento.

\subsection{DADOS DE ENSAIO EM TÚNEL DE VENTO}

Os dados utilizados neste trabalho foram obtidos em um teste em túnel de vento com um veículo nacional tipo compacto de quatro portas, com a participação deste autor. Por necessidade de preservar a propriedade intelectual e estratégia de negócios, não será possível especificar a empresa fabricante do veículo, o nome do veículo e a localidade do teste, já que este foi executado por empresa privada com fins comerciais. Na Tabela 3-1 encontram-se os dados obtidos.

\subsection{CARACTERÍSTICAS DO VEÍCULO}

Para os cálculos dos coeficientes de convecção externos e os ganhos de calor são necessárias as dimensões de cada superfície da envoltória do veículo, divididas entre superfícies opacas (teto, assoalho, laterais de portas, painel frontal e traseira) e transparentes (pára-brisas, vidros laterais e vidro traseiro), conforme apresentado na Figura 3-7.

As superfícies opacas podem ainda ser divididas entre as que estão expostas à radiação solar (teto, portas e traseira) e as que não estão expostas (assoalho e painel frontal). 


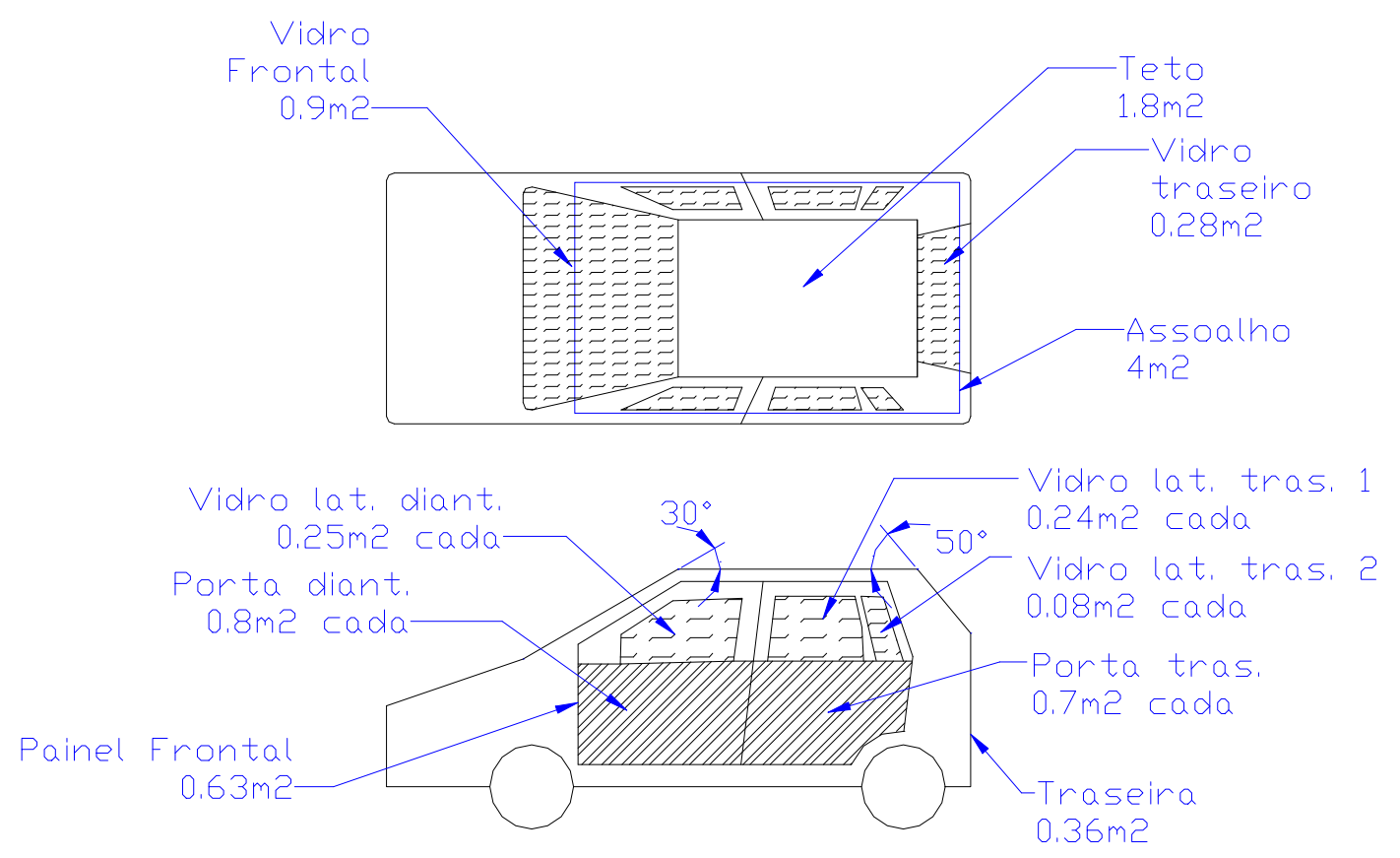

Figura 3-7 Características do veículo.

\subsubsection{Materiais das superfícies opacas}

As superfícies opacas expostas à radiação solar estão pintadas na cor vermelho escuro. O teto é composto de uma chapa de aço com $1 \mathrm{~mm}$ de espessura, seguido por uma camada de ar de $30 \mathrm{~mm}$ e um forro de material de fibras prensadas de $4 \mathrm{~mm}$ de espessura. As portas são compostas de chapa de aço com $1 \mathrm{~mm}$ de espessura, seguido por uma camada de ar de $150 \mathrm{~mm}$ e por um painel de acabamento de polipropileno com $3 \mathrm{~mm}$ de espessura. A traseira é composta de chapa de aço com $1 \mathrm{~mm}$ de espessura, seguido por uma camada de ar de $60 \mathrm{~mm}$ e um acabamento interno de polipropileno de $3 \mathrm{~mm}$ de espessura. $\mathrm{O}$ assoalho é composto de chapa de aço de $2 \mathrm{~mm}$ de espessura com um acabamento interno de carpete com $10 \mathrm{~mm}$ de espessura. O painel frontal tem um isolante externo com $6 \mathrm{~mm}$ de espessura, uma chapa de aço de $1 \mathrm{~mm}$ de espessura e um acabamento interno de carpete com $10 \mathrm{~mm}$ de espessura. Os dados das superfícies com as respectivas espessuras e condutividades térmicas são apresentados na Tabela 3-2.

As condutividades do aço, do ar e dos isolantes do tipo fibras e carpete foram obtidas usando-se o software Engineering Equation Solver (EES, 2003). Os dados do polipropileno foram obtidos em Abu-Isa (2000). 
Tabela 3-1 Dados obtidos em teste de túnel de vento.

\begin{tabular}{|c|c|c|c|c|}
\hline Leitura & Unidade & $\begin{array}{c}50 \mathrm{~km} / \mathrm{h} \\
30 \mathrm{~min}\end{array}$ & $\begin{array}{c}100 \mathrm{~km} / \mathrm{h} \\
30 \mathrm{~min}\end{array}$ & $\begin{array}{c}\text { Marcha lenta } \\
30 \mathrm{~min}\end{array}$ \\
\hline \multicolumn{5}{|l|}{ AMBIENTE } \\
\hline Temperatura de bulbo seco & ${ }^{\circ} \mathrm{C}$ & 43,3 & 43,3 & 43,2 \\
\hline Umidade relativa do ar & $\%$ & 40,4 & 39,8 & 40,1 \\
\hline Pressão atmosférica & $\mathrm{kPa}$ & 99,9 & 99,9 & 99,9 \\
\hline \multicolumn{5}{|l|}{ INTERIOR DO VEÍCULO } \\
\hline Temperatura média da cabina & ${ }^{\circ} \mathrm{C}$ & 27,8 & 23,9 & 34,3 \\
\hline Temperatura de retorno do ar & ${ }^{\circ} \mathrm{C}$ & 28,7 & 24,6 & 34,6 \\
\hline Temperatura de descarga nos difusores & ${ }^{\circ} \mathrm{C}$ & 11,5 & 9,3 & 21,5 \\
\hline Vazão de ar de descarga (1) & $\mathrm{m} 3 / \mathrm{s}$ & 0,12 & 0,12 & 0,12 \\
\hline \multicolumn{5}{|l|}{ CIRCUITO DE REFRIGERAÇÃO } \\
\hline Pressão alta (manométrica) & $\mathrm{kPag}$ & 2108 & 2094 & 2718 \\
\hline Pressão baixa (manométrica) & $\mathrm{kPag}$ & 218,4 & 188,4 & 396,8 \\
\hline Temperatura de entrada do evaporador & ${ }^{\circ} \mathrm{C}$ & 9,7 & 8,3 & 19,4 \\
\hline Temperatura de saída do evaporador & ${ }^{\circ} \mathrm{C}$ & 5,2 & 2,4 & 17,8 \\
\hline Temperatura de entrada do compressor & ${ }^{\circ} \mathrm{C}$ & 7,3 & 3,8 & 21,5 \\
\hline Temperatura de saída do compressor & ${ }^{\circ} \mathrm{C}$ & 95,0 & 104 & 96,9 \\
\hline Temperatura de entrada disp. expansão & ${ }^{\circ} \mathrm{C}$ & 59,4 & 56,8 & 76,8 \\
\hline \multicolumn{5}{|l|}{ CONDENSADOR } \\
\hline Tempertura do ar de entrada & ${ }^{\circ} \mathrm{C}$ & 44,4 & 44,2 & 64,2 \\
\hline \multicolumn{5}{|l|}{ COMPRESSOR } \\
\hline Rotação do compressor & $\min -1$ & 2036 & 3204 & 898 \\
\hline
\end{tabular}

(1) Medido com uma câmara de bocais antes do teste do túnel de vento.

Tabela 3-2 Características das superfícies opacas.

\begin{tabular}{|l|c|c|c|c|c|c|c|}
\cline { 2 - 9 } \multicolumn{1}{c|}{} & $\mathrm{A}$ & $\mathrm{e} 1$ & $\mathrm{e} 2$ & $\mathrm{e} 3$ & $\mathrm{k} 1$ & $\mathrm{k} 2$ & $\mathrm{k} 3$ \\
\cline { 2 - 9 } \multicolumn{1}{c|}{} & {$[\mathrm{m} 2]$} & \multicolumn{3}{c|}{$[\mathrm{m}]$} & \multicolumn{3}{c|}{$[\mathrm{W} / \mathrm{m}-\mathrm{K}]$} \\
\hline 1. Teto & 1,80 & 0,001 & 0,03 & 0,004 & 59,9 & 0,028 & 0,053 \\
\hline 2. Porta dianteira & 0,80 & 0,001 & 0,15 & 0,003 & 59,9 & 0,028 & 0,23 \\
\hline 3. Porta traseira & 0,70 & 0,001 & 0,15 & 0,003 & 59,9 & 0,028 & 0,23 \\
\hline 4. Traseira & 0,36 & 0,001 & 0,06 & 0,003 & 59,9 & 0,028 & 0,23 \\
\hline 5. Assoalho & 4,00 & 0,001 & 0,01 & & 59,9 & 0,053 & \\
\hline 6. Painel frontal & 0,63 & 0,006 & 0,001 & 0,01 & 0,053 & 59,9 & 0,053 \\
\hline
\end{tabular}




\subsubsection{Materiais das superfícies transparentes}

O veículo usa dois tipos de vidros, temperado (laterais e traseiro) e laminado (pára-brisas). As características dos vidros são apresentadas na Tabela 3-3.

Tabela 3-3 Características dos materiais transparentes (vidros) do veículo.

\begin{tabular}{|l|c|c|c|}
\cline { 2 - 4 } \multicolumn{1}{c|}{} & $\mathrm{A}$ & $\mathrm{e}$ & $\mathrm{k}$ \\
\cline { 2 - 4 } \multicolumn{1}{c|}{} & {$[\mathrm{m} 2]$} & {$[\mathrm{m}]$} & {$[\mathrm{W} / \mathrm{m}-\mathrm{K}]$} \\
\hline 1. Para-Brisas & 0,90 & 0,006 & 0,25 \\
\hline 2. Vidro traseiro & 0,28 & 0,006 & 1,4 \\
\hline 3. Vidro Porta dianteira & 0,25 & 0,006 & 1,4 \\
\hline 4. Vidro Porta traseira & 0,24 & 0,006 & 1,4 \\
\hline 5. Vidro Lat. Traseiro & 0,08 & 0,006 & 1,4 \\
\hline
\end{tabular}

\subsection{RESULTADOS DOS CÁLCULOS DOS GANHOS DE CALOR}

Os cálculos de carga térmica foram feitos para as três velocidades experimentadas no túnel de vento, considerando as condições de operação apresentadas no item 3.2 e as temperaturas internas da cabina conforme Tabela 3-1. Para o coeficiente de convecção interno $\left(\mathrm{h}_{\mathrm{i}}\right)$ foi adotado o valor recomendado pela ASHRAE (2001) de $8 \mathrm{~W} / \mathrm{m}^{2}-\mathrm{K}$ para convecção natural em ambientes ventilados (embora as altas velocidades de insuflação de um automóvel possam fornecer valores maiores de $h_{i}$ ). Os resultados estão apresentados nas Tabelas 3-4 a 3-6. Na Tabela 3.7 é apresentado um quadro resumo dos ganhos de calor calculados. 
Tabela 3-4 Ganhos de calor para veículo a $50 \mathrm{~km} / \mathrm{h}$.

\section{Condução por paredes e vidros}

\begin{tabular}{|l|c|c|c|c|c|c|}
\cline { 2 - 7 } \multicolumn{1}{c|}{} & $\mathrm{hi}$ & $\mathrm{Rt}$ & $\mathrm{Ti}$ & Tar-sol & he & $\dot{Q}_{k}$ \\
\cline { 2 - 8 } \multicolumn{1}{c|}{} & {$[\mathrm{W} / \mathrm{m} 2-\mathrm{K}]$} & {$[\mathrm{m} 2-\mathrm{K} / \mathrm{W}]$} & {$[\mathrm{K}]$} & {$[\mathrm{K}]$} & {$[\mathrm{W} / \mathrm{m} 2-\mathrm{K}]$} & {$[\mathrm{W}]$} \\
\hline 1. Teto & 8 & 1,27 & 300 & 335,8 & 30,2 & 50,7 \\
\hline 2. Porta_D (2x) & 8 & 5,50 & 300 & 329,6 & 27,9 & 8,6 \\
\hline 3. Porta_T (2x) & 8 & 5,50 & 300 & 330,0 & 27,0 & 7,6 \\
\hline 4. Traseira & 8 & 2,28 & 300 & 327,2 & 26,9 & 4,3 \\
\hline 5. Assoalho & 8 & 0,31 & 300 & 314,1 & 31,0 & 179,8 \\
\hline 6. Para-Brisas & 8 & 0,15 & 300 & 328,7 & 23,1 & 173,4 \\
\hline 7. Vidro traseiro & 8 & 0,13 & 300 & 330,3 & 25,6 & 65,6 \\
\hline 8. Vidro Porta_D (2x) & 8 & 0,13 & 300 & 325,4 & 23,5 & 98,2 \\
\hline 9. Vidro Porta_T (2x) & 8 & 0,13 & 300 & 326,9 & 18,2 & 99,9 \\
\hline 10. Vidro Lat. Tras. (2x) & 8 & 0,13 & 300 & 323,5 & 33,3 & 29,1 \\
\hline
\end{tabular}

2. Condução de calor do motor

\begin{tabular}{|c|c|c|c|c|c|c|}
\cline { 2 - 7 } \multicolumn{1}{c|}{} & $\mathrm{hi}$ & $\mathrm{Rt}$ & $\mathrm{Ti}$ & Tmotor & & $\dot{Q}_{\text {motor }}$ \\
\cline { 2 - 8 } & {$[\mathrm{W} / \mathrm{m} 2-\mathrm{K}]$} & {$[\mathrm{m} 2-\mathrm{K} / \mathrm{W}]$} & {$[\mathrm{K}]$} & {$[\mathrm{K}]$} & & {$[\mathrm{W}]$} \\
\hline 1. Painel frontal & 8 & 0,43 & 300 & 373,0 & & $\mathbf{1 0 7 , 7}$ \\
\hline
\end{tabular}

\section{Radiação solar}

\begin{tabular}{|l|c|c|c|c|c|c|}
\cline { 2 - 8 } \multicolumn{1}{c|}{} & $\mathrm{A}$ & Ang. & $\tau_{\mathrm{D}}$ & ID & & $\dot{Q}_{s}$ \\
\cline { 2 - 8 } \multicolumn{1}{c|}{} & {$[\mathrm{m} 2]$} & [graus] & - & {$[\mathrm{W} / \mathrm{m} 2]$} & & {$[\mathrm{W}]$} \\
\hline 1. Para-Brisas & 0,90 & 30 & 0,54 & 1000 & & 419,3 \\
\hline 2. Vidro traseiro & 0,28 & 50 & 0,59 & 1000 & & 105,3 \\
\hline
\end{tabular}

\section{Ventiladores}

\begin{tabular}{|c|c|c|c|c|c|c|}
\cline { 2 - 7 } \multicolumn{1}{c|}{} & $\mathrm{V}$ & $\mathrm{I}$ & & & & $\dot{Q}$ \\
\cline { 2 - 7 } & {$[\mathrm{V}]$} & {$[\mathrm{A}]$} & & & & {$[\mathrm{W}]$} \\
\hline 1. Ventilador & 12,8 & 20 & & & & $\mathbf{2 5 6 , 0}$ \\
\hline
\end{tabular}

\section{Infiltração}

\begin{tabular}{|c|c|c|c|c|c|}
\hline Vazão & $\dot{m}_{I}$ & hext & hint & & $\dot{Q}_{I}$ \\
\hline$[1 / \mathrm{s}]$ & $\mathrm{kg} / \mathrm{s}$ & $\mathrm{kJ} / \mathrm{kg}$ & $\mathrm{kJ} / \mathrm{kg}$ & & $\mathrm{W}$ \\
\hline 15 & 0,01588 & 101 & 53,42 & & $\mathbf{7 5 7 , 2}$ \\
\hline
\end{tabular}

GANHO DE CALOR TOTAL [W]: 
Tabela 3-5 Ganhos de calor para veículo a $100 \mathrm{~km} / \mathrm{h}$.

\section{Condução por paredes e vidros}

\begin{tabular}{|l|c|c|c|c|c|c|}
\cline { 2 - 7 } \multicolumn{1}{c|}{} & hi & Rt & Ti & Tar-sol & he & $\dot{Q}_{k}$ \\
\cline { 2 - 7 } \multicolumn{1}{c|}{} & {$[\mathrm{W} / \mathrm{m} 2-\mathrm{K}]$} & {$[\mathrm{m} 2-\mathrm{K} / \mathrm{W}]$} & {$[\mathrm{K}]$} & {$[\mathrm{K}]$} & {$[\mathrm{W} / \mathrm{m} 2-\mathrm{K}]$} & {$[\mathrm{W}]$} \\
\hline 1. Teto & 8 & 1,27 & 296 & 326,9 & 61,8 & 43,7 \\
\hline 2. Porta_D(2x) & 8 & 5,50 & 296 & 322,9 & 61,9 & 7,8 \\
\hline 3. Porta_T (2x) & 8 & 5,50 & 296 & 323,0 & 61,7 & 6,9 \\
\hline 4. Traseira & 8 & 2,28 & 296 & 325,0 & 45,1 & 4,6 \\
\hline 5. Assoalho & 8 & 0,31 & 296 & 314,7 & 59,9 & 238,4 \\
\hline 6. Para-Brisas & 8 & 0,15 & 296 & 322,0 & 59,9 & 157,0 \\
\hline 7. Vidro traseiro & 8 & 0,13 & 296 & 323,1 & 47,0 & 58,7 \\
\hline 8. Vidro Porta_D (2x) & 8 & 0,13 & 296 & 320,4 & 60,1 & 94,4 \\
\hline 9. Vidro Porta_T (2x) & 8 & 0,13 & 296 & 320,6 & 57,2 & 91,3 \\
\hline 10. Vidro Lat. Tras. (2x) & 8 & 0,13 & 296 & 321,3 & 47,0 & 31,3 \\
\hline
\end{tabular}

2. Condução de calor do motor

\begin{tabular}{|c|c|c|c|c|c|c|}
\cline { 2 - 7 } \multicolumn{1}{c|}{} & $\mathrm{hi}$ & $\mathrm{Rt}$ & $\mathrm{Ti}$ & Tmotor & & $\dot{Q}_{\text {motor }}$ \\
\cline { 2 - 8 } & {$[\mathrm{W} / \mathrm{m} 2-\mathrm{K}]$} & {$[\mathrm{m} 2-\mathrm{K} / \mathrm{W}]$} & {$[\mathrm{K}]$} & {$[\mathrm{K}]$} & & {$[\mathrm{W}]$} \\
\hline 1. Painel frontal & 8 & 0,43 & 300 & 373,0 & & $\mathbf{1 0 7 , 7}$ \\
\hline
\end{tabular}

\section{Radiação solar}

\begin{tabular}{|l|c|c|c|c|c|c|}
\cline { 2 - 8 } \multicolumn{1}{c|}{} & $\mathrm{A}$ & Ang. & $\tau_{\mathrm{D}}$ & ID & & $\dot{Q}_{s}$ \\
\cline { 2 - 8 } \multicolumn{1}{c|}{} & {$[\mathrm{m} 2]$} & [graus] & - & {$[\mathrm{W} / \mathrm{m} 2]$} & & {$[\mathrm{W}]$} \\
\hline 1. Para-Brisas & 0,90 & 30 & 0,54 & 1000 & & 419,3 \\
\hline 2. Vidro traseiro & 0,28 & 50 & 0,59 & 1000 & & 105,3 \\
\hline
\end{tabular}

\section{Ventiladores}

\begin{tabular}{|c|c|c|c|c|c|c|}
\cline { 2 - 7 } \multicolumn{1}{c|}{} & $\mathrm{V}$ & $\mathrm{I}$ & & & & $\dot{Q}$ \\
\cline { 2 - 7 } & {$[\mathrm{V}]$} & {$[\mathrm{A}]$} & & & & {$[\mathrm{W}]$} \\
\hline 1. Ventilador & 12,8 & 20 & & & & $\mathbf{2 5 6 , 0}$ \\
\hline
\end{tabular}

\section{Infiltração}

\begin{tabular}{|c|c|c|c|c|c|}
\hline Vazão & $\dot{m}_{I}$ & hext & hint & & $\dot{Q}_{I}$ \\
\hline$[1 / \mathrm{s}]$ & $\mathrm{kg} / \mathrm{s}$ & $\mathrm{kJ} / \mathrm{kg}$ & $\mathrm{kJ} / \mathrm{kg}$ & & $\mathrm{W}$ \\
\hline 15 & 0,01588 & 101 & 46,67 & & $\mathbf{8 6 4 , 3}$ \\
\hline
\end{tabular}

GANHO DE CALOR TOTAL $[$ W]: 2486,9 
Tabela 3-6 Ganhos de calor para veículo em marcha lenta

\begin{tabular}{|c|c|c|c|c|c|c|}
\hline \multicolumn{7}{|c|}{ 1. Condução por paredes e vidros } \\
\hline & hi & $\mathrm{Rt}$ & $\mathrm{Ti}$ & Tar-sol & he & $\dot{Q}_{k}$ \\
\hline & {$[\mathrm{W} / \mathrm{m} 2-\mathrm{K}]$} & {$[\mathrm{m} 2-\mathrm{K} / \mathrm{W}]$} & {$[\mathrm{K}]$} & {$[\mathrm{K}]$} & {$[\mathrm{W} / \mathrm{m} 2-\mathrm{K}]$} & [W] \\
\hline 1. Teto & 8 & 1,27 & 307 & 361,6 & 5,8 & 77,3 \\
\hline 2. Porta_D (2x) & 8 & 5,50 & 307 & 341,3 & 4,9 & 10,0 \\
\hline 3. Porta_T $(2 \mathrm{x})$ & 8 & 5,50 & 307 & 341,3 & 4,9 & 8,7 \\
\hline 4. Traseira & 8 & 2,28 & 307 & 340,7 & 4,8 & 5,3 \\
\hline 5. Assoalho & 8 & 0,31 & 307 & 316,0 & - & 114,8 \\
\hline 6. Para-Brisas & 8 & 0,15 & 307 & 342,1 & 6,9 & 212,0 \\
\hline 7. Vidro traseiro & 8 & 0,13 & 307 & 342,4 & 3,6 & 76,7 \\
\hline 8. Vidro Porta_D $(2 \mathrm{x})$ & 8 & 0,13 & 307 & 336,9 & 4,6 & 115,6 \\
\hline 9. Vidro Porta_T $(2 \mathrm{x})$ & 8 & 0,13 & 307 & 336,9 & 4,6 & 111,0 \\
\hline 10. Vidro Lat. Tras. (2x) & 8 & 0,13 & 307 & 336,9 & 4,6 & 37,0 \\
\hline
\end{tabular}

2. Condução de calor do motor

\begin{tabular}{|c|c|c|c|c|c|c|}
\cline { 2 - 7 } \multicolumn{1}{c|}{} & $\mathrm{hi}$ & $\mathrm{Rt}$ & $\mathrm{Ti}$ & Tmotor & & $\dot{Q}_{\text {motor }}$ \\
\cline { 2 - 7 } & {$[\mathrm{W} / \mathrm{m} 2-\mathrm{K}]$} & {$[\mathrm{m} 2-\mathrm{K} / \mathrm{W}]$} & {$[\mathrm{K}]$} & {$[\mathrm{K}]$} & & {$[\mathrm{W}]$} \\
\hline 1. Painel frontal & 8 & 0,43 & 300 & 373,0 & & $\mathbf{1 0 7 , 7}$ \\
\hline
\end{tabular}

3. Radiação solar

\begin{tabular}{|l|c|c|c|c|c|c|}
\cline { 2 - 7 } \multicolumn{1}{c|}{} & $\mathrm{A}$ & Ang. & $\tau_{\mathrm{D}}$ & $\mathrm{ID}$ & & $\dot{Q}_{s}$ \\
\cline { 2 - 8 } \multicolumn{1}{c|}{} & {$[\mathrm{m} 2]$} & [graus] & - & {$[\mathrm{W} / \mathrm{m} 2]$} & & {$[\mathrm{W}]$} \\
\hline 1. Para-Brisas & 0,90 & 30 & 0,54 & 1000 & & 419,3 \\
\hline 2. Vidro traseiro & 0,28 & 50 & 0,59 & 1000 & & 105,3 \\
\hline
\end{tabular}

4. Ventiladores

\begin{tabular}{|c|c|l|l|l|c|}
\hline $\mathrm{V}$ & $\mathrm{I}$ & & & & $\dot{Q}$ \\
\hline$[\mathrm{V}]$ & {$[\mathrm{A}]$} & & & & {$[\mathrm{W}]$} \\
\hline 12,8 & 20 & & & & $\mathbf{2 5 6 , 0}$ \\
\hline
\end{tabular}

\section{Infiltração}

\begin{tabular}{|c|c|c|c|l|c|}
\hline Vazão & $\dot{m}_{I}$ & hext & hint & & $\dot{Q}_{I}$ \\
\hline$[1 / \mathrm{s}]$ & $\mathrm{kg} / \mathrm{s}$ & $\mathrm{kJ} / \mathrm{kg}$ & $\mathrm{kJ} / \mathrm{kg}$ & & $\mathrm{W}$ \\
\hline 0 & 0 & 101 & 76,72 & & $\mathbf{0 , 0}$ \\
\hline
\end{tabular}

GANHO DE CALOR TOTAL $[W]: \begin{array}{ll}1656,8 \\ \end{array}$ 
Tabela 3-7 Quadro resumo dos ganhos de calor

\begin{tabular}{|lc|c|c|c|c|c|c|}
\cline { 3 - 8 } \multicolumn{1}{c|}{} & \multicolumn{2}{c|}{$50 \mathrm{~km} / \mathrm{h}$} & \multicolumn{2}{c|}{$100 \mathrm{~km} / \mathrm{h}$} & \multicolumn{2}{c|}{ M. Lenta } \\
\hline Condução & {$[\mathrm{W}]$} & 717,2 & $30,4 \%$ & 734,2 & $29,5 \%$ & 768,4 & $46,4 \%$ \\
\hline Motor & {$[\mathrm{W}]$} & 107,7 & $4,6 \%$ & 107,7 & $4,3 \%$ & 107,7 & $6,5 \%$ \\
\hline Radiação solar & {$[\mathrm{W}]$} & 524,6 & $22,2 \%$ & 524,6 & $21,1 \%$ & 524,6 & $31,7 \%$ \\
\hline Ventiladores & {$[\mathrm{W}]$} & 256,0 & $10,8 \%$ & 256,0 & $10,3 \%$ & 256,0 & $15,5 \%$ \\
\hline Infiltração & {$[\mathrm{W}]$} & 757,2 & $32,0 \%$ & 864,3 & $34,8 \%$ & 0,0 & $0,0 \%$ \\
\hline Total & {$[\mathrm{W}]$} & $\mathbf{2 3 6 2 , 7}$ & & $\mathbf{2 4 8 6 , 9}$ & & $\mathbf{1 6 5 6 , 8}$ & \\
\hline
\end{tabular}

\subsection{DETERMINAÇÃO DA CARGA TÉRMICA EFETIVA}

A partir dos dados obtidos em um ensaio de túnel de vento é possível calcular a carga térmica efetiva do equipamento de ar condicionado, por meio do uso das propriedades psicrométricas do ar úmido, usando a seguinte expressão:

$$
\dot{Q}_{-} \text {evap }=\dot{m}_{a r}\left(h_{\mathrm{int}}-h_{\text {desc }}\right) \quad[\mathrm{kW}]
$$

onde:

$$
\text { • }
$$

$m_{a r}=Q_{a r} \times \rho_{a r}=$ vazão mássica de ar do evaporador

hint, hdesc = entalpias do ar interno da cabina e do ar de descarga pelos difusores, respectivamente.

Com as temperaturas e umidades relativas do ar interno da cabine e de descarga é possível calcular a massa específica do ar e as entalpias, e daí calcular a carga térmica. Os resultados são apresentados na Tabela 3-8. Nota-se que a temperatura de descarga é menor ou muito próxima do ponto de orvalho, de maneira que é possível admitir que há condensação de água no evaporador e que o ar de descarga tem umidade relativa de $100 \%$.

É possível observar da análise da Tabela 3-7 e da Tabela 3-8 que a carga térmica efetiva é maior do que o ganho de calor em regime permanente, devido à necessidade de se reduzir a energia interna da cabina.. Vale ressaltar que os cálculos dos ganhos de calor foram feitos para uma condição específica de ensaio em túnel de vento com recirculador fechado. Com admissão de ar externo a carga térmica de renovação de ar deve ser reavaliada. 
Tabela 3-8 Carga térmica efetiva

\begin{tabular}{|l|l|c|c|c|c|}
\cline { 3 - 6 } \multicolumn{2}{c|}{} & $\mathbf{1}$ & $\mathbf{2}$ & $\mathbf{3}$ \\
\cline { 4 - 7 } & & $\mathbf{5 0} \mathbf{~ k m} / \mathbf{h}$ & $\mathbf{1 0 0 k m} / \mathbf{h}$ & M. Lenta \\
\hline Condições ambientais & T_int & {$\left[{ }^{\circ} \mathrm{C}\right]$} & 28,7 & 23,9 & 34,3 \\
\hline Temperatura interna & HR_int & $\%$ & $42 \%$ & $47 \%$ & $47 \%$ \\
\hline Umidade relativa interna & T_desc & {$\left[{ }^{\circ} \mathrm{C}\right]$} & 11,5 & 9,3 & 21,5 \\
\hline Temperatura de descarga & Dew & {$\left[{ }^{\circ} \mathrm{C}\right]$} & 14,5 & 11,9 & 21,4 \\
\hline Ponto de orvalho & Qar & {$[\mathrm{m} 3 / \mathrm{s}]$} & 0,12 & 0,12 & 0,12 \\
\hline Vazão volumétrica de ar & $\dot{Q}_{\text {evap }}$ & {$[\mathrm{kW}]$} & 4,3 & 3,7 & 3,5 \\
\hline Carga térmica & & & & & \\
\hline
\end{tabular}

\subsection{CONCLUSÕES}

Sabendo-se que a capacidade de refrigeração típica de automóveis de passeio tipo compactos é de $1 \mathrm{TR}$ a $1,5 \mathrm{TR}$ (cerca de $3,5 \mathrm{~kW}$ a $5,3 \mathrm{~kW}$ ), conclui-se que o cálculo pelo ganho de calor subestima a carga térmica real do teste em túnel de vento.

Essa diferença pode ser explicada pelos seguintes fatores:

- Energia interna do veículo - Os cálculos foram feitos assumindo a hipótese de ganho de calor em regime permanente, porém é possível que nos intervalos de tempo avaliados haja redução da energia interna do veículo. Stancato (1992) detectou esta diferença e considerou uma carga térmica correspondente à redução da energia interna do veículo, equivalente aproximadamente à metade da carga térmica total.

- A infiltração de ar externo pode ser maior do que o valor de $15 \mathrm{l} / \mathrm{s}$ adotado inicialmente.

- As resistências térmicas de condução através do teto, portas laterais e traseira levam em conta uma camada de ar que foi considerada simplesmente como um isolante, desconsiderando os efeitos de convecção e radiação que possam ocorrer naquele espaço, e podem estar superestimadas. O ganho de calor do motor através do painel frontal parece estar subestimado, fato que pode ser explicado por não ter sido considerado o ganho de calor por radiação.

- É provável que haja um ganho de calor proveniente do escapamento através do assoalho, que não foi considerado. 
A Tabela 3-9 apresenta um quadro comparativo dos resultados calculados para $50 \mathrm{~km} / \mathrm{h}$ (Tabela 3.4) no túnel de vento com os resultados encontrados por Ruth (1975) para um veículo compacto com um motorista e um passageiro, sob condições de sol ao meio dia, em direção oeste, latitude $49^{\circ} \mathrm{N}$ e no $190^{\circ}$ dia do ano (verão). A temperatura de bulbo seco externa é de $37.8^{\circ} \mathrm{C}$ e umidade relativa de $20 \%$, e a renovação de ar é $100 \%$.

Tabela 3-9 Quadro comparativo de carga térmica de veículos compactos

\begin{tabular}{|l|c|c|}
\cline { 2 - 3 } \multicolumn{1}{c|}{} & Tabela 3-4 & Ruth (1975) \\
\hline Condução & 824,9 & 518,4 \\
\hline Solar & 524,6 & 1309,2 \\
\hline Equipamentos & 256,0 & 58,6 \\
\hline Pessoas & 0 & 292,9 \\
\hline Ar externo & 757,2 & 1581,5 \\
\hline Total & $\mathbf{2 3 6 2 , 7}$ & $\mathbf{3 7 6 0 , 5}$ \\
\hline
\end{tabular}

Da análise dos resultados da Tabela 3-9 verifica-se que:

a) O ganho de calor de condução calculado para o túnel de vento é maior que o estimado por Ruth (1975). Parte desta diferença pode ser explicada pelo fato de que a temperatura externa ser maior no primeiro caso;

b) A diferença de carga solar pode ser devida ao fato de que em Ruth o veículo estava sujeito à radiação difusa que não foi considerada no túnel de vento. Além disto, os vidros usados no segundo caso eram incolores, com uma transmissividade de $85 \%$, maior que a do veículo do túnel de vento.

c) Descontando-se o ganho de calor relativo a pessoas e o excedente relativo à renovação de ar externo, o modelo de Ruth também provavelmente subestima a carga térmica real.

\subsubsection{Considerações para estudos futuros}

Um estudo futuro sobre as cargas térmicas em um ensaio de desempenho de ar condicionado poderia incorporar melhorias como segue:

- Durante o ensaio de desempenho, seria importante medir a umidade relativa interna do veículo, de modo a avaliar mais corretamente o efeito da infiltração de ar externo.

- Avaliar a radiação de calor no compartimento do motor para estimar melhor o ganho de calor pelo assoalho do carro. 
- Avaliar o ganho de calor do escapamento através do assoalho.

- Melhorar o modelo de condução térmica para as superfícies isoladas por um espaço de ar, como teto, portas e parte traseira.

- Incorporar um modelo para condição transiente, de modo a avaliar a carga térmica correspondente à redução da energia interna do veículo.

- Reavaliar a carga térmica de renovação de ar considerando admissão de ar externo. 


\section{CAPÍTULO 4 SISTEMA DE REFRIGERAÇÃO}

O processo de refrigeração da cabina de um automóvel consiste em remover o calor do seu interior e dissipar este calor no ambiente externo. O sistema capaz de executar essa função precisa ser leve e compacto, para que possa ser instalado nos pequenos espaços disponíveis no automóvel. Além disso, precisa ser o mais eficiente possível dentro das condições impostas, pois o consumo de energia envolvido no processo é significativo. $\mathrm{O}$ custo do sistema é um outro fator muito importante. Mesmo com todos os avanços tecnológicos e com a produção em escala, o sistema de refrigeração ainda é um dos opcionais de conforto mais caros de um automóvel.

Por esses motivos, entre as diversas formas de se transferir calor de um ambiente mais frio para um mais quente, o sistema adotado em automóveis é o ciclo de refrigeração por compressão de vapor. Este sistema vem sendo utilizado desde o primeiro veículo equipado com sistema de refrigeração, que foi o Packard em 1939 (utilizando refrigerante R12), até os dias de hoje (Bhatti, 1999a). Há relatos de sistemas como o ciclo aberto de refrigeração a ar (o ciclo Brayton), muito utilizado em aeronaves. Esse método, porém, ainda não se mostra viável para uso em automóveis. O ar (R-729) não oferece nenhum tipo de risco por ser não-tóxico e por não ser um gás de efeito estufa (Bhatti, 1998). No entanto Bhatti destaca como desvantagens do sistema o potencial aumento de consumo de combustível e a necessidade de alta eficiência do compressor e expansor (80\% a $85 \%$ ) e do trocador de calor ar-ar (75\% a $85 \%)$. Devido ao aumento do consumo de combustível, o impacto total equivalente do sistema R-729 no aquecimento global é maior do que o sistema R134a de acordo com Bhatti (1998).

\subsection{CICLO DE REFRIGERAÇÃO POR COMPRESSÃO DE VAPOR}

\subsubsection{O ciclo ideal de Carnot}

O bem conhecido ciclo de Carnot é um ciclo totalmente reversível que consiste em dois processos isotérmicos reversíveis e dois processos isoentrópicos. É o ciclo que oferece a maior eficiência para transferir o calor de um reservatório térmico a uma dada temperatura $\mathrm{T}_{\mathrm{L}}$ para um reservatório térmico a uma temperatura mais alta $\mathrm{T}_{\mathrm{H}}$. Esta transferência de calor somente é possível à custa de trabalho. 
A Figura 4-1 ilustra o esquema do ciclo de Carnot e a representação do ciclo no diagrama temperatura-entropia (T-s).
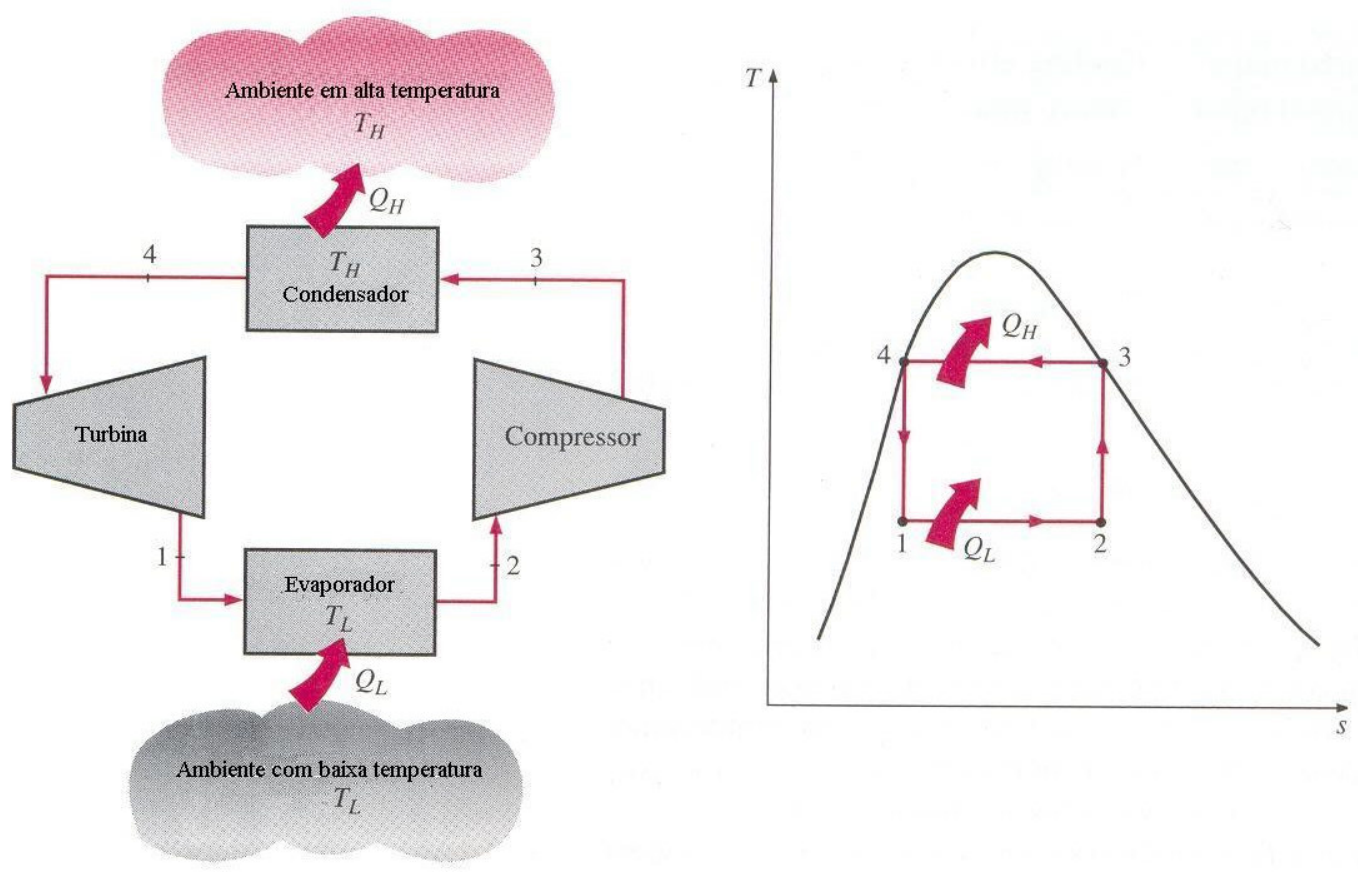

Figura 4-1 Esquema e diagrama T-s do ciclo de Carnot (Çengel e Boles, 1998)

O fluido refrigerante absorve o calor $\dot{Q}_{L}$ do reservatório frio durante o processo isotérmico 1-2, no evaporador. Em seguida ocorre a compressão isoentrópica durante o processo 2-3 no compressor. O fluido rejeita o calor $\dot{Q}_{H}$ para o reservatório quente durante o processo 3-4 no condensador, e finalmente é expandido isoentropicamente durante o processo 4-1 em uma turbina, completando o ciclo. O coeficiente de performance $\beta$ é deduzido do diagrama T-s pelas áreas sob o ciclo de refrigeração e é dado pela equação 4.1:

$$
\beta=\frac{T_{L}}{T_{H}-T_{L}}
$$

O ciclo de Carnot apresenta algumas limitações práticas. Os processos isotérmicos 1-2 e 3-4 são obtidos com relativa facilidade em evaporadores e condensadores, pois ocorrem na região bifásica à pressão constante e, portanto, à temperatura de saturação constante. No entanto a compressão úmida (processo 2-3) não é facilmente obtida, e a expansão em turbina no processo 4-1 nem sempre é economicamente viável. Executar o ciclo de Carnot fora da região de saturação poderia resolver o problema de compressão e expansão úmida, porém seria difícil obter os processos isotérmicos nessa região. O ciclo 
ideal de refrigeração por compressão de vapor distingue-se, portanto, do ciclo de Carnot.

\subsubsection{O ciclo ideal de refrigeração por compressão de vapor}

O problema da compressão úmida é resolvido fazendo-se a compressão com o fluido superaquecido, chamada de compressão seca. A turbina é normalmente substituída por uma válvula de expansão ou um tubo capilar. O trabalho gerado pela expansão em uma turbina seria pequeno se comparado com a potência gasta no processo de compressão. $\mathrm{O}$ sacrifício do trabalho que seria gerado pela turbina se justifica pelos custos menores de instalação e manutenção dos dispositivos de expansão (Moran e Shapiro, 2004).

O ciclo ideal de refrigeração por compressão de vapor é apresentado na Figura 4-2. Observa-se o processo de compressão do vapor superaquecido 1-2, que ocorre isoentropicamente atingindo a pressão de saturação correspondente à temperatura $T_{H}$ no ponto 2. O fluido entra superaquecido no condensador e é resfriado até a temperatura de saturação $\mathrm{T}_{\mathrm{H}}$, e passa a perder calor devido à mudança de fase até o ponto 3 . Durante o processo 2-3 o fluido rejeita o calor $\dot{Q}_{H}$ para o reservatório quente. A expansão ocorre em uma válvula de expansão ou tubo capilar durante o processo irreversível 3-4, onde se nota um aumento da entropia e uma redução da capacidade de refrigeração $\dot{Q}_{L}$ em relação à expansão em turbina representada pelo ponto 4'. A evaporação ocorre isotermicamente no processo 4-1 completando o ciclo.

Com exceção da expansão 3-4, os outros processos são internamente reversíveis. Fazendo uma análise em regime permanente, desprezando as mudanças de energia potencial e cinética, tem-se que para um volume de controle envolvendo o lado do refrigerante do evaporador o valor de $\dot{Q}_{L}$ é dado por:

$$
\dot{Q}_{L}=\dot{m}_{r}\left(h_{1}-h_{4}\right) \quad[\mathrm{kW}]
$$

O calor absorvido do reservatório térmico a baixa temperatura $\dot{Q}_{L}$ é chamado de capacidade de refrigeração. A diferença de entalpias $\mathrm{h}_{1}$ - $\mathrm{h}_{4}$ é chamada de efeito de refrigeração (Stoecker, 1985; Dossat e Horan, 2001).

Para um volume de controle envolvendo o compressor, assumindo que o processo é adiabático, a potência de eixo $\dot{W}_{\text {comp }}$ é dada por:

$$
\dot{W}_{\text {comp }}=\dot{m}_{r}\left(h_{2}-h_{1}\right) \quad[\mathrm{kW}]
$$



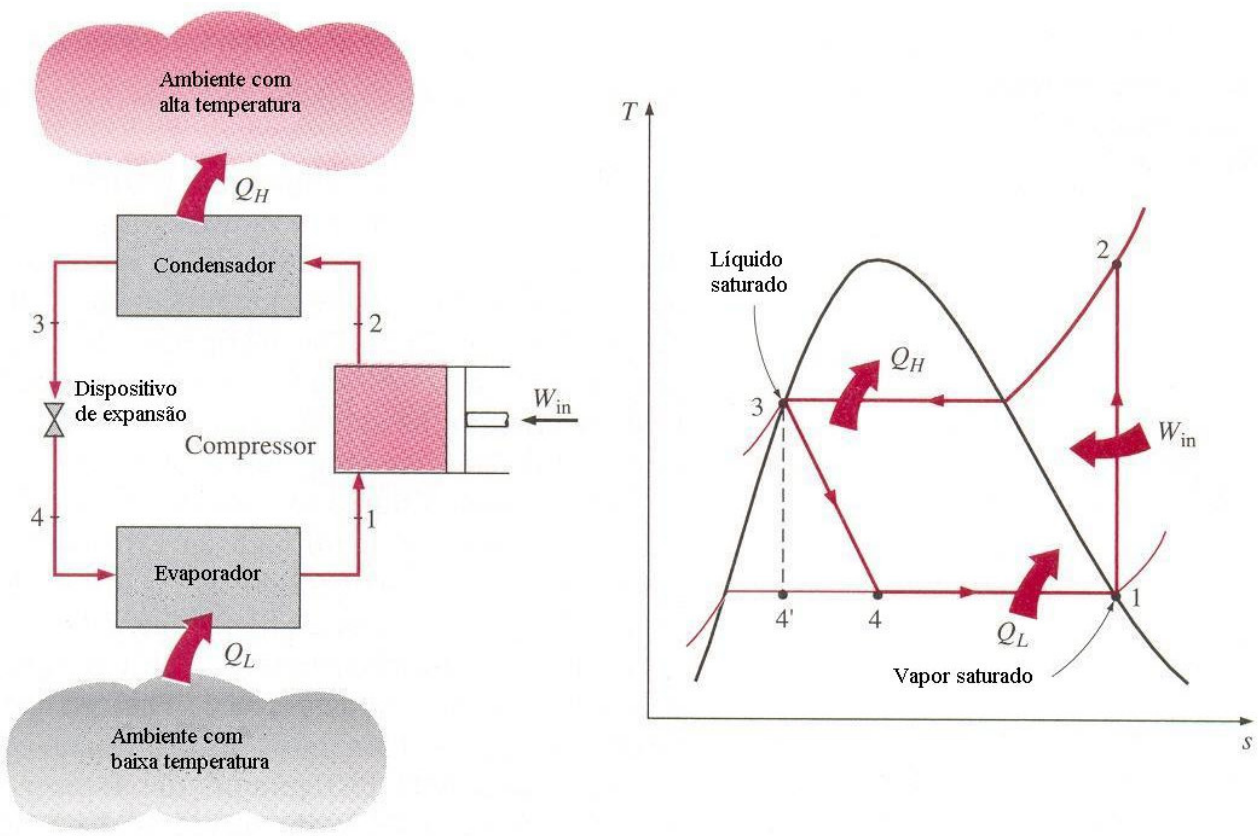

Figura 4-2 Esquema e diagrama $T$-s do ciclo ideal de refrigeração por compressão de vapor (Çengel e Boles, 1998)

A potência de eixo $\dot{W}_{\text {comp }}$ é também chamada de trabalho de compressão (Dossat e Horan, 2001).

Para um volume de controle envolvendo o lado do refrigerante do condensador, o calor rejeitado para o reservatório quente $\dot{Q}_{H}$ vale:

$$
\dot{Q}_{H}=\dot{m}_{r}\left(h_{3}-h_{2}\right) \quad[\mathrm{kW}]
$$

A expansão adiabática que ocorre no dispositivo de expansão é modelada como sendo isentálpica, de tal maneira que:

$$
h_{4}=h_{3} \quad[\mathrm{~kJ} / \mathrm{kg}]
$$

onde:

$\dot{\mathrm{m}}_{\mathrm{r}}=$ vazão mássica de refrigerante $(\mathrm{kg} / \mathrm{s})$

$\mathrm{h}_{1}, \mathrm{~h}_{2}, \mathrm{~h}_{3}, \mathrm{~h}_{4}=$ entalpias do refrigerante nos estados $1,2,3$ e 4 respectivamente $(\mathrm{kJ} / \mathrm{kg})$

O coeficiente de performance $\beta$ do ciclo ideal de refrigeração por compressão de vapor é dado pela razão entre a capacidade de refrigeração $\dot{Q}_{L}$ e a potência líquida consumida pelo sistema. Como não há potência entrando nem saindo no processo de expansão 3-4, a potência líquida consumida pelo sistema equivale à potência de eixo do 
compressor, $\dot{W}_{\text {comp }}$. Desta forma, $\beta$ é dado por:

$$
\beta=\frac{\dot{Q}_{L}}{\dot{W}_{\text {comp }}}=\frac{\dot{m_{r}}\left(h_{1}-h_{4}\right)}{\dot{m}_{r}\left(h_{2}-h_{1}\right)}
$$

A equação 4.6 define o máximo coeficiente de performance para um ciclo ideal de refrigeração por compressão de vapor, dadas as temperaturas de evaporação e condensação e as pressões de trabalho. Este coeficiente de performance será menor do que o coeficiente de performance do ciclo de Carnot, devido à expansão não-isoentrópica e à compressão seca do fluido.

Nas aplicações de refrigeração, é comum representar o ciclo usando um diagrama pressão-entalpia pela sua praticidade, pois a entalpia é uma propriedade importante para os cálculos e as pressões são obtidas facilmente (Stoecker, 1985). Um ciclo de refrigeração ideal representado em um diagrama pressão-entalpia é apresentado na Figura 4-3.

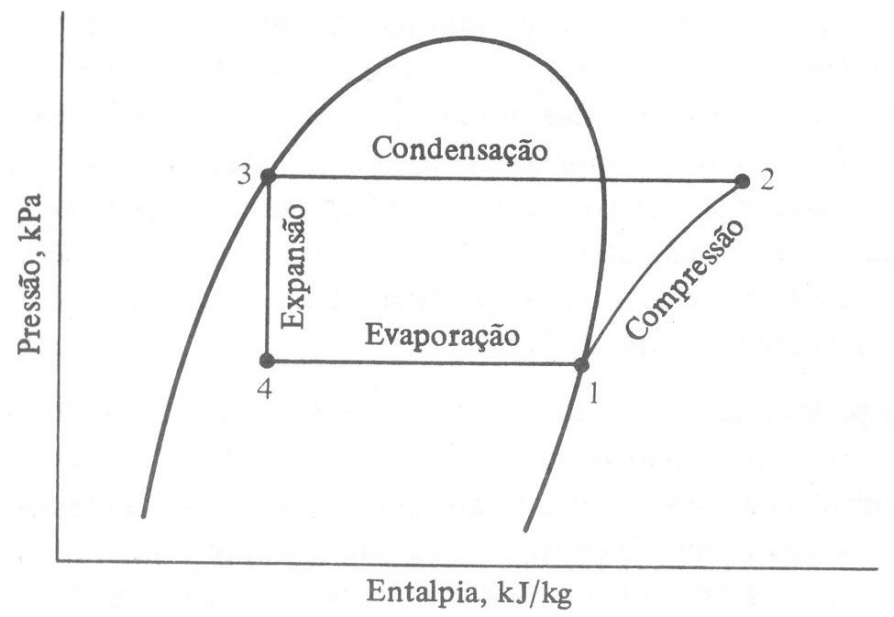

Figura 4-3 Diagrama p-h de um ciclo padrão de refrigeração (Stoecker, 1985 )

As pressões de evaporação e condensação são constantes e aparecem como retas horizontais. A expansão do fluido é isoentálpica, e aparece como uma reta vertical. A compressão do fluido aparece em uma linha isoentrópica.

Nos ciclos reais ocorrem outras irreversibilidades que fazem com que o coeficiente de performance seja reduzido ainda mais, como será visto a seguir.

\subsubsection{O ciclo real de refrigeração por compressão de vapor}

Em um ciclo real de refrigeração por compressão de vapor ocorrem outras irreversibilidades que acabam por reduzir a eficácia do sistema. O ciclo padrão admite que não há perda de carga nos trocadores de calor e nas tubulações. Devido ao atrito no fluido 
ao escoar entre as paredes internas dos trocadores e das tubulações, ocorre uma perda de carga no ciclo real, demonstrada na Figura 4-4 pelas linhas cheias D'-A e B'-C' ligeiramente inclinadas (condensador e evaporador), A-A' (linha de líquido), C'-C', (linha de sucção), C' -C', (válvulas de admissão do compressor) e D'-D', (válvulas de descarga do compressor). O trabalho de compressão também sofre um aumento devido aos atritos no compressor, resultando em uma compressão não-isoentrópica, conforme ilustrado pela linha tracejada na Figura 4-5.

É difícil garantir que o refrigerante que sai do condensador e o que sai do evaporador estejam exatamente sobre a linha de saturação. Uma prática comum nas aplicações de refrigeração é adotar algum subresfriamento na saída do condensador e um superaquecimento na saída do evaporador, conforme ilustrado na Figura 4-4, o que resulta em mais um desvio em relação ao ciclo padrão. É importante observar que algum subresfriamento é conveniente, pois além de garantir que somente refrigerante líquido entre no dispositivo de expansão, o efeito de refrigeração aumenta proporcionalmente à diferença de entalpias dos pontos A e A' da Figura 4-4.

Por fim, para se atingir uma transferência de calor adequada com trocadores de calor de dimensões praticáveis, é preciso projetar a temperatura de condensação acima da temperatura do reservatório quente (que no caso das aplicações automotivas é a temperatura do ar externo) e a temperatura de evaporação abaixo da temperatura do reservatório frio (temperatura desejada no interior da cabina), como pode ser visto na Figura 4-5. Este fator acaba por reduzir significativamente o coeficiente de performance.

\subsubsection{Fluido refrigerante}

A escolha do refrigerante deve levar em conta fatores como as temperaturas dos meios quente e frio, as pressões de trabalho, flamabilidade, toxicidade, e miscibilidade com o óleo lubrificante. O fluido deve ser não-corrosivo e quimicamente estável, e deve ser disponível ao menor custo possível.

Para que haja uma transferência de calor a uma taxa razoável, a diferença de temperatura entre o refrigerante e o meio com o qual ocorre a troca térmica deve ser de $5^{\circ}$ a $10^{\circ} \mathrm{C}$ (Çengel e Boles, 1998). A menor pressão do sistema deve ficar acima da pressão atmosférica para evitar infiltrações de ar. A temperatura de condensação não deve ficar abaixo da temperatura do meio externo, e a pressão de saturação deve preferencialmente ficar bem abaixo da pressão crítica para garantir uma condensação mais próxima possível de uma isotérmica (fato que não ocorre, por exemplo, com o $\mathrm{CO}_{2}$ ). 


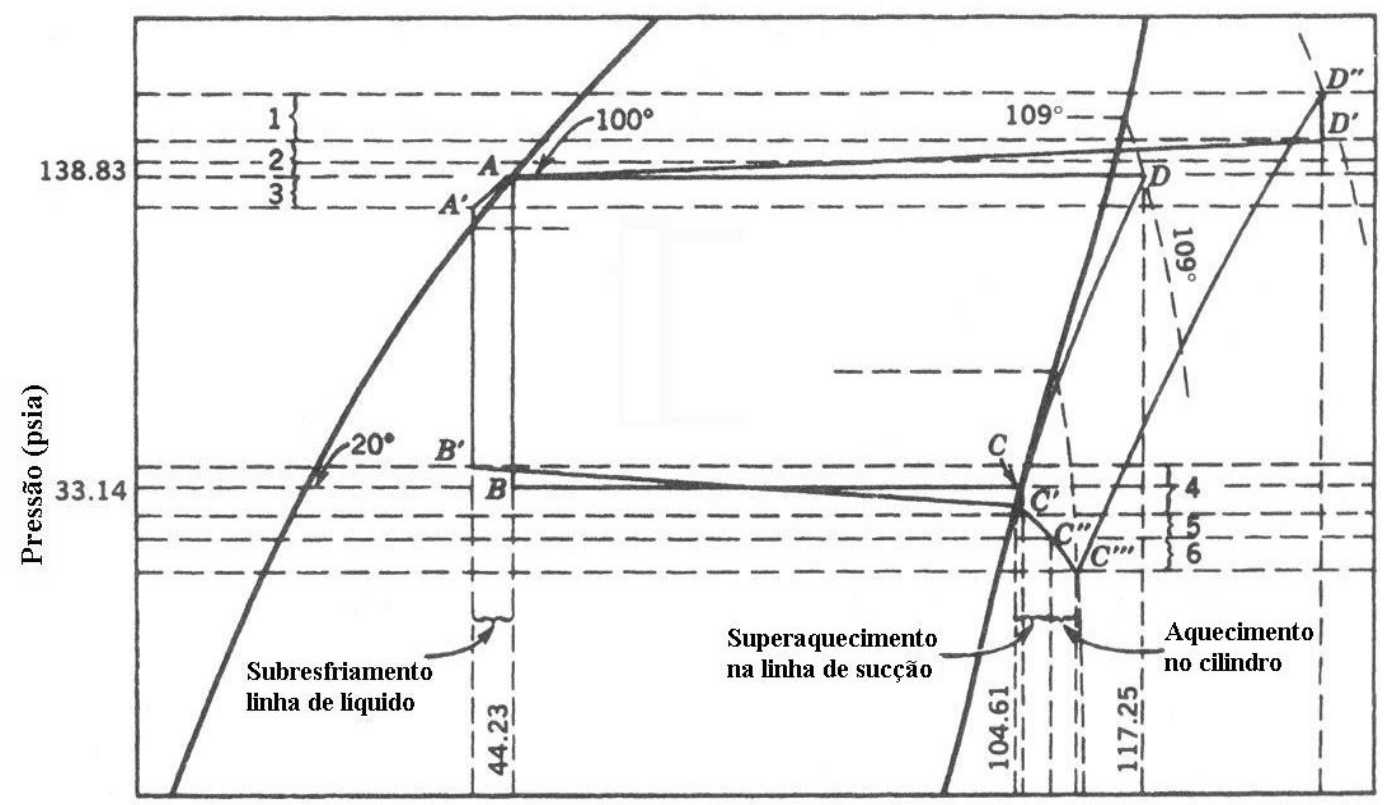

Entalpia (Btu/lb)

Quedas de pressão

1. Válvulas de descarga do compressor 4. Evaporador

2. Linha de descarga e condensador 5. Linha de sucção

3. Linha de líquido

6. Válvulas de sucção do compressor

Figura 4-4 Diagrama p-h de um ciclo real de refrigeração, ilustrando os efeitos do subresfriamento e superaquecimento, e das quedas de pressão (Dossat e Horan, 2001).

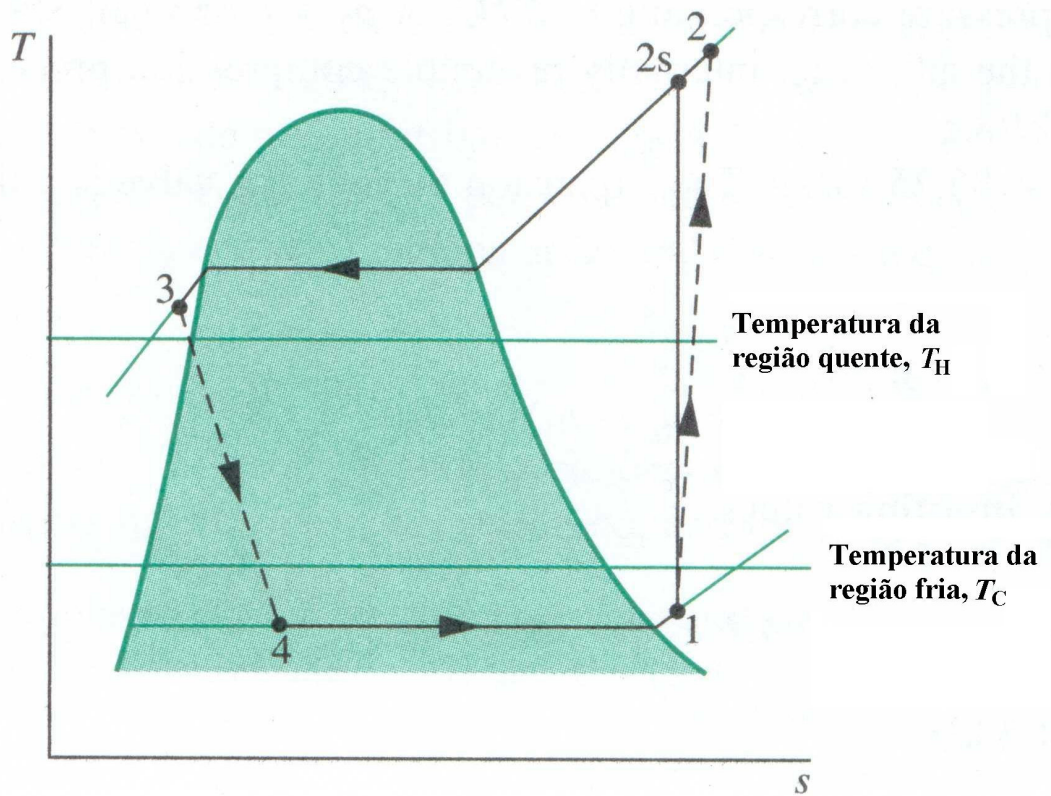

Figura 4-5 Diagrama T-s de um ciclo real de refrigeração por compressão de vapor (Moran e Shapiro, 2004). 
O desenvolvimento do refrigerante R12 (Clorofluorcarbono) em 1928, impulsionou a aplicação de sistemas de refrigeração em automóveis a partir de 1939 (Forrest e Bhatti, 2002). Além de ser um refrigerante não tóxico, atende às condições de operação previamente mencionadas. O R12 foi usado praticamente na totalidade das aplicações automotivas até o estabelecimento da sua relação com a destruição da camada de ozônio em 1974. A produção de clorofluorcarbonos, incluindo R12 foi banida pelo Protocolo de Montreal de 1981 e somente em 1992 os fabricantes iniciaram a substituição do clorofluorcarbono pelo tetrafluoretano, ou R134a (Bhatti, 1997). O refrigerante R134a atende às condições de operação previamente mencionadas, é considerado não tóxico em concentrações de até 400ppm e não inflamável quando testado com ar a $14,7 \mathrm{psia}$ e $18,3^{\circ} \mathrm{C}$, sendo adequado para o uso automotivo (Dossat e Horan, 2001) e é o refrigerante utilizado atualmente.

O refrigerante R134a tem sido recentemente associado com o efeito estufa, e por esse motivo há várias discussões no meio científico e entre os fabricantes de automóveis sobre o uso de refrigerantes alternativos como o dióxido de carbono $\left(\mathrm{CO}_{2}\right)$ e outras misturas azeotrópicas. Os fabricantes têm mostrado um interesse em particular na aplicação do $\mathrm{CO}_{2}$ em veículos híbridos ou movidos a células de hidrogênio, pois o mesmo se mostra apropriado para sistemas reversíveis, podendo ser utilizado como refrigerador e como bomba de calor, suprindo a necessidade de fonte de calor desse tipo de veículos. $\mathrm{O}$ estudo de refrigerantes alternativos não é o escopo deste trabalho, e por este motivo os cálculos, desenvolvimentos e dados reais apresentados irão considerar o refrigerante usado atualmente, ou seja, o R134a.

\subsection{COMPONENTES DO CICLO DE REFRIGERAÇÃO}

O sistema completo de climatização de um automóvel compreende os componentes do ciclo de refrigeração e aquecimento, o módulo de condensador e ventilador frontal, o sistema de captação do ar externo, o conjunto de controle da ventilação, distribuição e temperatura do ar interno, os dutos e difusores, o painel de controles e os sensores do sistema. Neste capítulo serão abordados os componentes do ciclo de refrigeração e o módulo de condensador e ventilador frontal. Como dito anteriormente, serão apresentados os componentes do sistema de refrigeração por compressão de vapor utilizando o refrigerante R134a.

Os componentes utilizados no ciclo de refrigeração variam de acordo com o dispositivo de expansão e controle de refrigerante para o evaporador adotado no sistema. 
Os dispositivos de expansão mais comuns são a válvula de expansão termostática e o tubo com orifício calibrado. A Figura 4-6 e a Figura 4-7 apresentam ciclos de refrigeração usando um dispositivo de expansão tipo tubo com orifício calibrado e válvula de expansão termostática, respectivamente.

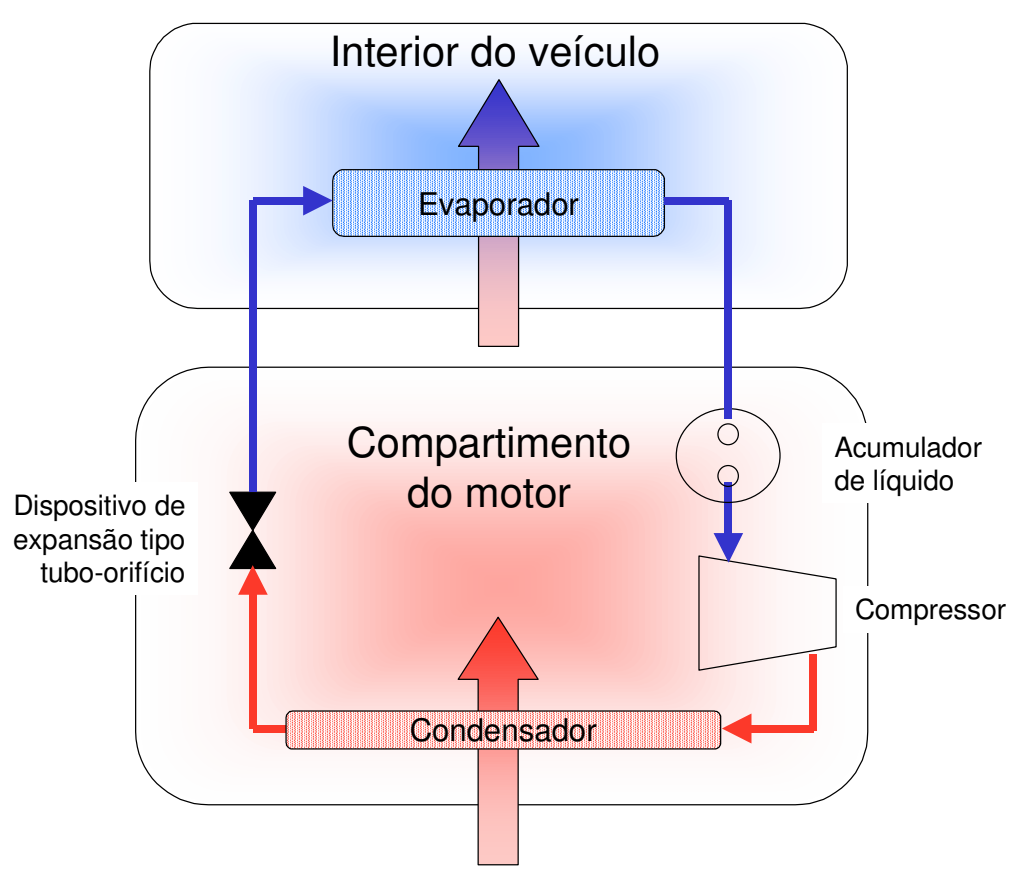

Figura 4-6 Ciclo de refrigeração com dispositivo de expansão tipo tubo de orifício.

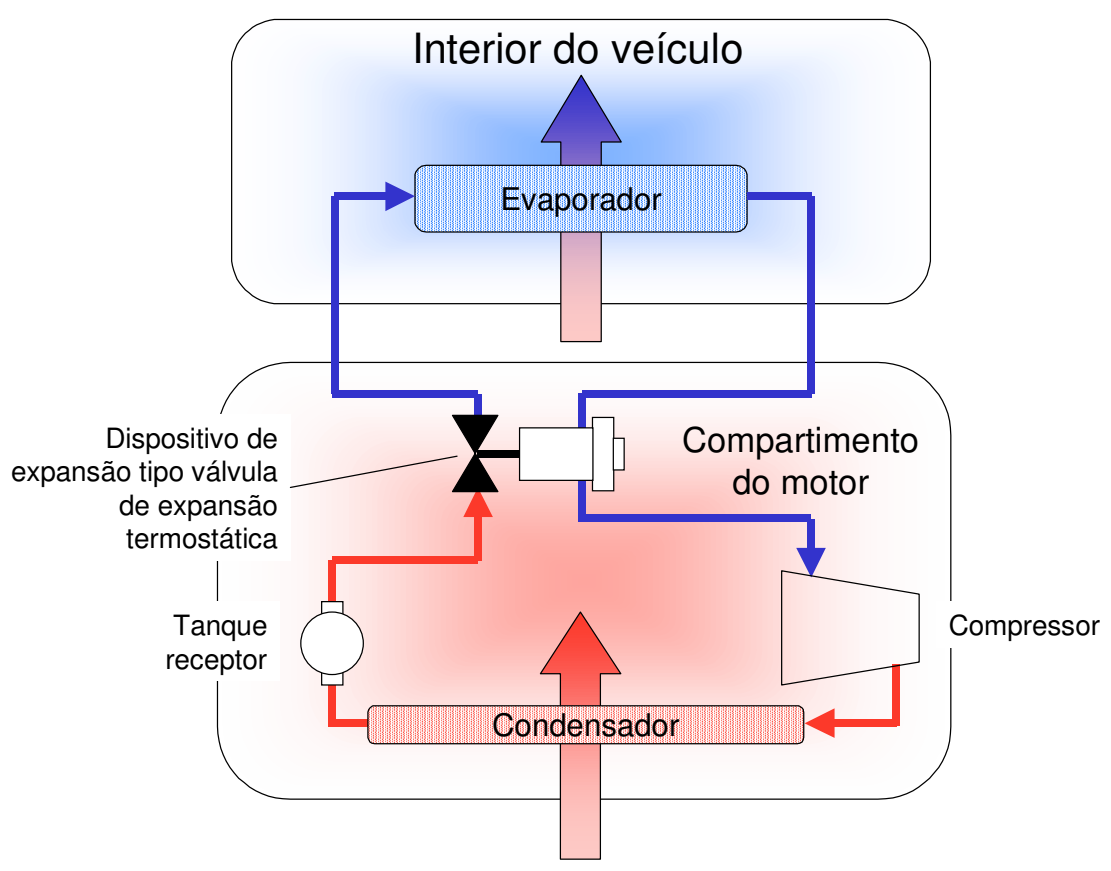

Figura 4-7 Ciclo de refrigeração com dispositivo de expansão tipo válvula termostática. 
No diagrama da Figura 4-6 (tubo de orifício), o evaporador com o respectivo sistema de ventilação estão instalados no interior do veículo, embora haja configurações onde estes componentes são instalados do lado externo da cabina, por exemplo na área de captação de ar externo ou mesmo no compartimento do motor. O dispositivo de expansão é normalmente instalado no interior da tubulação de alta pressão próxima à entrada do evaporador. A tubulação é provida de conexões que permitem a sua desmontagem para acesso ao dispositivo de expansão. Como o sistema de expansão em tubo de orifício não consegue garantir refrigerante superaquecido na saída do evaporador, há um acumulador de líquido na sucção do compressor para evitar a chegada de refrigerante líquido ao mesmo.

A Figura 4-7 ilustra a válvula de expansão instalada no compartimento do motor, embora existam instalações onde este componente se encontra no interior do veículo, ou mesmo adjacente ao painel frontal que separa a cabina do compartimento do motor. Similarmente ao sistema com tubo-orifício, o evaporador pode estar instalado fora da cabina do veículo. A válvula de expansão termostática é capaz de garantir refrigerante superaquecido na saída do evaporador, dispensando a necessidade do acumulador. Neste sistema existe um tanque receptor na entrada da válvula para garantir que somente refrigerante líquido chegue à mesma.

O sistema estudado neste trabalho utiliza um dispositivo tipo tubo de orifício calibrado conforme ilustrado na Figura 4-6, de maneira que o funcionamento da válvula de expansão termostática não será aprofundado além da breve descrição aqui apresentada.

\subsection{COMPRESSOR}

\subsubsection{Construção mecânica}

Existem diversos tipos de construções mecânicas para compressores de sistemas de refrigeração para aplicação em automóveis. Em seu trabalho, Ávila (2002) descreve os tipos principais de compressores para aplicações em automóveis, listados abaixo:

- Compressor alternativo radial de pistões (em desuso)

- Compressor alternativo de pistões com prato oscilante ('Swashplate" ou 'Wobbleplate")

- Compressor rotativo de palhetas

- Compressor rotativo caracol ('Scroll”'). 
As grandes variações de carga térmica e larga faixa de rotações de trabalho do compressor impulsionaram o desenvolvimento de compressores com deslocamento variável. Os tipos mais comuns de compressor de deslocamento variável são o de pistão com prato oscilante e o scroll.

O caso em estudo neste trabalho utiliza um compressor alternativo de pistões com prato oscilante, de deslocamento fixo. Este modelo de compressor será analisado com maior profundidade.

\subsubsection{Funcionamento e características}

Inicialmente uma breve descrição do funcionamento do compressor alternativo de pistões se faz necessária para se compreender as suas características e o seu comportamento em um sistema de refrigeração. Uma descrição completa pode ser encontrada em Dossat e Horan (2001), cujo trabalho foi usado como referência para a descrição a seguir.

O funcionamento de um compressor alternativo de pistão pode mais facilmente ser compreendido tomando-se, inicialmente, como exemplo o caso do compressor radial apresentado na Figura 4-8.

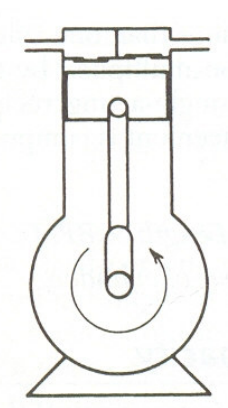

(a)

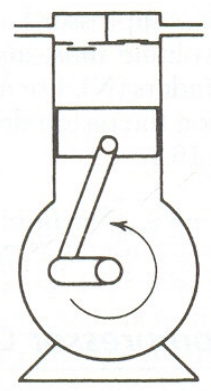

(b)

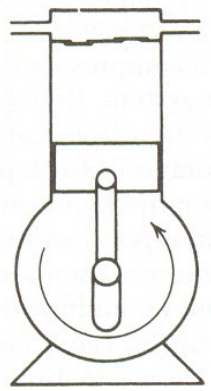

(c)

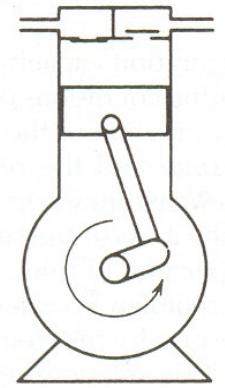

(d)

Figura 4-8 Compressor alternativo de pistão. (a) Pistão no ponto morto superior. (b) Válvula de sucção aberta. (c) Pistão no ponto morto inferior. (d) Válvula de descarga aberta (Dossat e Horan, 2001)

O ciclo demonstrado na Figura 4-8 repete-se várias vezes por segundo dependendo da rotação do eixo do compressor. No ponto morto superior o pistão se encontra à mínima distância das válvulas. Para evitar que o pistão venha a colidir com as válvulas, é preciso manter um pequeno espaço conhecido como espaço morto (ou volume morto $)^{7}$. O diagrama teórico da pressão no cilindro ao longo da posição angular do eixo é

\footnotetext{
7 O termo original utilizado pelo autor é "clearance volume", traduzido como "espaço morto". A tradução de Stoecker (1985) utiliza o termo "espaço nocivo" para denominar esta característica do compressor
} 
apresentado na Figura 4-9.

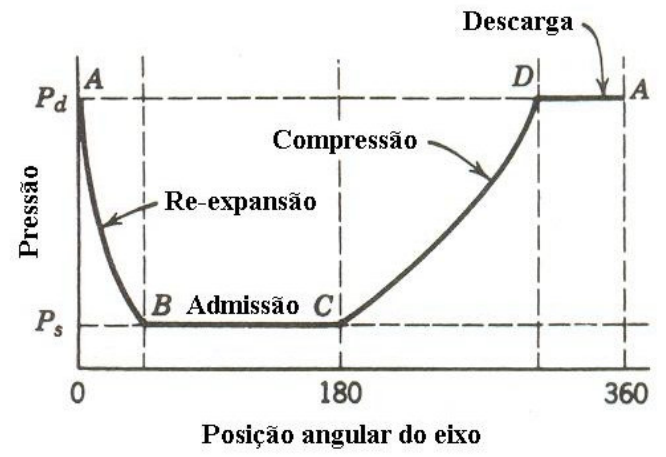

Figura 4-9 Diagrama teórico da pressão no cilindro ao longo da posição angular do eixo (Dossat e Horan, 2001)

$\mathrm{O}$ volume $\mathrm{V}_{\mathrm{a}}$ indicado na Figura 4-10 corresponde ao espaço morto. $\mathrm{O}$ volume $\mathrm{V}_{\mathrm{c}}$ corresponde ao volume máximo do cilindro e o volume $\mathrm{V}_{\mathrm{b}}$ corresponde ao volume ocupado pela re-expansão do vapor que se encontrava no espaço morto à pressão de descarga. A redução do volume do cilindro devido à re-expansão do vapor do espaço morto afeta a eficiência volumétrica do compressor.

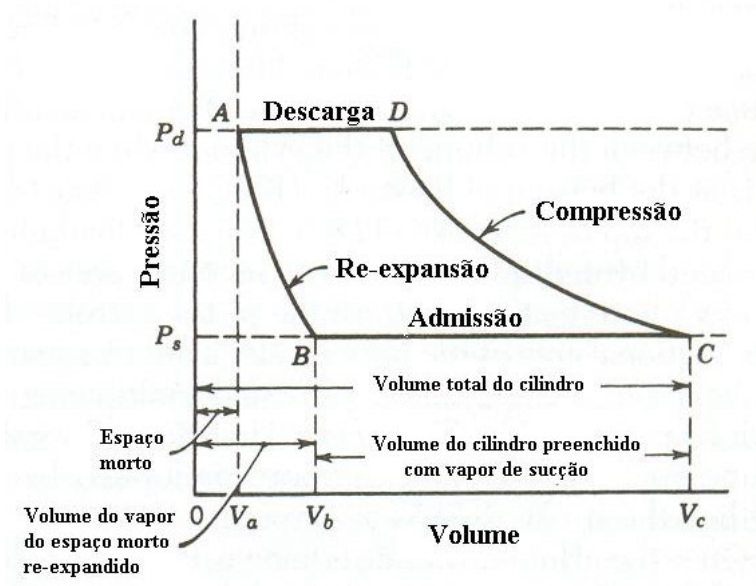

Figura 4-10 Diagrama Pressão - Volume para um ciclo de compressão típico (Dossat e Horan, 2001)

Como pode ser deduzido da Figura 4-10, o volume do cilindro que será preenchido pelo vapor de sucção depende da relação entre as pressões absolutas de sucção $\left(\mathrm{p}_{\mathrm{s}}\right)$ e descarga $\left(\mathrm{p}_{\mathrm{d}}\right)$, chamada razão de compressão $(\mathrm{PR})$, conforme equação 4.7.

$$
P R=\frac{p_{d}}{p_{s}}
$$


A Figura 4-11 ilustra o efeito da razão de compressão sobre a eficiência volumétrica do compressor.

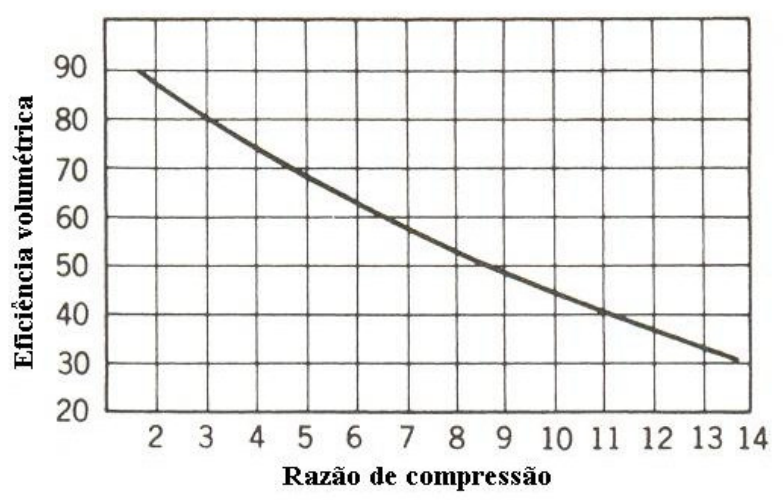

Figura 4-11 Efeito da razão de compressão na eficiência volumétrica (Dossat, 2001)

O compressor alternativo de pistão utilizado em aplicações automotivas tem um construtivo diferente do que é apresentado na Figura 4-8. Um diagrama simplificado na figura Figura 4-12 apresenta em vista explodida o conjunto de um compressor de prato oscilante de deslocamento fixo. Esta imagem não tem a intenção de representar fielmente os componentes reais, portanto não ilustra componentes como as válvulas, os rolamentos, o conjuto da polia e embreagem magnética, vedações, portas de sucção e descarga e parafusos de montagem. No entanto serve para facilitar a compreensão do funcionamento do conjunto. Nota-se que o contato entre os pistões e o prato oscilante é feito por sapatas semi-esféricas que deslizam sobre a superfície de contato com o prato. A lubrificação das superfícies em contato é feita pelo óleo lubrificante do sistema, que é solúvel no refrigerante e circula juntamente com este.

À exceção do mecanismo de acionamento dos pistões, o compressor de prato oscilante se comporta da mesma maneira que o compressor da Figura 4-8 no que diz respeito ao comportamento Pressão - Volume. O compressor de prato oscilante também apresenta um volume de espaço morto, entre o ponto morto superior do pistão e a placa de válvulas. Uma seção transversal do conjunto pode ser vista na Figura 4-13. 


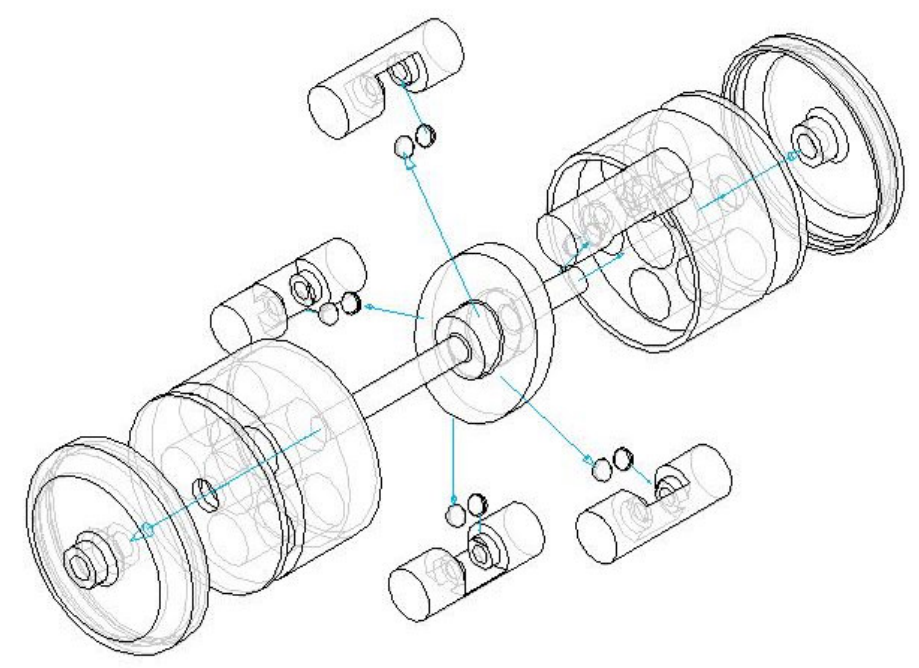

Figura 4-12 Diagrama explodido ilustrativo de um compressor de prato oscilante de deslocamento fixo

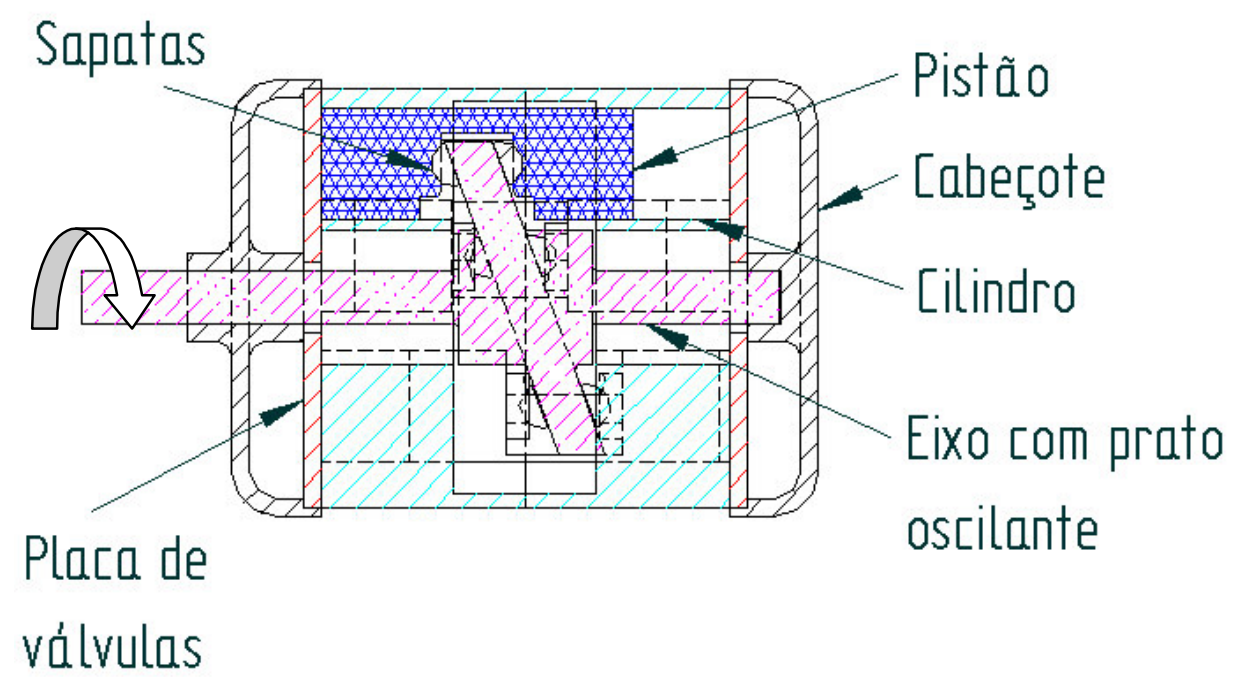

Figura 4-13 Seção transversal de um modelo simplificado de compressor de prato oscilante

\subsubsection{Deslocamento volumétrico}

Dado um compressor de pistões, com $\mathrm{N}$ pistões com diâmetro de cilindro D (m), curso do pistão $\mathrm{L}(\mathrm{m})$, trabalhando a um regime de rotação $\mathrm{n}\left(\mathrm{min}^{-1}\right)$, o seu deslocamento volumétrico $\dot{V}\left(\mathrm{~m}^{3} / \mathrm{s}\right)$ é dado por:

$$
\dot{V}=\frac{\pi D^{2}}{4} \times L \times \frac{n}{60} \times \mathrm{N} \quad\left[\mathrm{m}^{3} / \mathrm{s}\right]
$$




\subsubsection{Eficiência volumétrica}

A eficiência volumétrica é a razão entre o volume realmente deslocado por um compressor e o seu deslocamento volumétrico teórico dado pela equação 4.8. A eficiência volumétrica teórica (de espaço morto) pode ser calculada a partir do volume morto $\mathrm{V}_{\mathrm{a}} \mathrm{e}$ do volume total do compressor $\mathrm{V}_{\mathrm{c}}$ conforme ilustrado na Figura 4-10. A eficiência volumétrica de um compressor será zero quando a razão de compressão for suficientemente alta a ponto da re-expansão do vapor do volume morto $\mathrm{V}_{\mathrm{a}}$ ocupar todo o volume do cilindro, $\mathrm{V}_{\mathrm{c}}$. A eficiência será $100 \%$ quando as pressões de sucção e descarga forem iguais.

A eficiência volumétrica real de um compressor é menor que a eficiência volumétrica de espaço morto. Em um compressor real, além do espaço morto, a eficiência volumétrica é afetada pelos seguintes fatores:

- Quedas de pressão nas válvulas de sucção e descarga

- Aquecimento do vapor de sucção pelas superfícies quentes do cilindro do compressor

- Vazamento pelas válvulas de sucção e descarga

- Vazamento pelos pistões

- Rotação do compressor (causa aumento da velocidade do refrigerante e consequentemente aumento da queda de pressão nas válvulas devido ao efeito da "vena contracta")

Esta diferença entre a eficiência volumétrica teórica e a eficiência volumétrica real é bem ilustrada na Figura 4-14 extraída de Stoecker (1985). A determinação da eficiência volumétrica real de um compressor a partir de cálculos é uma tarefa bastante complexa, de maneira que as curvas de eficiência de compressores reais são levantadas em ensaios em calorímetros, para diversas condições de trabalho.

\subsubsection{Vazão mássica de refrigerante}

A vazão mássica de um compressor é igual à massa do vapor da sucção que entra nos cilindros por unidade de tempo, e pode ser obtida pela multiplicação do deslocamento volumétrico do compressor pela eficiência volumétrica e pelo volume específico do vapor de sucção na condição específica de trabalho deste. Para um deslocamento volumétrico $\dot{V}\left(\mathrm{~m}^{3} / \mathrm{s}\right)$, uma eficiência volumétrica $\eta_{\nu}$ e uma densidade de refrigerante na sucção $\rho_{\mathrm{s}}$ $\left(\mathrm{kg} / \mathrm{m}^{3}\right)$, a vazão mássica será dada por: 


$$
\dot{m}=\dot{V} \times \eta_{v} \times \rho_{s} \quad[\mathrm{~kg} / \mathrm{s}]
$$

\subsubsection{Capacidade de refrigeração}

A capacidade de refrigeração de um compressor depende das condições de operação do sistema. A capacidade de refrigeração é função da massa de refrigerante que circula por unidade de tempo e do efeito de refrigeração por unidade de massa. É comum especificar o compressor pela sua capacidade de refrigeração. Naturalmente, para isto é preciso especificar também a condição de operação.

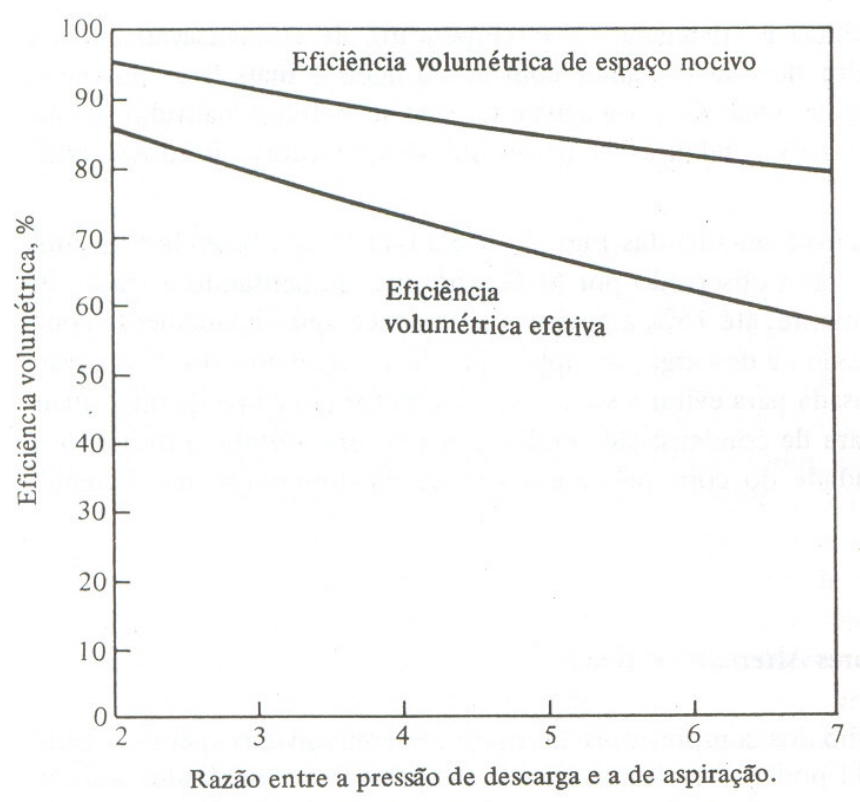

\section{Figura 4-14 Eficiência volumétrica teórica e real de um compressor com refrigerante R22 (Stoecker, 1985)}

A Figura 4-15 apresenta um exemplo de curvas de desempenho de um compressor de pistão com prato oscilante, obtida através do website do fabricante (Sanden, 2005). O gráfico apresenta a capacidade de refrigeração do compressor em função da rotação e da razão de pressões. Nota-se o efeito da razão de compressão sobre a capacidade de refrigeração. As curvas tendem a reduzir a inclinação à medida que a rotação aumenta, demonstrando o efeito do aumento das velocidades sobre a eficiência. Esta informação é pouco relevante para as aplicações estacionárias pois nestas geralmente o compressor trabalha em uma rotação fixa. Porém é importante para a aplicação automotiva, pois como o compressor é acionado pelo motor do veículo, o mesmo fica sujeito à faixa de rotações deste. 


\subsubsection{Eficiência isoentrópica}

A eficiência isoentrópica (ou de compressão) é a razão entre o trabalho de compressão isoentrópico definido na equação 4.3 e o trabalho de eixo real necessário para movimentar o compressor. O trabalho real de eixo será sempre maior que o trabalho de compressão isoentrópico devido ao atrito entre as superfícies com movimento relativo (Stoecker, 1985). A eficiência isoentrópica $\eta_{\text {iso }}$ é dada por:

$$
\eta_{i s o}=\frac{\text { Trabalho de compressão isoentrópica, } \mathrm{kJ} / \mathrm{kg}}{\text { Trabalho real de compressão, } \mathrm{kJ} / \mathrm{kg}} \times 100 \%
$$

Compressor: SD5H14 Refrigerant: R134a

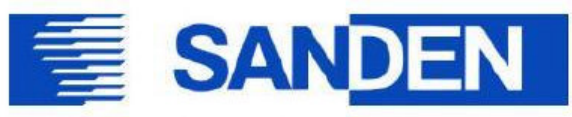

Refrigerating Capacity

(Capacidade de Refrigeração)

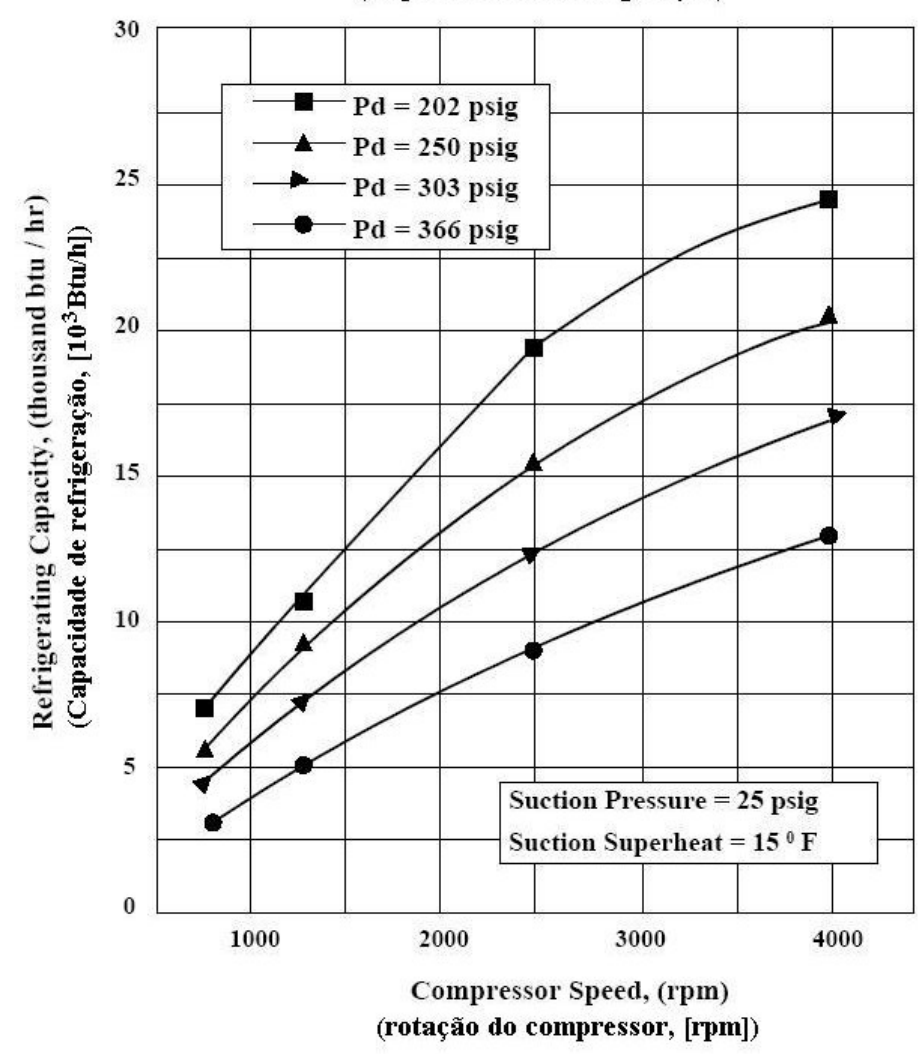

Sanden Engineering Labs

Tested to Standards: ASHRAE 23-78, ISO 917, JIS B8606

Figura 4-15 Curva de capacidade de um compressor Sanden modelo SD5H14, com cinco pistões acionados por prato oscilante, $138 \mathrm{~cm}^{3}$, (Sanden Corp., 2005) 


\subsection{CONDENSADOR}

Um condensador, no contexto de um sistema de refrigeração, é um trocador de calor que tem a função de remover o calor do fluido refrigerante e rejeitar este calor para o meio externo, ou seja o reservatório a alta temperatura, conforme Figura 4-1, ao mesmo tempo que condensa o fluido e entrega refrigerante líquido para o dispositivo de expansão. No caso das aplicações automotivas, o meio externo é o ar ambiente.

\subsubsection{Construção mecânica}

De acordo com as definições de Kays e London (1984), o condensador de um sistema de refrigeração automotivo é um trocador de calor compacto. Mais adiante será visto que o evaporador para o sistema de refrigeração automotivo também se enquadra nesta classificação. Tanto o condensador como o evaporador usam o ar como um dos fluidos (o refrigerante é o outro). Devido ao baixo calor específico, grandes quantidades de ar são necessárias para que se possa remover a quantidade de calor necessária do condensador. A limitação de área de troca de calor, característica da aplicação automotiva, faz com que as velocidades de ar sejam elevadas. Para fluidos com baixa densidade como o ar, a energia necessária para vencer os atritos é um fator limitante para o aumento das velocidades. Estes fatores fazem com que os condensadores e evaporadores tenham que ser compactos, ou seja, tenham alta relação de área de troca de calor por unidade de volume, da ordem de $700 \mathrm{~m}^{2} / \mathrm{m}^{3}$ (Shah, Kraus e Metzger, 1990)

Existem diversos tipos de construções mecânicas para o condensador compacto para uso em automóveis. No condensador automotivo o fluido refrigerante circula dentro de tubos metálicos e o ar circula através de aletas soldadas a estes. Inicialmente os condensadores eram fabricados em metais como cobre ou aço, porém atualmente o alumínio vem sendo utilizado praticamente em todas as aplicações automotivas, devido à menor massa e à facilidade de reciclagem. Em seu trabalho, Ávila (2002) descreve alguns tipos de condensadores usados em automóveis, como os condensadores de tubo-aletas (Figura 4-16 ) e os de serpentina de tubos planos com aletas tipo "louver" ( Figura 4-17). Além desses dois tipos de condensadores, existem também os condensadores de fluxo paralelo com tubos planos e aletas tipo 'louver" ( Figura 4-18), que é o tipo de condensador mais utilizado no momento e é também o tipo utilizado neste trabalho. 


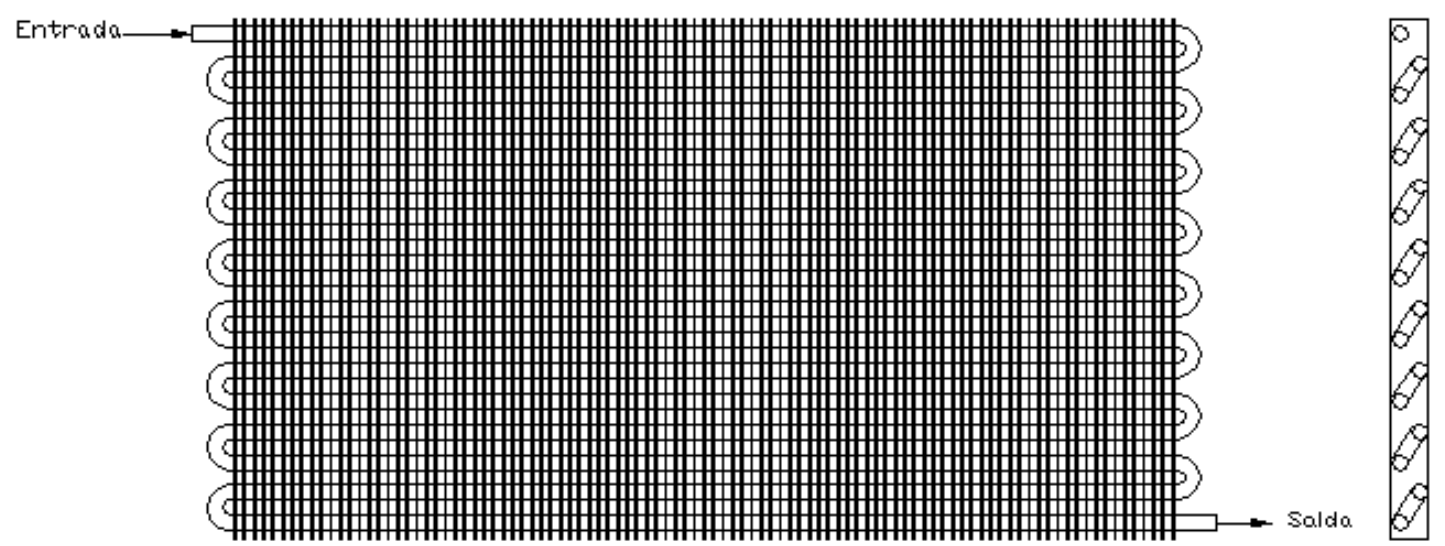

Figura 4-16 Esquema típico de um condensador tipo tubo-aletas

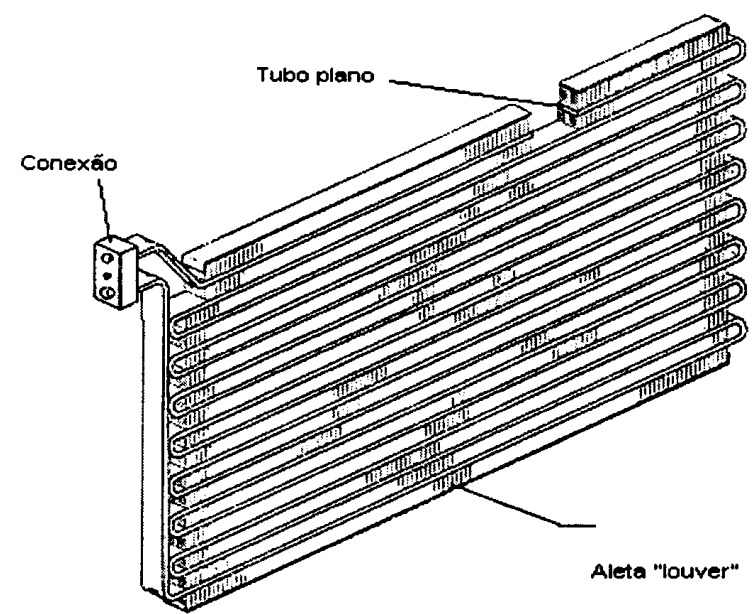

Figura 4-17 Condensador de serpentina de tubos planos e aletas tipo "louver" (Ávila, 2002)

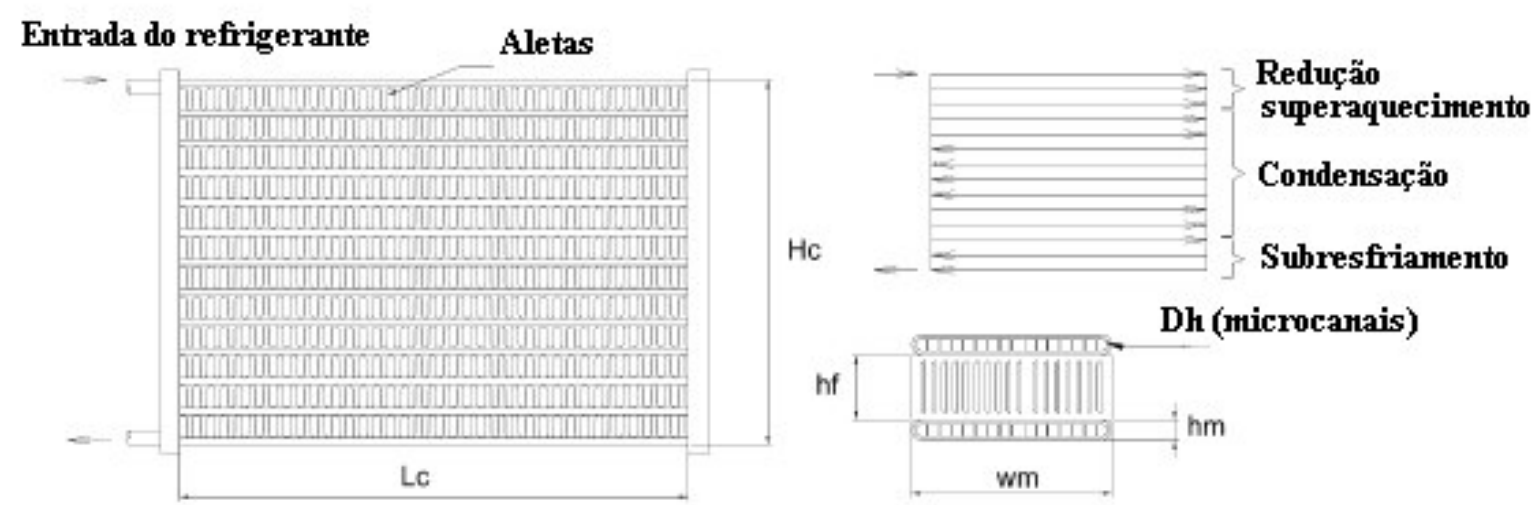

Saída do refrigerante

Figura 4-18 Esquema de um condensador de tubos planos com microcanais e aletas tipo "louver", com fluxo paralelo, dividido em seções de resfriamento do vapor superaquecido, condensação e subresfriamento (Jabardo et al, 2002). 
Na Figura 4-18 é possível notar algumas técnicas construtivas de um condensador compacto. Como pode ser visto na seção transversal do tubo, as aletas tipo "louver" têm pequenos recortes que têm a função de evitar a formação de uma camada limite de escoamento de ar muito espessa. Neste mesmo corte é possível notar os microcanais com pequeno diâmetro hidráulico da ordem de $1 \mathrm{~mm}$. O coeficiente de troca de calor por convecção, $h_{e}$, varia com a potência negativa do diâmetro hidráulico, de maneira que os microcanais oferecem maior $h_{e}$ (Kays e London, 1984).

\subsubsection{Funcionamento e características}

Dentro do condensador ocorre o processo de mudança de fase do refrigerante, de vapor para líquido. O condensador pode ser dividido em três regiões distintas sob o ponto de vista do estado do refrigerante. Uma região monofásica de redução do superaquecimento (vapor), uma região de mudança de fase (condensação) e uma região de subresfriamento (líquido).

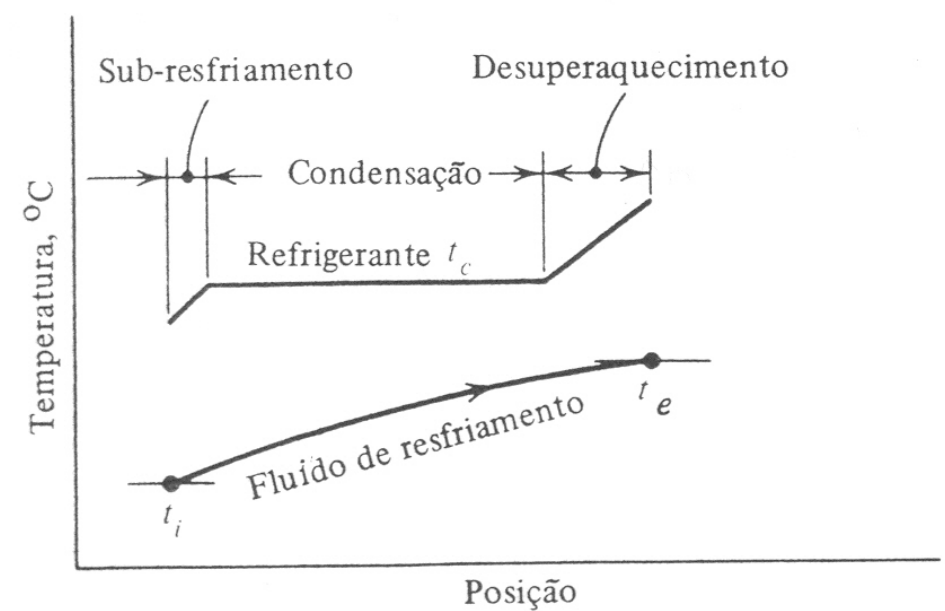

Figura 4-19 Distribuição de temperaturas em um condensador (Stoecker, 1985)

A Figura 4-19 apresenta esta distribuição de temperaturas ao longo do condensador e a Figura 4-18 apresenta as passagens relativas a cada seção. Devido às diferenças de comportamento em cada região do condensador, alguns autores modelam cada uma dessas regiões como um trocador de calor separado (Jabardo e Mamani, 2003; Jabardo et al, 2002; Huang et al, 1999).

O condensador precisa rejeitar para o ambiente a quantidade de calor $\dot{Q}_{C O N D}$ equivalente ao que foi removido do ambiente refrigerado, $\dot{Q}_{L}$, mais o calor transferido para 
o refrigerante durante o processo de compressão, que equivale a $\dot{W}_{\text {comp }}$, mais os ganhos de calor através das tubulações e do compressor, $\dot{Q}_{\text {GANHO }}$. Utilizando a expressão 4.4, sabendo que $\dot{Q}_{C O N D}=\dot{Q}_{H}$, tem-se o balanço de energia global do sistema de refrigeração:

$$
\dot{Q}_{H}=\dot{Q}_{C O N D}=\dot{Q}_{L}+\dot{W}_{\text {comp }}+\dot{Q}_{G A N H O}=\dot{m}\left(h_{3}-h_{2}\right)
$$

\subsubsection{Coeficiente global de transferência de calor}

O conceito de coeficiente global de transferência de calor foi introduzido nesta seção porque será utilizado no projeto e simulação do sistema, e vale tanto para o condensador como para o evaporador. O coeficiente global de transferência de calor U é uma constante de proporcionalidade que multiplicada pela área de troca de calor A e pela diferença de temperatura entre os fluidos fornece a taxa de troca de calor (Stoecker, 1985). O coeficiente global de troca de calor é uma condutância térmica que combina os mecanismos de convecção e condução responsáveis pela transferência de calor do fluido quente para o fluido frio em uma única equação similar à lei de Ohm para a corrente elétrica em regime permanente (Kays e London, 1984):

$$
\frac{d q}{d A}=U\left(t_{h}-t_{L}\right)
$$

ou,

$$
q \equiv U A(\Delta t)
$$

A determinação do coeficiente global de transferência de calor depende de vários fatores construtivos do trocador de calor como a geometria das superfícies, o uso de aletas, a escolha da direção dos escoamentos (paralelo, contracorrente, fluxo cruzado), a quantidade de passes e outros. Não é o objetivo principal deste trabalho aprofundar-se neste assunto específico. A literatura sobre fundamentos das transferências de calor pode ser encontrada em (Incropera e DeWitt, 1998; Shah, Kraus e Metzger, 1990; Kays e London, 1984).

\subsubsection{Avaliação de trocadores de calor pelo método da Efetividade-NUT $(\varepsilon-\mathrm{NUT})$}

Os projetos de trocadores de calor até antes de 1940 eram feitos através do método da MLDT (Média Logarítmica das Diferenças de Temperatura). O método da 
Efetividade - Número de Unidades de Transferência ( $\varepsilon$-NUT) foi introduzido em 1941 por Alexander Louis London e Ralph Seban, da Universidade de Stanford, EUA, como um método alternativo mais conveniente do que o MLDT (Shah, Kraus e Metzger, 1990). O método MLDT continua sendo utilizado por alguns autores conforme encontrado em alguns exemplos da literatura (Dossat e Horan, 2001; Stoecker, 1985). Os dois métodos oferecem o mesmo resultado, no entanto dependendo do tipo de problema a ser equacionado é melhor utilizar o método $\varepsilon$-NUT, especialmente pela sua praticidade quando se trata de um problema de cálculo de desempenho de um trocador de calor conhecido (Jabardo e Mamani, 2003; Stewart, 2003; Jabardo et al, 2002; Aspelund, 2001; Huang et al, 1999; Bhatti, 1999b).

Neste trabalho o método $\varepsilon$-NUT também será utilizado para os cálculos dos trocadores de calor devido à sua praticidade principalmente no caso da simulação de desempenho do sistema (Capítulo 6). Mais detalhes sobre o cálculo de trocadores de calor pelo método $\varepsilon$-NUT podem ser encontrados em Kays e London (1984) e Incropera e DeWitt (1998).

\subsection{EVAPORADOR}

O evaporador é um trocador de calor que tem a função de remover o calor do ambiente refrigerado. No interior do evaporador ocorre a evaporação do fluido refrigerante, processo que absorve calor do fluido quente que neste caso é o ar de insuflação da cabina.

O refrigerante entra no evaporador como uma mistura bifásica e pode sair como um vapor superaquecido ou como uma mistura bifásica. Tipicamente os sistemas com expansão em tubos de orifício permitem que haja algum líquido na saída do evaporador, ou seja, um título ligeiramente menor que $100 \%$.

\subsubsection{Construção mecânica}

O evaporador, assim como o condensador, pode ser considerado como um trocador de calor compacto. Existem diversos tipos de construções mecânicas para um evaporador compacto para aplicação automotiva (Figura 4-20). Em aplicações automotivas, considerações sobre espaço e custo têm um forte impacto sobre o projeto dos evaporadores. Os evaporadores utilizados atualmente possuem superfícies complexas que proporcionam alta efetividade, manufatura em larga escala e custos menores. 


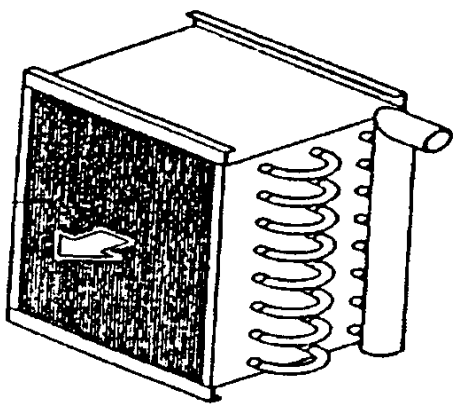

a) Tubos e aletas

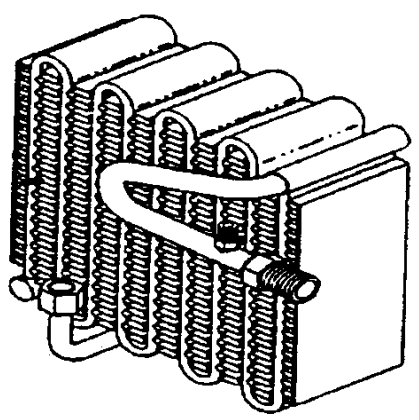

b) Serpentina

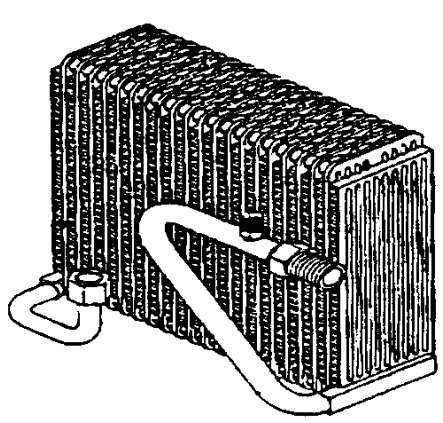

c) Placas

Figura 4-20 Tipos de evaporadores (Ávila, 2002)

A Figura 4-20a apresenta um evaporador de tubos e aletas, onde o refrigerante passa no interior dos tubos e o ar circula pelas aletas. A Figura 4-20b apresenta uma evolução do tipo tubo-aletas, que é o tipo de serpentina com tubos planos. Tanto o evaporador de tubos e aletas como o de serpentina têm sido descontinuados e substituídos pelo evaporador de placas planas e aletas tipo louver (Figura 4-20c), constituído de pares de placas de alumínio estampadas de maneira a formar os canais por onde circula o refrigerante, com fileiras de aletas finas de alumínio soldadas entre os pares de placas por um processo de brasagem. Este tipo de evaporador é largamente utilizado na indústria automobilística, e é o mesmo tipo utilizado na aplicação em estudo neste trabalho.

\subsubsection{Funcionamento e características}

O evaporador é analisado praticamente da mesma forma que o condensador no sentido de que também se considera que tenha um coeficiente global de troca de calor U. No entanto um aspecto fundamental faz com que o modelamento do evaporador seja um pouco mais complexo, que é a presença de condensação de água na superfície do lado ar. Sempre que a temperatura de evaporação for menor que o ponto de orvalho haverá formação de condensação, que pode se apresentar em forma de pequenas gotas até um filme de água sobre a superfície do evaporador. Na entrada do evaporador não há presença de condensação, e a temperatura do ar é reduzida à medida que ele passa pelo evaporador. Esta região é chamada região seca. Quando a temperatura do ar atinge o ponto de orvalho dá-se a formação de condensação, o que ocorre a uma dada profundidade do evaporador. Esta região é conhecida como região úmida. Na região seca ocorre apenas troca de calor regulada pela diferença de temperaturas $\left(\dot{Q}_{\Delta t}\right)$, enquanto que na região úmida ocorre 
também a troca de calor devido à condensação do vapor d’água ( $\dot{Q}_{h l v}$ ). O desempenho do evaporador é afetado pela capacidade do mesmo remover a água condensada em suas aletas.

Um estudo aprofundado sobre os fenômenos de troca de calor em um evaporador compacto pode ser encontrado em Shah, Kraus e Metzger (1990). Neste trabalho o cálculo das trocas de calor no evaporador utiliza o método da $\varepsilon$-NUT e as propriedades psicrométricas do ar úmido.

\subsubsection{Capacidade de refrigeração}

A capacidade de refrigeração $\dot{Q}_{L}$ é a soma dos fluxos de calor regulado por diferença de temperatura, $\dot{Q}_{\Delta t}$ e devido à condensação do vapor d'água, $\dot{Q}_{h l v}$, conforme segue:

$$
\dot{Q}_{L}=\dot{Q}_{\Delta t}+\dot{Q}_{\mathrm{h}_{\mathrm{lv}}}
$$

\subsection{DISPOSITIVO DE EXPANSÃO}

O sistema de refrigeração por compressão de vapor precisa de um dispositivo de expansão que controle a passagem do refrigerante para o evaporador. No mercado automobilístico, os dispositivos de expansão mais comuns são a válvula de expansão termostática e o tubo de orifício calibrado, sendo este último o foco deste estudo.

\subsubsection{Construção mecânica}

O tubo de orifício do sistema de refrigeração automotivo tem uma construção simples e barata, e de fácil manutenção. Um esquema de um tubo de orifício típico é apresentado na Figura 4-21. Os tubos são disponíveis em um comprimento padrão e em diferentes diâmetros, para adequação à necessidade de vazão de refrigerante de cada aplicação.

O tubo de orifício fixo consiste de um tubo curto de seção constante que, juntamente com o compressor, permite dois níveis de pressão para promover o efeito de refrigeração. Se comparado com os tubos capilares, o tubo de orifício apresenta uma montagem mais robusta e permite vazões maiores de refrigerante para a operação em um sistema automotivo (Hernandez Neto, 1998). 


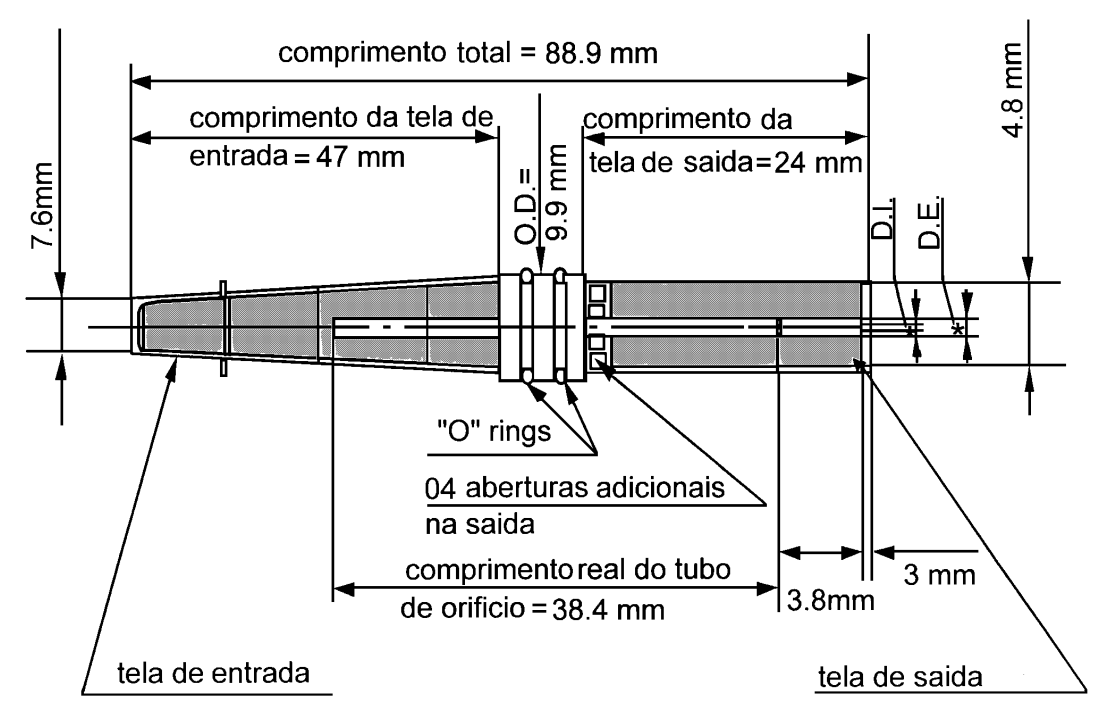

Figura 4-21 Esquema de um tubo de orifício (Hernandez Neto, 1998).

\subsubsection{Funcionamento e características}

O escoamento do refrigerante no interior do tubo envolve um aspecto conhecido como "flashing", que consiste na vaporização de parte do refrigerante responsável pela redução da sua própria temperatura, de modo que parte do efeito de refrigeração disponível é consumida neste processo (Dossat e Horan, 2001). Um outro aspecto é a condição de blocagem. Nesta condição o escoamento atinge a velocidade sônica, fazendo com que a vazão de refrigerante independa da pressão de saída do tubo. A vazão do refrigerante depende da pressão e do subresfriamento na entrada do tubo orifício e das propriedades dimensionais do tubo. Quanto maior o subresfriamento, a pressão de entrada ou o diâmetro do tubo, maior será a vazão de refrigerante. Hernandez Neto (1998) apresenta um estudo aprofundado sobre o escoamento do refrigerante R134a em tubos de orifício, com um modelo analítico e um modelo semi-empírico baseado em vários experimentos com R134a e com nitrogênio. Os resultados dos experimentos de Hernandez Neto são utilizados no projeto e simulação do sistema deste trabalho.

\subsection{ACUMULADOR DE LÍQUIDO}

Os sistemas de refrigeração automotivos que utilizam tubos de orifício calibrado necessitam de um acumulador de líquido entre o evaporador e o compressor, porque este sistema não é capaz de garantir o superaquecimento do refrigerante na saída do evaporador. A passagem de refrigerante líquido para o compressor poderia causar danos ao mesmo. 


\subsubsection{Construção mecânica}

O acumulador é constituído de um reservatório cilíndrico de alumínio com um tubo de entrada e um tubo de saída e em alguns casos com uma conexão para o pressostato de monitoramento da pressão de sucção do sistema, conforme apresentado na Figura 4-22. No interior do acumulador há um filtro para reter partículas sólidas que poderiam causar danos ao sistema, uma pequena bolsa com material higroscópico para remover a umidade do refrigerante e um pequeno filtro de óleo com um orifício calibrado.

\subsubsection{Funcionamento e características}

O acumulador recebe o fluido refrigerante misturado com óleo lubrificante pelo tubo de entrada. O refrigerante líquido e o óleo se acumulam no fundo do reservatório, e o vapor de refrigerante ocupa o restante do espaço superior. O tubo de saída capta o vapor de refrigerante e passa pelo fundo do reservatório, onde é feito um furo para a instalação do filtro de óleo, conforme apresentado na Figura 4-23.

O vapor de refrigerante succionado arrasta uma pequena quantidade de óleo através do filtro com furo calibrado, garantindo a lubrificação do compressor. Para que este sistema funcione, deve haver óleo suficiente acumulado no fundo do reservatório. Por essa razão, procura-se instalar o acumulador no ponto mais baixo do sistema.

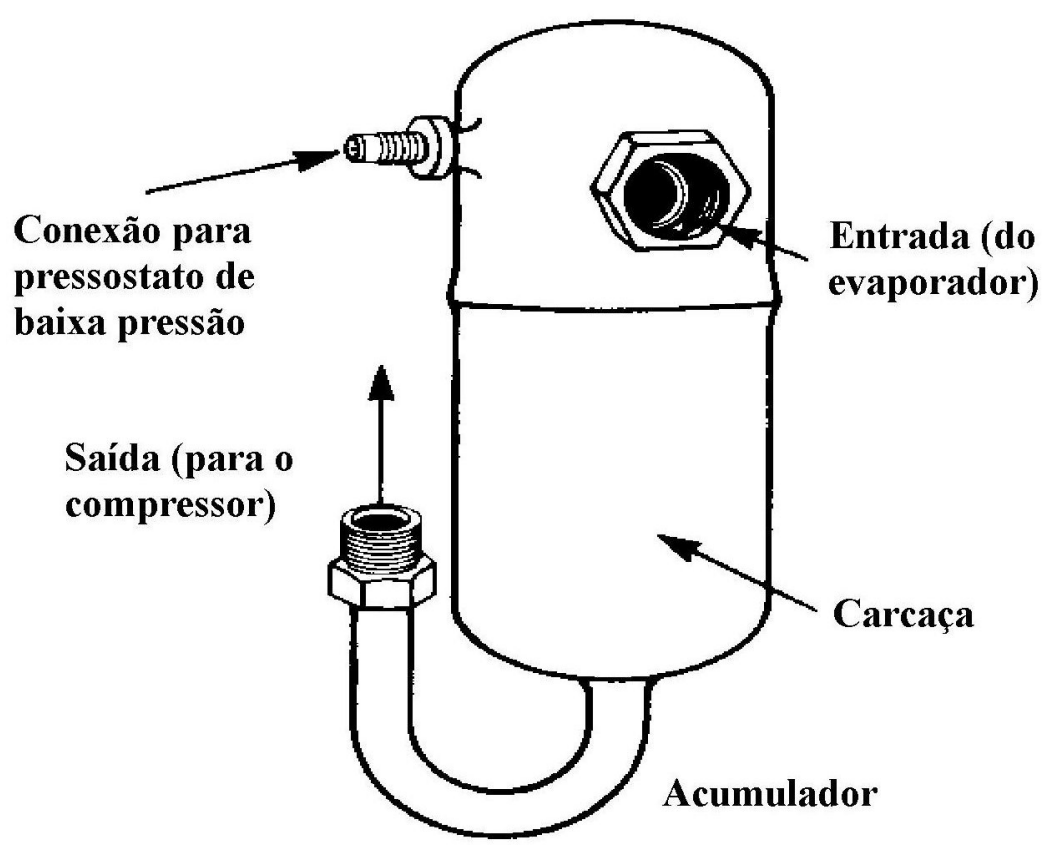

Figura 4-22 Acumulador de líquido (Ávila, 2002) 


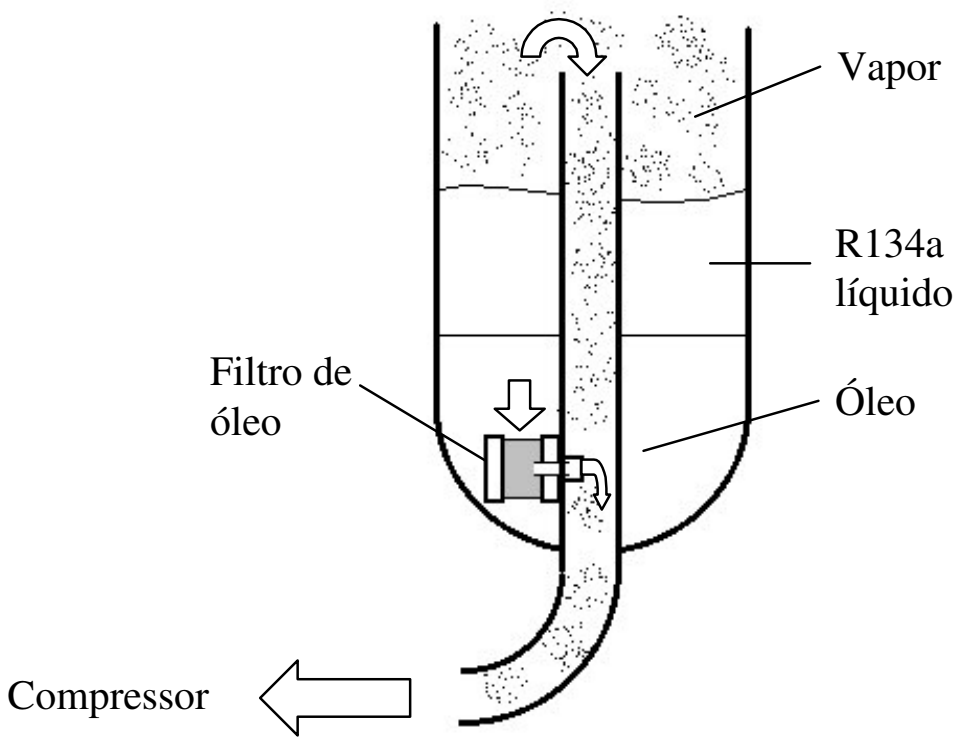

Figura 4-23 Esquema de captação de vapor de refrigerante e óleo

Embora não seja parte do ciclo de refrigeração em si, o acumulador de líquido tem quatro funções importantes, como segue:

- Evitar que refrigerante líquido chegue ao compressor, já que a expansão em tubo de orifício fixo permite que haja líquido na saída do evaporador. Por esta razão, o acumulador está instalado na linha de sucção do compressor;

- Servir como reservatório para o excedente de refrigerante no sistema;

- Filtrar e remover a umidade do refrigerante;

- Garantir e controlar a circulação de óleo refrigerante pelo sistema. O óleo fica acumulado no fundo do reservatório e é aspirado junto com o refrigerante através de um filtro com um orifício calibrado.

Do ponto de vista do ciclo de refrigeração, o acumulador apenas aumenta ligeiramente o superaquecimento do refrigerante. A presença de óleo em circulação reduz a capacidade de refrigeração do sistema, porém o acumulador garante que esta quantidade seja pequena (cerca de $4 \%$ a $6 \%$ da massa de refrigerante em circulação). No presente trabalho o efeito do óleo em circulação foi desprezado.

\subsection{CONTROLE DO SISTEMA}

Embora o controle do sistema não seja o foco deste trabalho, esta breve descrição é necessária para que se tenha uma abordagem completa do ciclo de refrigeração para aplicação automotiva. 


\subsubsection{Controle de temperatura}

O controle de temperatura do sistema de condicionamento de ar automotivo é feito através do reaquecimento do ar refrigerado. O aquecimento é obtido pelo aquecedor, que usa o rejeito do calor do motor por meio do fluido de arrefecimento do motor. $\mathrm{O}$ controle é feito normalmente de duas maneiras:

a) Por meio do controle da mistura dos fluxos de ar quente e frio dentro da unidade de controle da distribuição de ar. O controle dos fluxos de ar é feito por uma porta de mistura de ar. Este sistema controla a quantidade de ar que circula através do aquecedor, que posteriormente mistura-se com o ar frio para obter a temperatura desejada.

b) Por meio do controle do fluxo do fluido de arrefecimento para o aquecedor, feito por uma válvula que pode ser de acionamento mecânico ou elétrico. Neste sistema todo o ar de insuflação passa pelo evaporador e pelo aquecedor, e a válvula controla a quantidade de fluido de arrefecimento que passa pelo aquecedor.

Em cargas parciais, o controle de temperatura por meio de reaquecimento de certa forma "desfaz" o trabalho do sistema de refrigeração, porém é feito desta forma porque mantém a umidade relativa do ar baixa, garantindo que não haja embaçamento dos vidros. Há estudos para reduzir o reaquecimento como forma de reduzir o consumo de energia do sistema (Forrest e Bhatti, 2002).

\subsubsection{Controle do ciclo de refrigeração}

O ciclo de refrigeração possui quatro controles:

a) Acionamento do sistema através da embreagem magnética do compressor;

b) Controle de temperatura do evaporador (para evitar o congelamento do mesmo);

c) Controle de ventilação do condensador;

d) Controle de sobre-pressão;

O controle do acionamento do sistema (a) é feito através da embreagem magnética do compressor por um comando do usuário. O controle do congelamento do evaporador (b) é feito normalmente de duas maneiras diferentes. Uma delas é a medição direta da temperatura do evaporador através de um termostato, que desliga a embreagem do compressor quando a temperatura chega próximo do ponto de congelamento da água 
condensada no evaporador. A outra maneira é a medição da pressão de sucção através de um pressostato que desliga a embreagem do compressor. A pressão de sucção está associada à temperatura de evaporação, e uma vez que esta se encontre próxima do ponto de congelamento da água, o pressostato interrompe o circuito da embreagem do compressor. O pressostato é instalado na linha de sucção ou no acumulador (Figura 4-22). Em ambos os casos, quando a temperatura do evaporador se eleva, o sistema volta a funcionar automaticamente.

A maioria dos sistemas de refrigeração em automóveis têm um sistema que controla a velocidade do ventilador (c) do condensador em função da pressão de condensação. Este controle é feito por meio da leitura da pressão alta do sistema em um pressostato ou por meio de um transdutor de pressão. Para pressões de condensação baixas o ventilador trabalha com uma velocidade menor, e para pressões altas o sistema aciona o ventilador na velocidade máxima.

Um sistema de segurança evita que as pressões atinjam valores muito altos, o que poderia causar danos. Este controle (d) é feito por meio da leitura da pressão de condensação por um pressostato ou um transdutor de pressão, que desligam a embreagem do compressor. Os sistemas de R134a ainda possuem uma válvula mecânica de alívio que se abre a uma pressão acima da pressão de desligamento automático do compressor, para evitar uma falha catastrófica, conforme determinado na norma SAE-J639 (SAE, 1999a). A válvula de alívio libera refrigerante para a atmosfera, voltando a se fechar com a redução da pressão do sistema. 


\section{CAPÍTULO 5 \\ DIMENSIONAMENTO DO CICLO DE \\ REFRIGERAÇÃO}

O dimensionamento do ciclo de refrigeração consiste em selecionar componentes para o sistema de maneira que o veículo atenda aos requerimentos de carga térmica nas condições de pressões e temperaturas desejadas.

O objetivo deste capítulo é apresentar uma sequência para os cálculos e a seleção das características dos componentes, dadas algumas condições de entrada para o projeto. $\mathrm{O}$ sistema de refrigeração é o de compressão mecânica de vapor, com expansão em tubo curto de orifício calibrado e demais componentes, conforme descrito no capítulo 4.

\subsection{CONDIÇÕES DE ENTRADA DE PROJETO}

Os dados de entrada para o projeto são agrupados conforme as diferentes áreas do sistema, como segue:

- CONDIÇÕES AMBIENTAIS

- Carga térmica

$\dot{Q}_{\text {evap }} \quad \mathrm{kW}$

- Temperatura interna desejada

$\mathrm{T}_{\text {int }} \quad{ }^{\circ} \mathrm{C}$

- Umidade relativa do ar interno

$\phi_{\text {int }} \%$

- Temperatura de descarga

$\mathrm{T}_{\text {desc }}$

${ }^{\circ} \mathrm{C}$

- Vazão de ar da ventilação interna

Qar $\quad \mathrm{m}^{3} / \mathrm{s}$

- Temperatura externa

$\mathrm{T}_{\text {ar_ext }}$

${ }^{\circ} \mathrm{C}$

- Umidade relativa do ar externo

$\phi_{\text {ext }}$

$\%$

- Temp. do ar de entrada do condensador

$\mathrm{T}_{\text {ar_cond }}$

${ }^{\circ} \mathrm{C}$

- CONDIÇÕES DO CICLO DE REFRIGERAÇÃO

- Superaquecimento desejado

$\mathrm{SH}$

${ }^{\circ} \mathrm{C}$

- Subresfriamento desejado

SC

${ }^{\circ} \mathrm{C}$

- Rotação do compressor

$\mathrm{n}$

$\min ^{-1}$

- COMPRESSOR

- Curva de eficiência volumétrica

- Curva de eficiência isentrópica 
- TROCADORES DE CALOR

- Efetividade do evaporador

$$
\varepsilon_{\text {evap }} \quad \text { Adimensional }
$$

- Efetividade do condensador $\quad \varepsilon_{\text {cond }} \quad$ Adimensional

\subsection{PROCEDIMENTO DE PROJETO}

Existem diferentes maneiras de se executar um projeto de um sistema de refrigeração que atenda a uma determinada carga térmica, dependendo das condições de temperatura e umidade e do modo de operação desejados. O procedimento descrito neste capítulo tem por objetivo projetar um sistema que atenda às condições requeridas em um ensaio de túnel de vento, conforme descrito no Capítulo 3, seção 3.2.

\subsubsection{Evaporador}

O procedimento se inicia pela seleção de um evaporador que atenda à carga térmica desejada com a temperatura interna e de descarga requeridas, e com a vazão de ar desejada. Espera-se obter como resultado as dimensões do evaporador. Haverá provavelmente uma vasta gama de tecnologias de fabricação, geometrias e dimensões que possam atender ao projeto, e não será parte do escopo deste trabalho determinar a escolha de uma ou outra tecnologia. Por esse motivo, o resultado será apresentado na forma do produto do coeficiente global de transferência de calor pela área de troca de calor, UA $\left(\mathrm{kW} /{ }^{\circ} \mathrm{C}\right) . \mathrm{O}$ evaporador irá impor uma restrição à passagem do ar que dependerá das suas dimensões e da tecnologia escolhida, e essa perda de carga será um dos fatores determinantes para o projeto do ventilador. Isso geralmente resulta em um compromisso entre custo e espaço disponível, e não será aqui abordado.

O evaporador será calculado pelo método da Efetividade-NUT. O procedimento adota como premissa um valor recomendado para a efetividade do evaporador, baseandose nas práticas do setor automobilístico. A escolha dos valores de efetividade tem um impacto importante no projeto dos trocadores de calor, portanto algumas considerações devem ser feitas. A vazão de ar insuflado no veículo é limitada pela área dos difusores tipicamente pequena, pelos espaços limitados para o ventilador e pelo nível de ruído. Simultaneamente, a temperatura de evaporação não pode ser muito baixa, para evitar o congelamento do evaporador. Esses dois fatores impõem que o evaporador tenha uma efetividade mínima para que se possa remover a quantidade de calor necessária.. O valor máximo da efetividade é limitado por questões de espaço e custo. Em seu artigo, Bhatti 
(1999b) analisa que os evaporadores usados em automóveis operam com uma efetividade bastante alta, da ordem de $0,8<\varepsilon_{\text {evap }}<0,9$, e esses valores serão aqui adotados.

\subsubsection{Ciclo de refrigeração}

O passo seguinte do procedimento de projeto é determinar os pontos de trabalho do ciclo de refrigeração. O projeto será desenvolvido conforme o ciclo real de refrigeração por compressão de vapor descrito no Capítulo 4, seção 4.1.3, exceto pela queda de pressão nos componentes, que é admitida como sendo pouco importante para este caso de projeto básico e, portanto, será desprezada.

Admite-se que os valores desejados de subresfriamento e superaquecimento na entrada do compressor são dados de entrada para o projeto. Como o dispositivo de expansão adotado será o tubo curto de orifício calibrado, admite-se que não há superaquecimento na saída do evaporador. Espera-se como resultado calcular as pressões de condensação e evaporação, a temperatura de condensação, e a vazão mássica necessária de refrigerante.

\subsubsection{Compressor}

O objetivo desta parte do procedimento é determinar qual o deslocamento volumétrico que o compressor deve ter para que ele seja capaz de fornecer a vazão mássica necessária. Como visto no Capítulo 4, a vazão mássica depende da rotação, do deslocamento volumétrico, da densidade do refrigerante na entrada do compressor e da eficiência volumétrica. Para a determinação do deslocamento volumétrico, portanto, será necessário conhecer de antemão as curvas de eficiência volumétrica de uma gama de compressores disponíveis que se pretende utilizar. Uma vez calculado o deslocamento volumétrico requerido, verifica-se a adequação do compressor ao projeto.

Outros resultados deste procedimento são a quantidade adicional de calor resultante da compressão não-isoentrópica, $\dot{W}_{\text {real }}(\mathrm{kW})$, o COP e a temperatura de descarga do compressor $\mathrm{T}_{\text {desc }}\left[{ }^{\circ} \mathrm{C}\right]$. Para esses cálculos será necessário conhecer as curvas de eficiência isoentrópica do compressor ( $\eta_{\text {iso_comp }}$ ).

\subsubsection{Condensador}

O cálculo do condensador é feito pelo método da Efetividade-NUT da mesma forma que para o evaporador. O condensador pode ser dividido em três regiões distintas 
sob o ponto de vista do estado do refrigerante. Uma região monofásica de redução do superaquecimento (vapor), uma região de mudança de fase (condensação) e uma região de subresfriamento (líquido). Na região de redução de superaquecimento o coeficiente global de troca de calor é menor que na região de condensação, porém esta redução é compensada pelo fato das diferenças de temperaturas serem maiores (Stoecker, 1985). A região de subresfriamento ocupa um pequeno volume do condensador. Com estas considerações, admite-se que a maior parte da troca de calor ocorre na região de condensação, de maneira que a relação Efetividade-NUT adotada é aquela em que um dos fluidos sofre mudança de fase (eq. 5.1).

$$
\varepsilon=1-e^{-N U T} \text { (relação Efetividade-NUT ) }
$$

Da mesma forma que para o evaporador, admite-se um valor recomendado para a efetividade do condensador. Esta efetividade tem um limite máximo definido pela máxima temperatura admissível na entrada do "radiador" (já que na maioria das aplicações automotivas o condensador é colocado à frente do "radiador", compartilhando o mesmo sistema de ventilação). Também tem um limite mínimo definido pela pressão máxima de condensação e pela máxima temperatura de descarga para que não haja danos ao compressor. Diferentemente do evaporador, a vazão de ar pelo condensador é tipicamente alta. Devido a esses fatores, o condensador automotivo trabalha com uma efetividade menor que a do evaporador. Bhatti (1999b) apresenta valores de efetividade $0,2<\varepsilon_{\text {cond }}<$ 0,4, e esses valores serão adotados. A relação Efetividade-NUT é a mesma utilizada para o condensador (eq. 5.1).

O resultado do procedimento será o valor do produto UA $\left(\mathrm{kW} /{ }^{\circ} \mathrm{C}\right)$ e a vazão de ar necessária, para a efetividade adotada.

\subsubsection{Dispositivo de expansão}

O dispositivo de expansão adotado para este caso de projeto é o tubo curto de orifício calibrado, conforme definido no Capítulo 4, seção 4.6. O objetivo é calcular o diâmetro do tubo de orifício adequado para que ele proporcione uma vazão de refrigerante igual àquela calculada para o compressor, sob as condições de subresfriamento e pressão do refrigerante na entrada do tubo de orifício.

\subsubsection{Carga Térmica}

Conforme verificado no capítulo 3, projetar o sistema para o ganho de calor em 
regime permanente resultaria em um subdimensionamento. Por esta razão, a carga térmica considerada para o projeto foi calculada a partir das temperaturas interna e de descarga e da vazão de ar no evaporador usando a eq. 5.2.

$$
\dot{Q}_{\text {evap }}=\dot{m}_{a r}\left(h_{\mathrm{int}}-h_{\text {desc }}\right) \quad[\mathrm{kW}]
$$

onde:

$\dot{Q}_{\text {evap }}=$ Carga térmica do evaporador

$\mathrm{kW}$

$\dot{m}_{a r}=$ Vazão mássica de ar do evaporador

$\mathrm{kg} / \mathrm{s}$

$h_{\text {int }}=$ Entalpia do ar interno da cabina

$\mathrm{kJ} / \mathrm{kg}$

$h_{\text {desc }}=$ Entalpia do ar de descarga do evaporador

$\mathrm{kJ} / \mathrm{kg}$

As temperaturas são dados de entrada do projeto e as entalpias podem ser determinadas a partir dos valores de temperatura e umidade relativa por meio das propriedades psicrométricas do ar úmido.

\subsubsection{Fluxograma}

Um fluxograma que ilustra a sequência de cálculos para o projeto do sistema de refrigeração por compressão mecânica de vapor, com expansão em tubo curto de orifício calibrado, para uma aplicação automotiva, é apresentado na Figura 5-1.

\subsection{DADOS DE ENTRADA E RESULTADOS}

Os dados de entrada para o projeto estão listados na tabela 5-1. Adotou-se usar como dados de entrada as mesmas condições encontradas no ensaio do túnel de vento apresentados no capítulo 3, exceto pela carga térmica, que foi calculada a partir das temperaturas interna e de descarga e pela vazão de ar, utilizando as propriedades psicrométricas do ar úmido. O método aqui apresentado pode ser aplicado para outras condições de operação normalmente encontradas em uma aplicação automotiva, como por exemplo um veículo maior que necessite de uma maior vazão de ar, diferentes temperaturas de operação interna e externa, etc. 


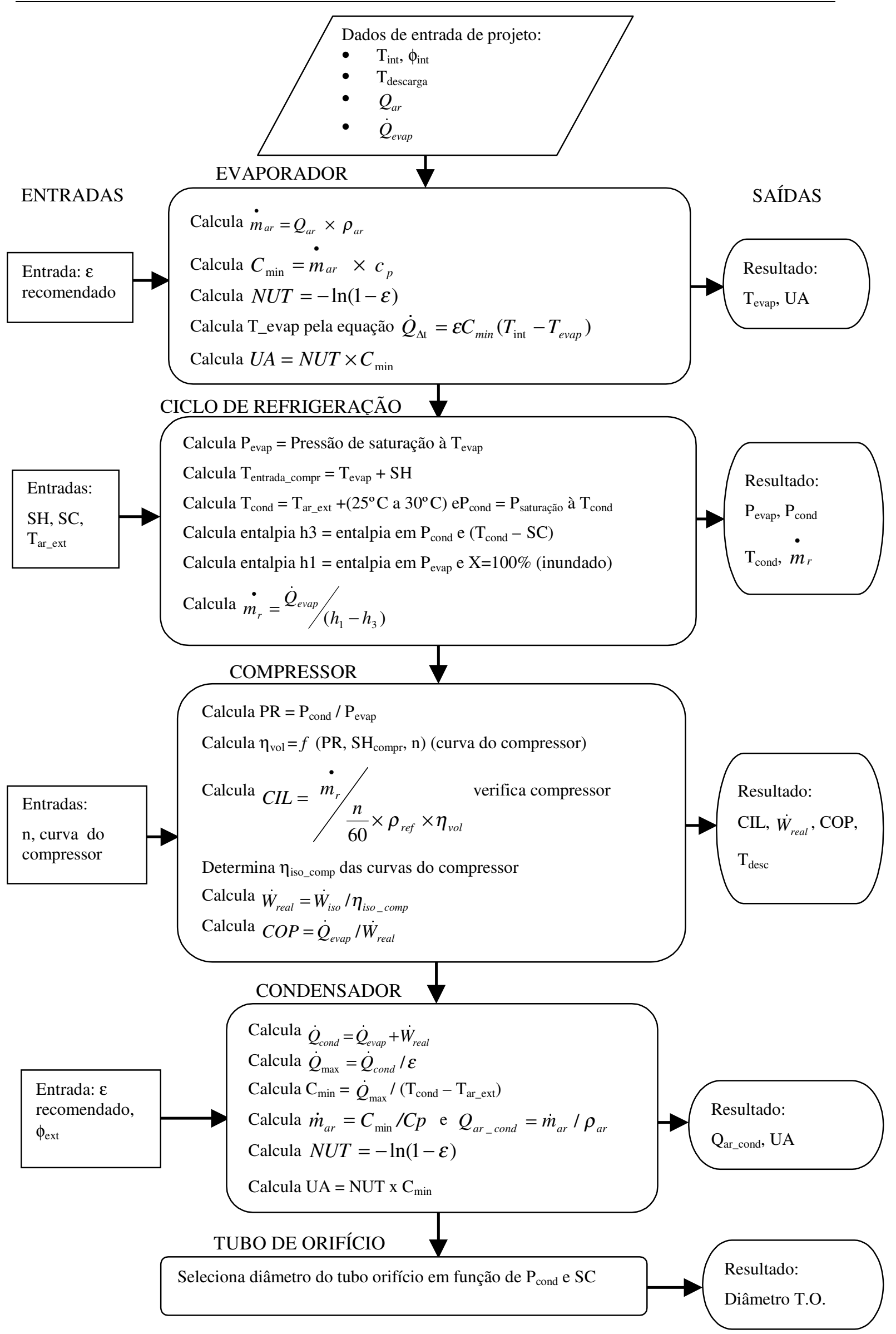

Figura 5-1 Fluxograma de projeto do sistema de refrigeração. 
Tabela 5-1 Dados de entrada para o projeto do sistema de refrigeração

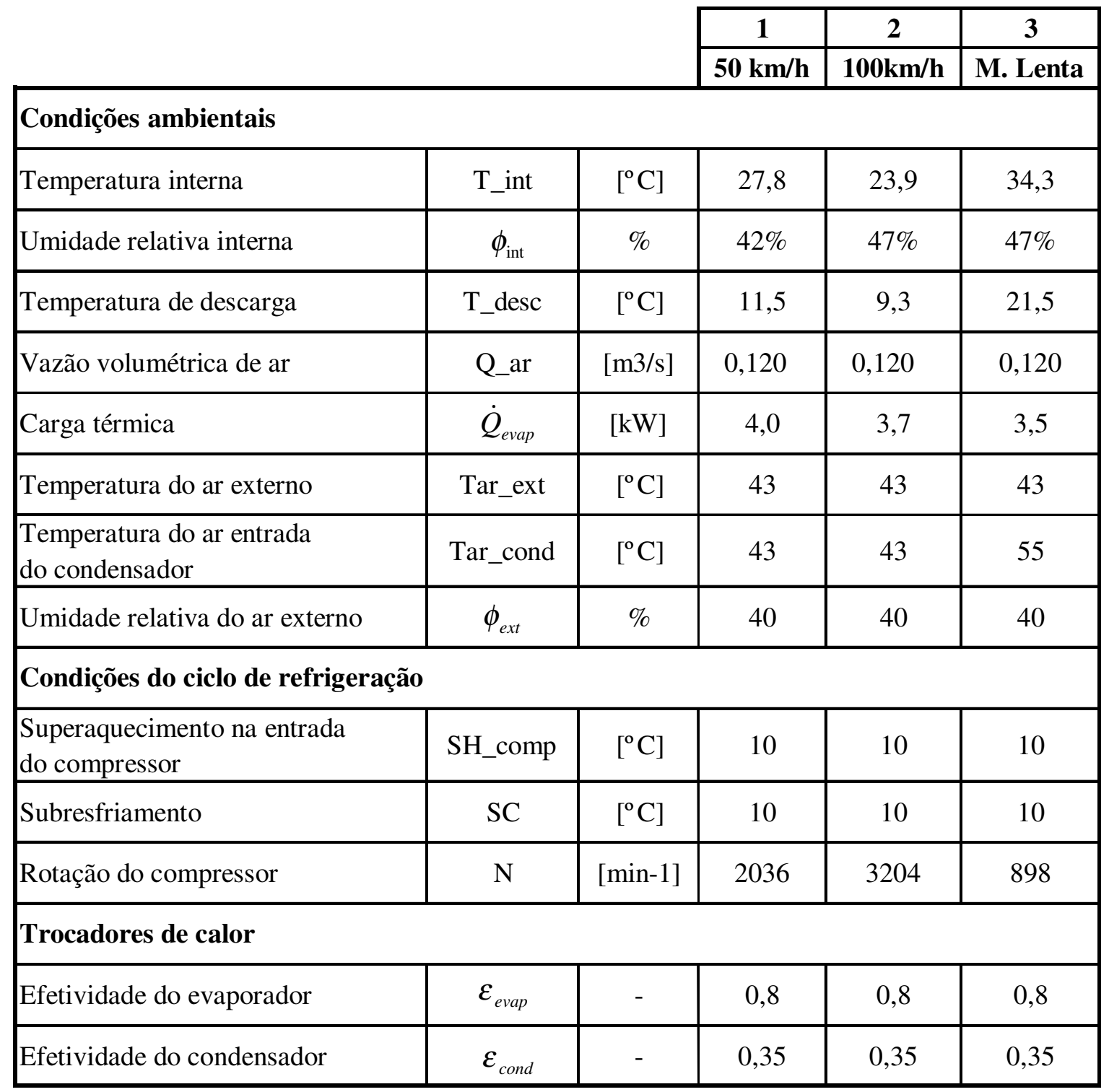

Iniciando pelo evaporador, calcula-se a temperatura de evaporação e o valor de UA para cada condição de operação. Os resultados estão apresentados na tabela 5-2.

Em seguida determina-se as condições de operação do ciclo de refrigeração usando o refrigerante R134a. Os resultados obtidos estão apresentados na tabela 5-3. Notase o aumento da temperatura e pressão de condensação, fato que se deve à uma maior temperatura de entrada de ar no condensador. Em condições de marcha-lenta com o veículo parado, o ar quente no interior do compartimento do motor vaza por aberturas existentes na parte frontal do veículo e é recirculado através do condensador, fazendo subir a temperatura de entrada do ar para o condensador. 
Tabela 5-2 Resultados do cálculo do evaporador

\begin{tabular}{|l|c|c|c|c|c|}
\cline { 4 - 7 } \multicolumn{2}{c}{} & \multicolumn{1}{|c|}{} & $\mathbf{2}$ & $\mathbf{3}$ \\
\cline { 4 - 7 } & & $\mathbf{5 0} \mathbf{~ k m} / \mathbf{h}$ & $\mathbf{1 0 0} \mathbf{k m} / \mathbf{h}$ & $\mathbf{M}$. Lenta \\
\hline Temperatura de evaporação & T_evap & {$\left[{ }^{\circ} \mathrm{C}\right]$} & 2,3 & 0,5 & 13,1 \\
\hline UA Evaporador & UA_evap & {$\left[\mathrm{kW} /{ }^{\circ} \mathrm{C}\right]$} & 0,224 & 0,227 & 0,220 \\
\hline
\end{tabular}

Tabela 5-3 Condições de operação do ciclo de refrigeração

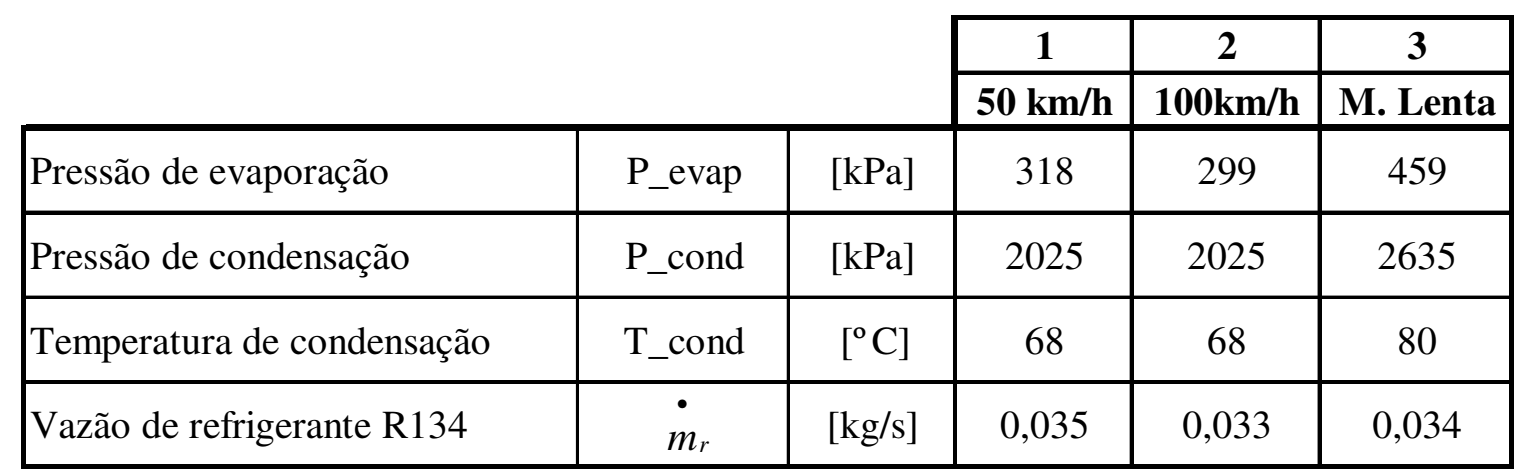

Com os resultados do ciclo de refrigeração é possível determinar as necessidades do compressor, como o deslocamento volumétrico CIL $\left(\mathrm{cm}^{3}\right)$, o trabalho de compressão, a temperatura de descarga e o COP. Os resultados estão apresentados na tabela 5-4.

As eficiências do compressor foram obtidas por meio das curvas do compressor utilizado no veículo testado. As curvas foram obtidas por meio do ajuste dos dados experimentais do compressor obtidos em teste em calorímetro. Os coeficientes de ajuste das curvas podem ser encontrados no apêndice A.

As curvas de eficiência volumétrica do compressor estão apresentados na Figura 5-2 e a curva de eficiência isoentrópica é apresentada na Figura 5-3. 


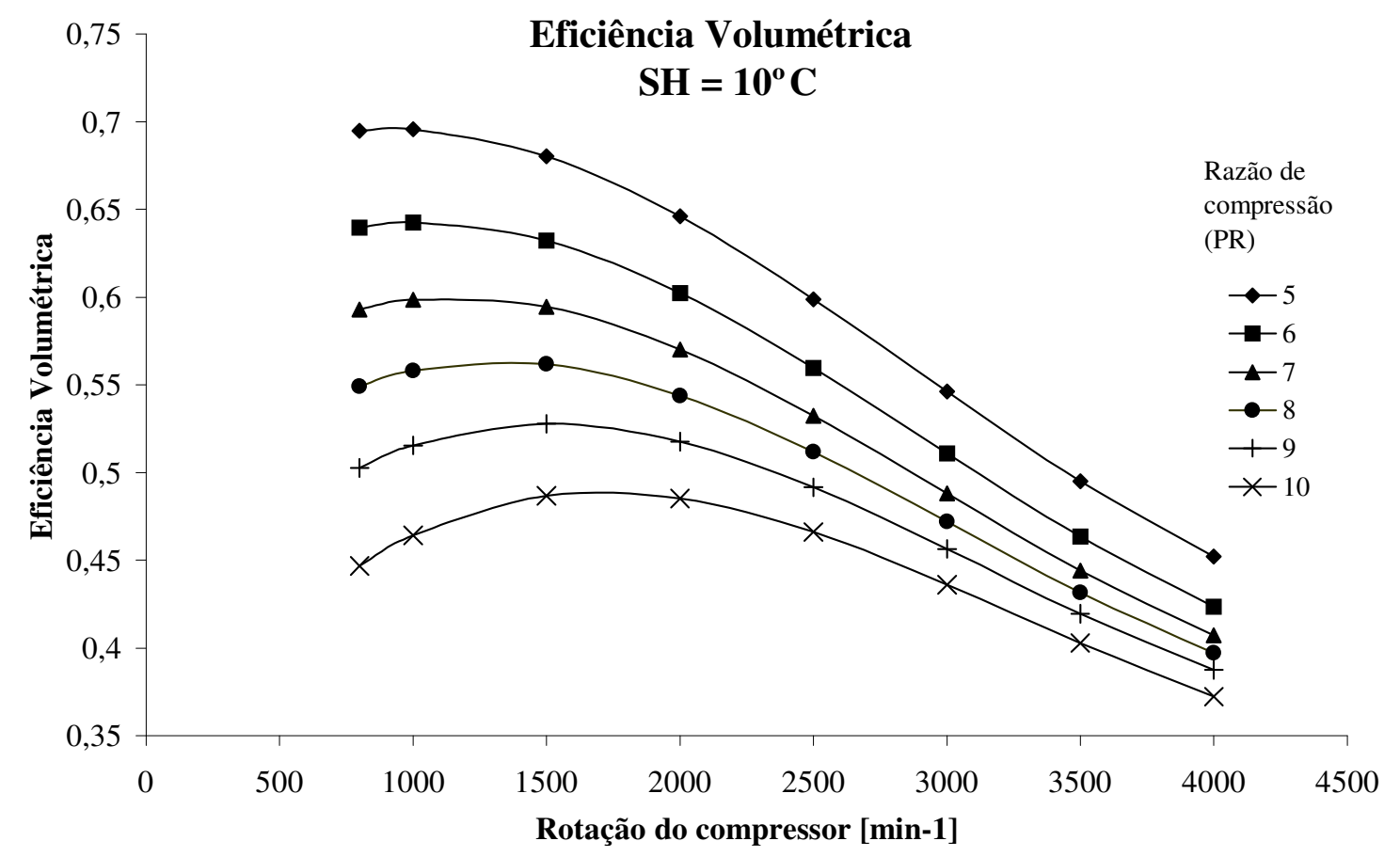

Figura 5-2 Curvas de eficiência volumétrica do compressor

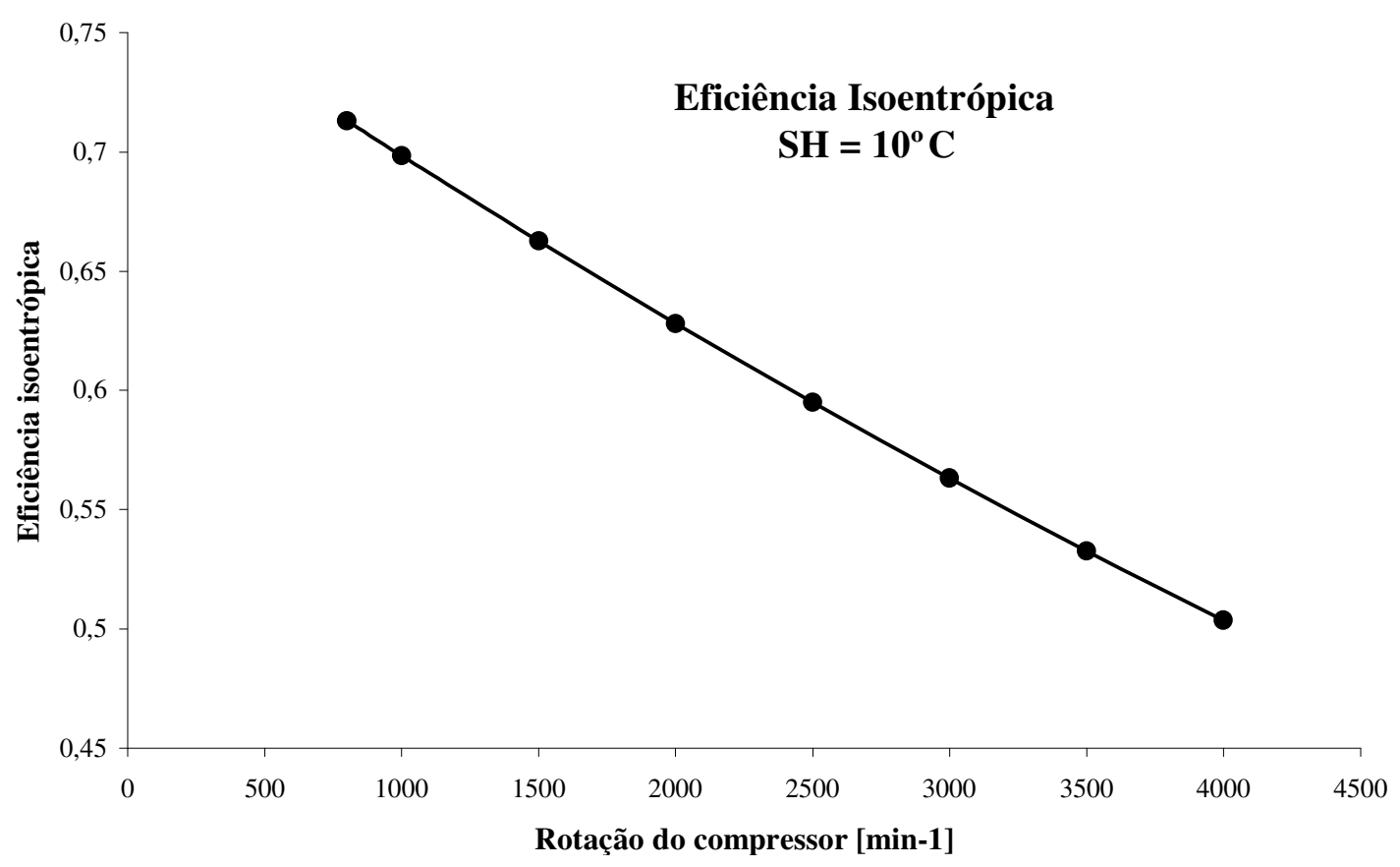

Figura 5-3 Curva de eficiência isoentrópica do compressor 
Tabela 5-4 Resultados dos cálculos do compressor

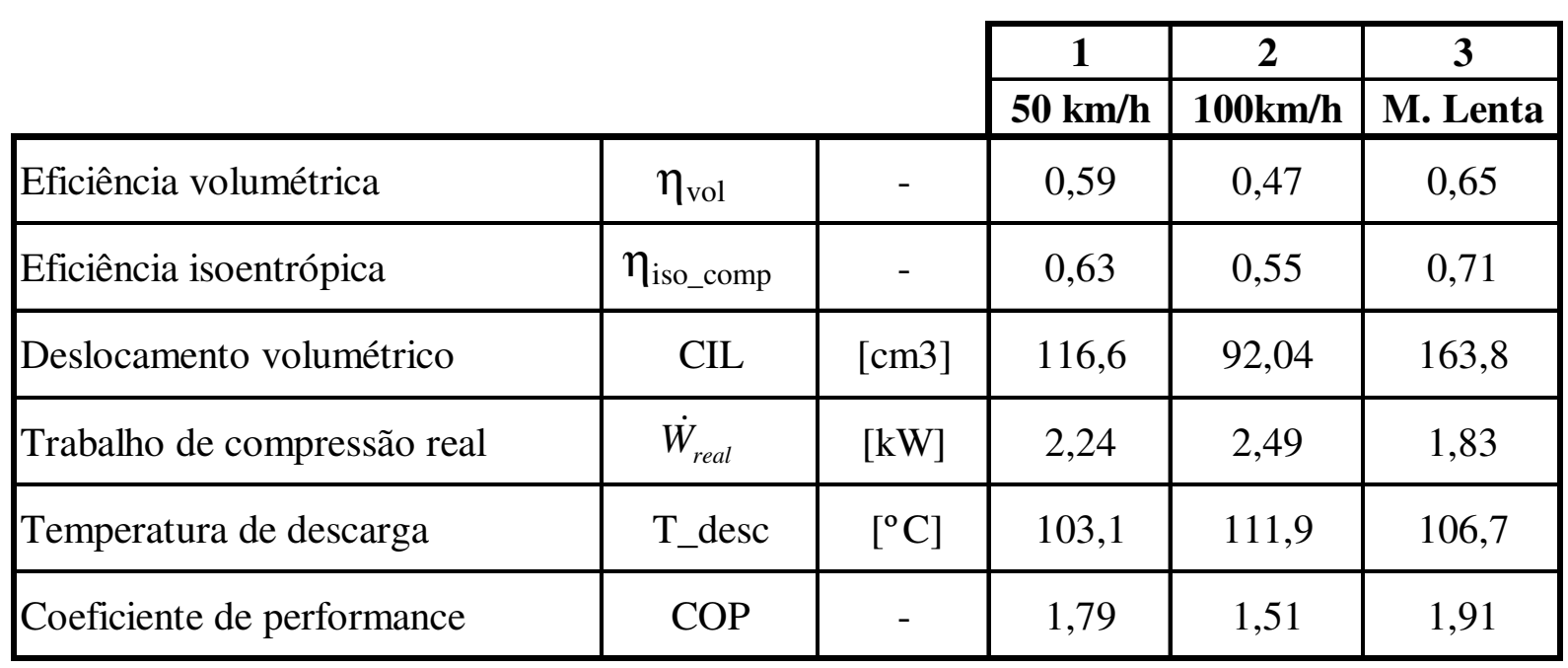

Prossegue-se então para o cálculo do condensador, onde se pretende determinar a vazão de ar necessária e o produto $\mathrm{UA}_{\text {cond. }}$ Os resultados estão apresentados na tabela 5-5.

Tabela 5-5 Resultados dos cálculos do condensador

\begin{tabular}{|c|c|c|c|c|c|}
\hline & & & \multirow{2}{*}{$\begin{array}{c}1 \\
50 \mathrm{~km} / \mathrm{h}\end{array}$} & \multirow{2}{*}{$\begin{array}{c}2 \\
100 \mathrm{~km} / \mathrm{h} \\
\end{array}$} & \multirow{2}{*}{$\begin{array}{c}3 \\
\text { M. Lenta }\end{array}$} \\
\hline & & & & & \\
\hline Rejeito de calor no condensador & $\dot{Q}_{\text {cond }}$ & {$[\mathrm{kW}]$} & 6,24 & 6,23 & 5,31 \\
\hline Vazão de ar do condensador & Qar_cond & {$[\mathrm{m} 3 / \mathrm{s}]$} & 0,56 & 0,56 & 0,50 \\
\hline UA Condensador & UA_cond & {$\left[\mathrm{kW} /{ }^{\circ} \mathrm{C}\right]$} & 0,319 & 0,318 & 0,272 \\
\hline
\end{tabular}

O último passo é selecionar um tubo de orifício que estabeleça a mesma vazão mássica de refrigerante $\dot{m}_{r}$ que é proporcionada pelo compressor. O tipo de tubo de orifício utilizado neste trabalho é o mesmo que foi avaliado por Hernandez Neto (1998), de maneira que é possível utilizar os resultados experimentais de seu trabalho para a seleção do componente.

Os tubos de orifício são fabricados com um comprimento padrão, com cinco diâmetros diferentes. $\mathrm{O}$ diâmetro adequado foi selecionado em um gráfico gerado a partir do ajuste dos dados experimentais de Hernandez Neto (1998). O polinômio de ajuste e os coeficientes são apresentados no Apêndice B. O gráfico da Figura 5-4 apresenta as curvas de vazão para o subresfriamento de $10^{\circ} \mathrm{C}$ adotado no projeto, em função da pressão de entrada, para os cinco diâmetros disponíveis. 


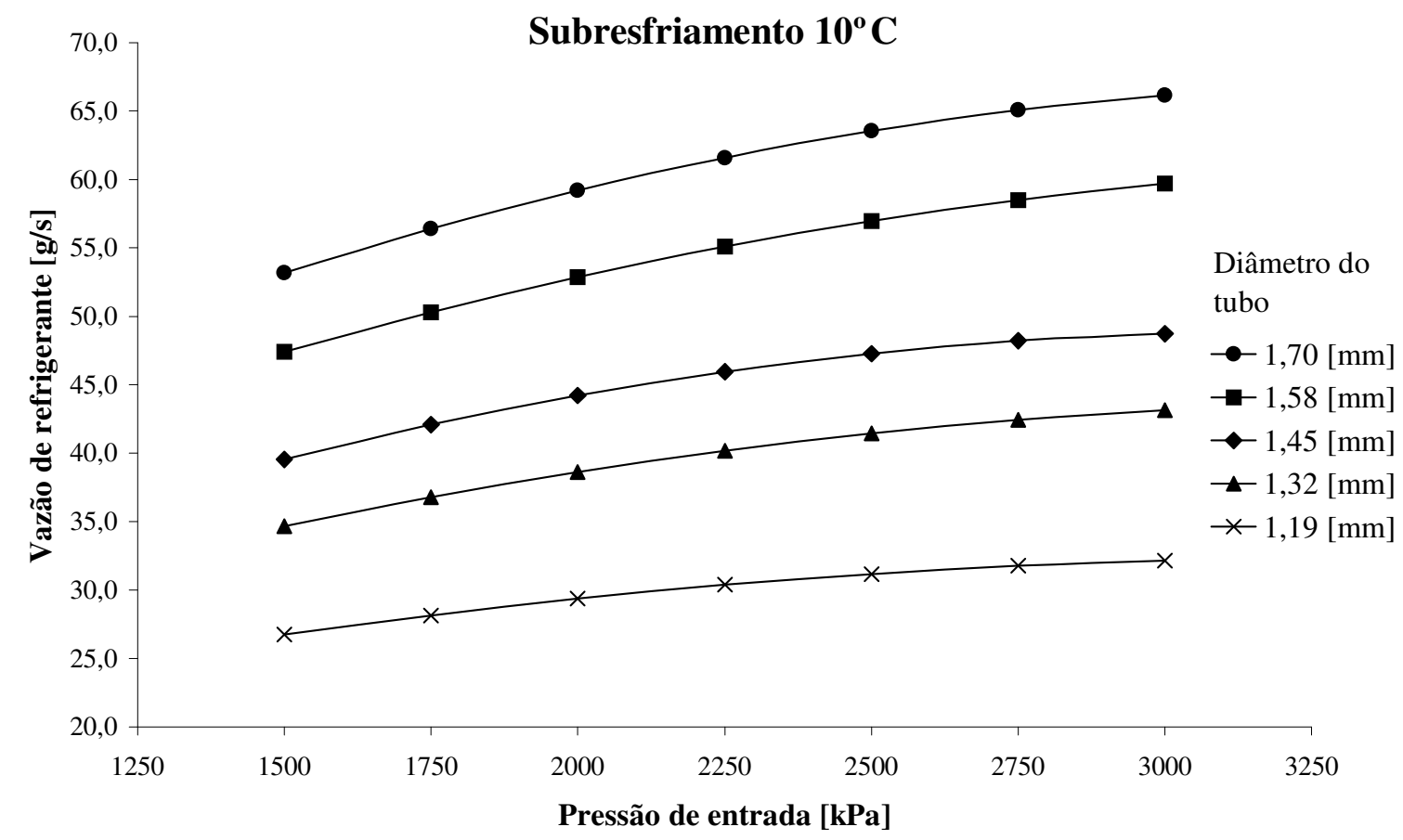

Figura 5-4 Curvas de vazão de refrigerante para $\mathrm{SC}=10^{\circ} \mathrm{C}$

Os resultados de vazão para os pontos de operação estão apresentados na tabela 56. Observa-se que o tubo de 1,32mm estabelece uma vazão superior ao necessário, enquanto o tubo $1,19 \mathrm{~mm}$ fica aquém do necessário. A melhor escolha para este projeto, portanto, é o tubo de $1,32 \mathrm{~mm}$.

Tabela 5-6 Vazões de refrigerante para cada diâmetro de tubo para os pontos de operação do projeto.

\begin{tabular}{|c|c|c|c|c|c|c|}
\cline { 3 - 7 } \multicolumn{2}{c|}{} & \multicolumn{5}{|c|}{ Diâmetros dos tubos } \\
\cline { 3 - 7 } \multicolumn{2}{c|}{} & 1,70 & 1,58 & 1,45 & 1,32 & 1,19 \\
\hline P_cond & SC & {$[\mathrm{mm}]$} & {$[\mathrm{mm}]$} & {$[\mathrm{mm}]$} & {$[\mathrm{mm}]$} & {$[\mathrm{mm}]$} \\
\hline$[\mathrm{kPa}]$ & {$\left[{ }^{\circ} \mathrm{C}\right]$} & & \multicolumn{5}{|c|}{ Vazão [g/s] } \\
\hline 2025 & 10 & 59,5 & 53,1 & 44,4 & 38,8 & 29,5 \\
\hline 2635 & 10 & 64,4 & 57,8 & 47,8 & 42,0 & 31,5 \\
\hline
\end{tabular}

\subsection{CONCLUSÃO}

O resultado do cálculo de UA_evap $=0,224 \mathrm{~kW} /{ }^{\circ} \mathrm{C}$ (média) apresenta-se muito próximo do trocador efetivamente utilizado na aplicação, que tem UA médio de 0,2348 $\mathrm{kW} /{ }^{\circ} \mathrm{C}$, o que confirma a validade do cálculo.

Para o compressor fica evidente que a necessidade de deslocamento volumétrico para cada regime de operação é muito diferente, variando entre $92,0 \mathrm{~cm}^{3}$ a $163,8 \mathrm{~cm}^{3}$ (para 
$100 \mathrm{~km} / \mathrm{h}$ e marcha-lenta respectivamente). O compressor utilizado na aplicação tem deslocamento fixo de $154 \mathrm{~cm}^{3}$, ficando ligeiramente subdimensionado para marcha-lenta, ligeiramente sobredimensionado para $50 \mathrm{~km} / \mathrm{h}$, e claramente sobredimensionado para o regime de $100 \mathrm{~km} / \mathrm{h}$. Espera-se, portanto, que o sistema opere em condições distintas da condição de projeto, o que se confirma na prática.

O mesmo fenômeno ocorre para o tubo de orifício, onde se observa que o diâmetro de $1,32 \mathrm{~mm}$ oferece uma vazão muito próxima da calculada para $50 \mathrm{~km} / \mathrm{h}$, mas fica sobredimensionado na condição de marcha-lenta, o que na prática resulta em que o sistema se acomodará com um subresfriamento menor e uma pressão de condensação menor para que haja igualdade entre a vazão mássica no compressor e no tubo de orifício. O tubo de orifício escolhido para a aplicação real foi o de $1,45 \mathrm{~mm}$, provavelmente como resultado da escolha de um subresfriamento menor do que $10^{\circ} \mathrm{C}$ ou de uma carga térmica maior do que a carga térmica considerada para o projeto.

Conclui-se que o sistema não estará otimizado para todas as condições de operação, o que sugere que tenha que se fazer algumas soluções de compromisso para se obter o melhor resultado global. Este procedimento pode ser usado para o projeto básico do sistema de refrigeração, e a partir deste projeto básico deve-se fazer ajustes e simulações para predizer qual o comportamento do sistema opera em condições diferentes da condição ideal de projeto. 


\section{CAPÍTULO 6 AVALIAÇÃO DE DESEMPENHO DO CICLO DE REFRIGERAÇÃO}

Freqüentemente se faz necessário estimar qual o desempenho de um ciclo de refrigeração trabalhando sob condições diferentes da condição de projeto. Neste tipo de problema, em geral as características dos componentes são conhecidas, e pretende-se saber qual o ponto de equilíbrio em que o sistema irá trabalhar sob diferentes condições. Este caso é um pouco mais complexo do que o caso de projeto, porque exige que se faça estimativas iniciais e diversas iterações até convergir para o resultado final.

O objetivo deste capítulo é apresentar um procedimento para a avaliação do desempenho do ciclo de refrigeração por compressão mecânica de vapor com compressor fixo de pistões e expansão em tubo de orifício calibrado, conforme descrito no capítulo 4, operando sob condições determinadas. Em seguida comparar os resultados de simulação com dados obtidos em um ensaio em túnel de vento com o sistema real.

A variação de qualquer parâmetro operacional do sistema de refrigeração afeta todos os componentes e altera o ponto de equilíbrio. Utilizando este procedimento, será possível prever o comportamento do sistema, em regime permanente, por exemplo para variações de rotação do compressor ou das temperaturas internas e externas.

O método aqui utilizado para a simulação do sistema consiste na aplicação de equações de balanços de energia e na igualdade entre a vazão mássica de refrigerante fornecida pelo compressor e pelo tubo de orifício calibrado, em conjunto com modelos semi-empíricos dos componentes, obtidos a partir de dados de fabricante. O desempenho do sistema será determinado por um ponto de equilíbrio que satisfaça as equações de balanço de massa e de energia e também os modelos dos componentes.

O ponto de equilíbrio estará completamente descrito quando forem determinadas as pressões de trabalho, as temperaturas de condensação e saída do evaporador, a vazão mássica de refrigerante e os fluxos de calor pelo evaporador e pelo condensador. Adicionalmente é possível determinar qual o consumo de energia do compressor e o COP.

Para a determinação do ponto de equilíbrio neste trabalho é adotada a mesma simplificação usada por Huang et al (1999) e Takeuchi, Kakishita e Khori (2002), que consiste em fixar o valor do superaquecimento na saída do evaporador. 


\subsection{PARÂMETROS DE ENTRADA PARA A SIMULAÇÃO}

Para a simulação do sistema são fixados alguns parâmetros de entrada que correspondem à condição de operação para a qual se pretende determinar o ponto de equilíbrio. Outro conjunto de parâmetros de entrada são estimados inicialmente e ajustados a cada iteração até que haja igualdade entre a vazão de refrigerante pelo compressor e pelo tubo de orifício.

\subsubsection{Parâmetros de operação}

- Temperatura interna desejada

$\begin{array}{ll}\mathrm{T}_{\text {int }} & { }^{\circ} \mathrm{C} \\ \phi_{\text {int }} & \% \\ \text { Q }_{\text {ar_evap }} & \mathrm{m}^{3} / \mathrm{s} \\ \mathrm{T}_{\text {ar_ext }} & { }^{\circ} \mathrm{C} \\ \phi_{\text {ext }} & \% \\ \mathrm{~T}_{\text {ar_cond }} & { }^{\circ} \mathrm{C} \\ \text { Q }_{\text {ar_cond }} & \mathrm{m}^{3} / \mathrm{s} \\ \mathrm{SH}_{\text {evap }} & { }^{\circ} \mathrm{C} \\ \mathrm{SH}_{\text {comp }} & { }^{\circ} \mathrm{C} \\ \mathrm{n} & \mathrm{min}^{-1} \\ \mathrm{CIL} & \mathrm{m}^{3}\end{array}$

- Umidade relativa do ar interno

- Vazão de ar da ventilação interna

- Temperatura externa

- Umidade relativa do ar externo

- Temperatura do ar de entrada do condensador

- Vazão de ar do condensador

- Superaquecimento na saída do evaporador

- Superaquecimento na saída do compressor

- Rotação do compressor

- Deslocamento volumétrico do compressor

\subsubsection{Parâmetros estimados}

- Razão de compressão

PR

Adimensional

- Temperatura de evaporação

$\mathrm{T}_{\text {evap }}$

${ }^{\circ} \mathrm{C}$

- Subresfriamento

SC

${ }^{\circ} \mathrm{C}$

\subsection{PROCEDIMENTO DA SIMULAÇÃO}

\subsubsection{Ciclo de refrigeração}

A primeira etapa da simulação do sistema é localizar os pontos de operação 1, 2, 3 e 4 do ciclo de refrigeração apresentado na Figura 6-1.

A partir da temperatura de evaporação $\mathrm{T}_{\text {evap }}$ adotada inicialmente, calcula-se a pressão de evaporação $\mathrm{P}_{\text {evap}}$, que corresponde à temperatura de saturação do R134a para a $\mathrm{T}_{\text {evap. }}$ 
Calcula-se a pressão de condensação pela equação 6.1:

$$
P \_ \text {cond }=P R \times P \_ \text {evap } \quad[\mathrm{kPa}]
$$

A temperatura de condensação corresponde à temperatura de saturação do R134a para a pressão $\mathrm{P}_{\text {cond }}$.

Calcula-se a temperatura de saída do evaporador pela equação 6.2:

$$
T s_{-} \text {evap }=T_{\_} \text {evap }+S H_{-} \text {evap } \quad\left[{ }^{\circ} \mathrm{C}\right]
$$

Calcula-se a temperatura de saída do condensador a partir do subresfriamento adotado inicialmente, pela equação 6.3:

$$
T s_{-} \text {cond }=T_{-} \text {cond }-S C
$$

Conhecendo-se as pressões e temperaturas nos pontos 1 e 3 ( $^{T_{\text {evap }}}$ e $\left.T s_{\text {cond }}\right)$ e as

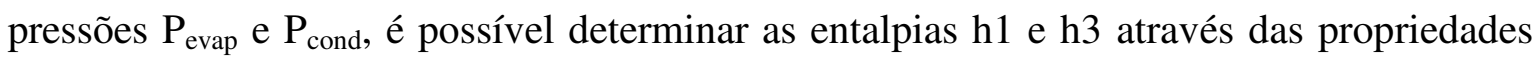
do fluido R134a. A entropia no ponto 2 s é a mesma do ponto 1, portanto é possível determinar a entalpia h2s. A entalpia h3 é igual a h4, e com isso o ciclo ideal de refrigeração está caracterizado. A entalpia real no ponto h2 será conhecida a partir da eficiência isoentrópica do compressor.

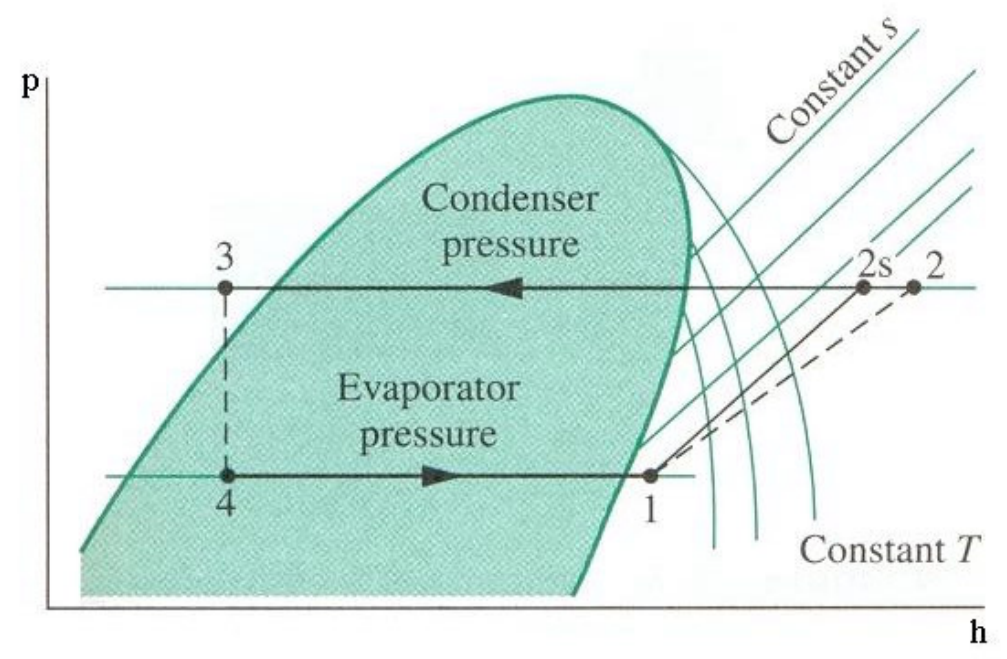

Figura 6-1 Ciclo real de refrigeração por compressão de vapor (Moran e Shapiro, 2004). 


\subsubsection{Evaporador}

O evaporador utilizado nesta aplicação é do tipo de placas, conforme apresentado na Figura 4-21(c); que é largamente utilizado na indústria automobilística. A característica do evaporador é descrita pelo seu coeficiente global de troca de calor $\mathrm{UA}_{\text {evap. }}$ Os valores de $\mathrm{UA}_{\text {evap }}$ foram obtidos do fabricante, e mostram uma relação diretamente proporcional com a vazão de ar (pois com maiores velocidades de ar o coeficiente de troca de calor por convecção aumenta). Os dados não mostram correlação com a diferença de temperatura do ar de entrada e de evaporação ( $\mathrm{Ta}$ - Te) de modo que admite-se apenas uma relação linear com a vazão de ar (Figura 6-2). Para a vazão de ar do veículo analisado $\left(0,12 \mathrm{~m}^{3} / \mathrm{s}\right) \mathrm{o}$ valor de UA é $0,234 \mathrm{~kW} /{ }^{\circ} \mathrm{C}$. O polinômio de ajuste encontra-se no apêndice $\mathrm{C}$.

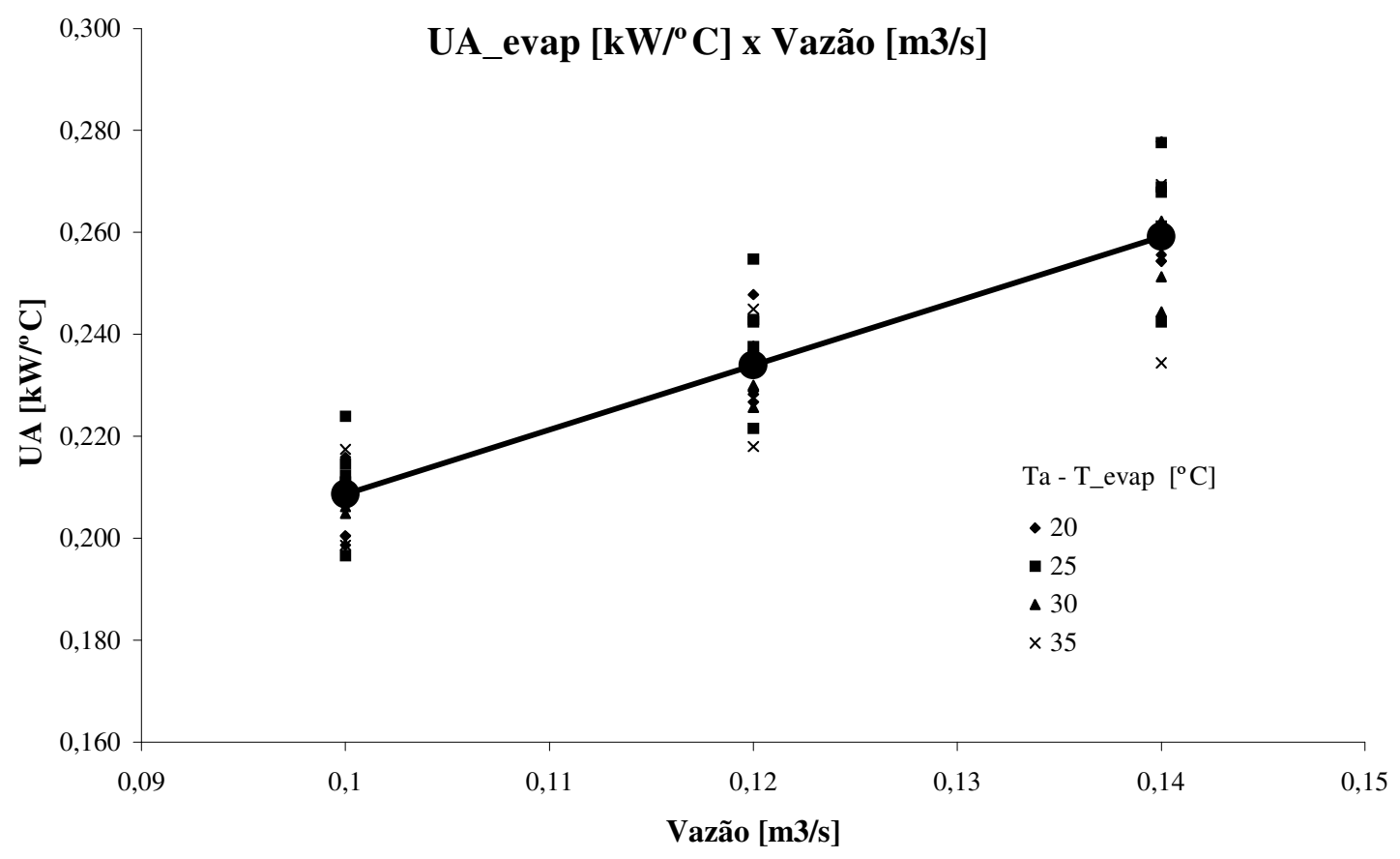

Figura 6-2 Relação UA_evap x Vazão de ar para o evaporador de placas

As trocas térmicas no evaporador devem-se à diferença de temperatura, $\dot{Q}_{\Delta \mathrm{t}}$, e à condensação de vapor d'água, $\dot{Q}_{h_{l v}}$. A parcela devido à diferença de temperatura é calculado pelo método da Efetividade-NUT e é dada por:

$$
\dot{Q}_{\Delta \mathrm{t}}=\varepsilon_{\text {evap }} C \min _{\text {evap }}\left(T_{\mathrm{int}}-T_{\text {evap }}\right) \quad[\mathrm{kW}]
$$


onde:

$\varepsilon_{\text {evap }}=$ efetividade do evaporador (adimensional)

$$
\varepsilon_{\text {evap }}=1-e^{-N U T_{\text {evap }}} \quad \text { (relação } \varepsilon_{\text {evap }} \text { NUT ) }
$$

$\mathrm{NUT}_{\text {evap }}=\mathrm{UA}_{\text {evap }} / \mathrm{Cmin}_{\text {evap }} \quad($ adimensional $)$

$\mathrm{Cmin}_{\text {evap }}=$ capacidade calorífica do fluxo de ar pelo evaporador $\left[\mathrm{kW} /{ }^{\circ} \mathrm{C}\right]$.

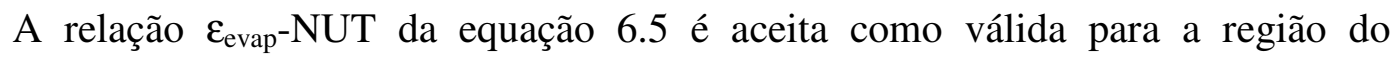
evaporador onde o estado do refrigerante é bifásico (Kays e London, 1984; Incropera e DeWitt, 1998; Jabardo et al; 2002).

A parcela devido à condensação é calculada pela equação 6.6:

$$
\dot{Q}_{h l v}=\dot{m}_{a r} \times\left(w_{\text {int }}-w_{d e s c}\right) \times h_{l v} \quad[\mathrm{~kW}]
$$

onde:

$$
\begin{array}{ll}
\dot{m}_{a r}=\text { Vazão mássica de ar pelo evaporador } & {[\mathrm{kg} / \mathrm{s}]} \\
\mathrm{h}_{\mathrm{lv}}=\text { Entalpia de condensação do vapor d’água } & {[\mathrm{kJ} / \mathrm{kg}]} \\
\mathrm{W}_{\text {int }}=\text { Umidade absoluta do ar interno da cabina } & {[\mathrm{kg} / \mathrm{kg}]} \\
\mathrm{W}_{\text {desc }}=\text { Umidade absoluta do ar de descarga } & {[\mathrm{kg} / \mathrm{kg}]}
\end{array}
$$

A umidade absoluta do ar de descarga é determinada pelas propriedades do ar úmido para uma temperatura de descarga do evaporador $T_{\text {desc }}$, calculada pela equação 6.7 :

$$
\varepsilon_{\text {evap }}=\frac{T_{\mathrm{int}}-T_{\text {desc }}}{T_{\mathrm{int}}-T_{\text {evap }}}
$$

Havendo condensação, a umidade relativa do ar de descarga do evaporador é assumida como $100 \%$. Não havendo condensação, $\dot{Q}_{h l v}=0$.

A troca de calor total pelo evaporador $\dot{Q}_{\text {evap }}$ é dada pela soma de $\dot{Q}_{\Delta \mathrm{t}}$ e $\dot{Q}_{h_{l v}}$ (equação 6.8).

$$
\dot{Q}_{\text {evap }}=\dot{Q}_{\Delta t}+\dot{Q}_{h l v}
$$

A partir de $\dot{Q}_{\text {evap }}$ é possível determinar a vazão mássica de refrigerante $\dot{m}_{r}$ pela equação 6.9: 


$$
\dot{m}_{r}=\frac{\dot{Q}_{\text {evap }}}{\left(h_{1}-h_{4}\right)} \quad[\mathrm{kg} / \mathrm{s}]
$$

\subsubsection{Compressor}

O objetivo desta etapa do processo é determinar a vazão de refrigerante pelo compressor e o trabalho real de compressão.

A vazão mássica de refrigerante pelo compressor $\dot{m}_{r \text { comp }}$ é calculada pela equação 6.10 :

$$
\dot{m}_{\text {rcomp }}=C I L \times \frac{n}{60} \times \rho_{\text {ref }} \times \eta_{\text {vol }} \quad[\mathrm{kg} / \mathrm{s}]
$$

onde:

$\rho_{\text {ref }}=$ massa específica do refrigerante na sucção do compressor $\quad\left[\mathrm{kg} / \mathrm{m}^{3}\right]$

$\eta_{\mathrm{vol}}=$ Eficiência volumétrica, determinada pelo gráfico da Figura 5-1 a partir dos valores de PR e n.

O valor da razão de compressão PR assumido inicialmente deve ser ajustado até que haja igualdade entre os valores de $\dot{m}_{r}$ e $\dot{m}_{r_{\text {comp }}}$. Quando isto ocorrer, o ponto de equilíbrio entre a demanda do evaporador e a capacidade do compressor terá sido encontrado.

Em seguida determina-se a eficiência isoentrópica $\eta_{\text {iso }}$ a partir da Figura 5-2, para o cálculo do trabalho real de compressão dado por:

$$
\dot{W}_{\text {real }}=\dot{m}_{r} \times\left(h_{2}-h_{1}\right)
$$

A entalpia $\mathrm{h}_{2}$ do refrigerante na saída do compressor é determinada pela eficiência isoentrópica como sendo:

$$
h_{2}=\frac{h_{2 s}+h_{1}\left(\eta_{\text {iso }}-1\right)}{\eta_{\text {iso }}} \quad[\mathrm{kJ} / \mathrm{kg}]
$$

\subsubsection{Condensador}

O condensador usado nesta aplicação é do tipo de tubos planos com aletas tipo 
louver, conforme apresentado na Figura 4-18. A característica do condensador é descrita pelo seu coeficiente global de troca de calor $\mathrm{UA}_{\text {cond. }}$ Os valores de $\mathrm{UA}_{\text {cond }}$ foram obtidos do fabricante e mostram uma relação diretamente proporcional com a vazão de ar (pois com maiores velocidades de ar o coeficiente de troca de calor por convecção aumenta). Diferentemente do evaporador, os dados do fabricante para o condensador mostram uma relação de proporcionalidade com a diferença de temperaturas $\mathrm{T}_{\text {cond }}-\mathrm{T}_{\text {ar_ext }}$, como pode ser visto na Figura 6-3. Os dados foram ajustados por um polinômio de segunda ordem (Apêndice D).

O objetivo desta etapa é verificar se o condensador é capaz de rejeitar a quantidade de calor $\dot{Q}_{\text {cond }}$ dada pela equação 6.13 nas temperaturas de entrada de ar no condensador $\mathrm{T}_{\text {ar_cond }}$ e de condensação $\mathrm{T}_{\text {cond, }}$ com a vazão de ar disponível.

$$
\dot{Q}_{\text {cond }}=\dot{Q}_{\text {evap }}+\dot{W}_{\text {real }}
$$

A quantidade de calor que o condensador é capaz de rejeitar, $\dot{Q}_{\text {cond_real }_{\text {re }} \text {, é }}$ determinada pela equação 6.14 :

$$
\dot{Q}_{\text {cond_real }}=\varepsilon_{\text {cond }} \times C \min _{\text {cond }} \times\left(T_{\text {cond }}-T_{\text {ar_ext }}\right) \quad[\mathrm{kW}]
$$

onde:

$\varepsilon_{\text {cond }}=$ Efetividade do condensador (adimensional)

$$
\varepsilon_{\text {cond }}=1-e^{-N U T_{\text {cond }}} \quad\left(\text { relação } \varepsilon_{\text {cond }}-\mathrm{NUT}\right)
$$

$\mathrm{NUT}_{\text {cond }}=\mathrm{UA}_{\text {cond }} / \mathrm{Cmin}_{\text {cond }}$ (adimensional)

$\mathrm{Cmin}_{\text {cond }}=$ capacidade calorífica do fluxo de ar pelo condensador $\left[\mathrm{kW} /{ }^{\circ} \mathrm{C}\right]$.

Neste ponto verifica-se a diferença entre $\dot{Q}_{\text {cond }}$ e $\dot{Q}_{\text {cond_real }_{\text {real }}}$ e ajusta-se a estimativa inicial de $\mathrm{T}_{\text {evap }}$ até que haja igualdade. Caso $\dot{Q}_{\text {cond }}$ seja maior que $\dot{Q}_{\text {cond_real }}$ a estimativa de $\mathrm{T}_{\text {evap }}$ é menor que a temperatura correta, ou seja foi admitido que o fluxo de calor pelo evaporador foi maior que o que o condensador é capaz de rejeitar, e vice-versa. A cada novo valor de $\mathrm{T}_{\text {evap }}$ deverá ser encontrado um novo balanço de vazão mássica entre o evaporador e o compressor. 


\section{UA_cond $\left[\mathrm{kW} /{ }^{\circ} \mathrm{C}\right] \mathrm{x}(\mathrm{Tcond}-\mathrm{Ta})\left[{ }^{\circ} \mathrm{C}\right]$}

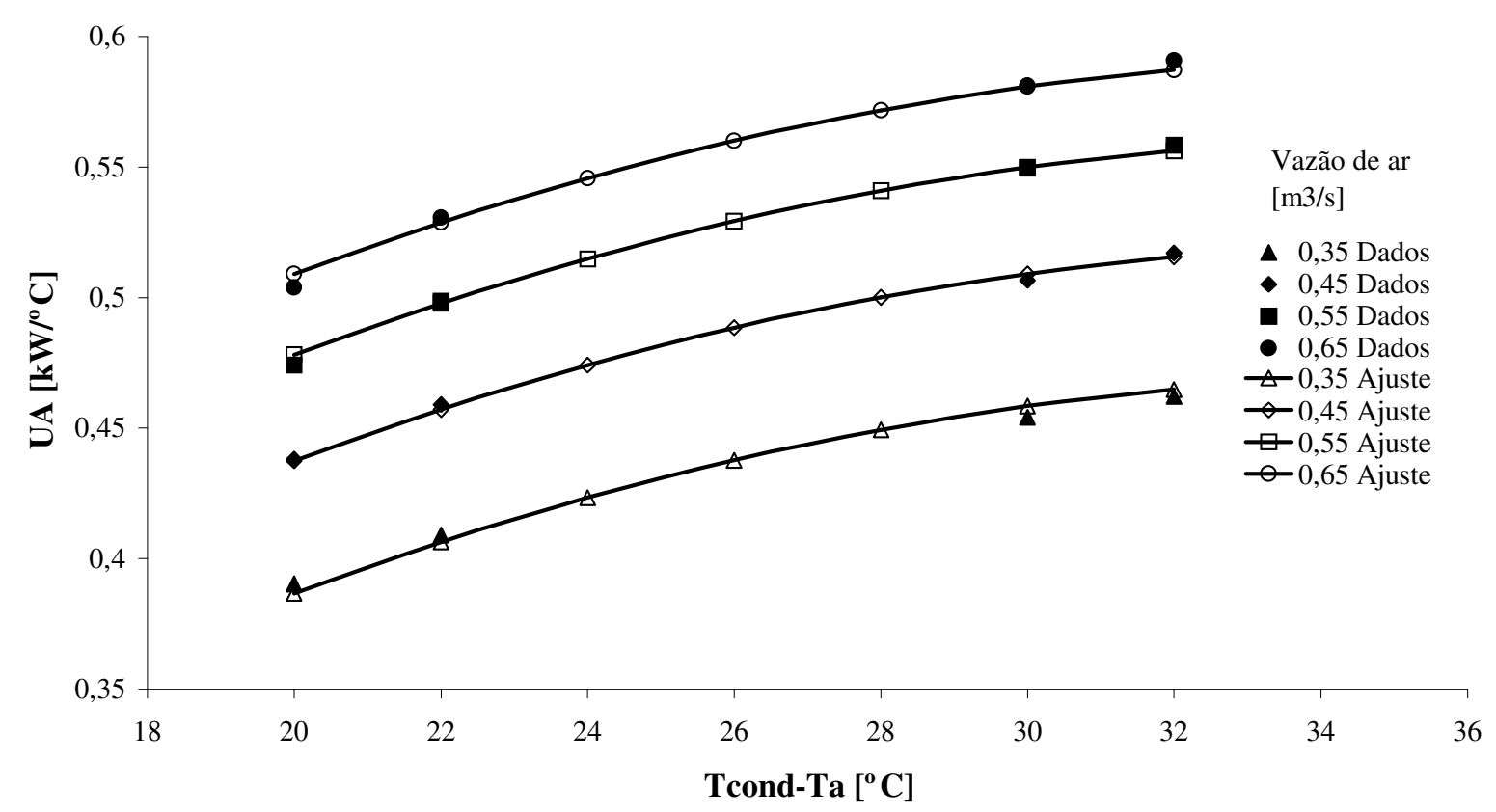

Figura 6-3 Relação UA_cond $x$ Vazão de ar e Tcond-Tar_ext para $o$ condensador de tubos planos e aletas tipo louver

\subsubsection{Tubo de orifício}

O último passo é verificar o balanço entre a vazão mássica de refrigerante pelo compressor e pelo tubo orifício. A vazão mássica do tubo orifício, $\dot{m} r_{\text {T.o. }}$ é determinada por meio da regressão linear dos dados do tubo orifício (Apêndice B), para os valores da pressão de condensação calculada $\mathrm{P}_{\text {cond }}$ e o subresfriamento estimado inicialmente, SC. O tubo de orifício usado na aplicação é o de $1,45 \mathrm{~mm}$.

Um valor de vazão mássica de refrigerante permitido pelo tubo de orifício significa que o subresfriamento adotado inicialmente é maior do que o real. O valor do subresfriamento adotado afeta a entalpia na entrada do evaporador e, portanto, para cada novo valor de SC todo o procedimento de cálculo deve ser repetido, até que se obtenha o ponto de equilíbrio entre todos os componentes do sistema.

\subsubsection{Fluxograma do processo}

Na Figura 6. 4 é apresentado o fluxograma do processo de simulação do sistema 


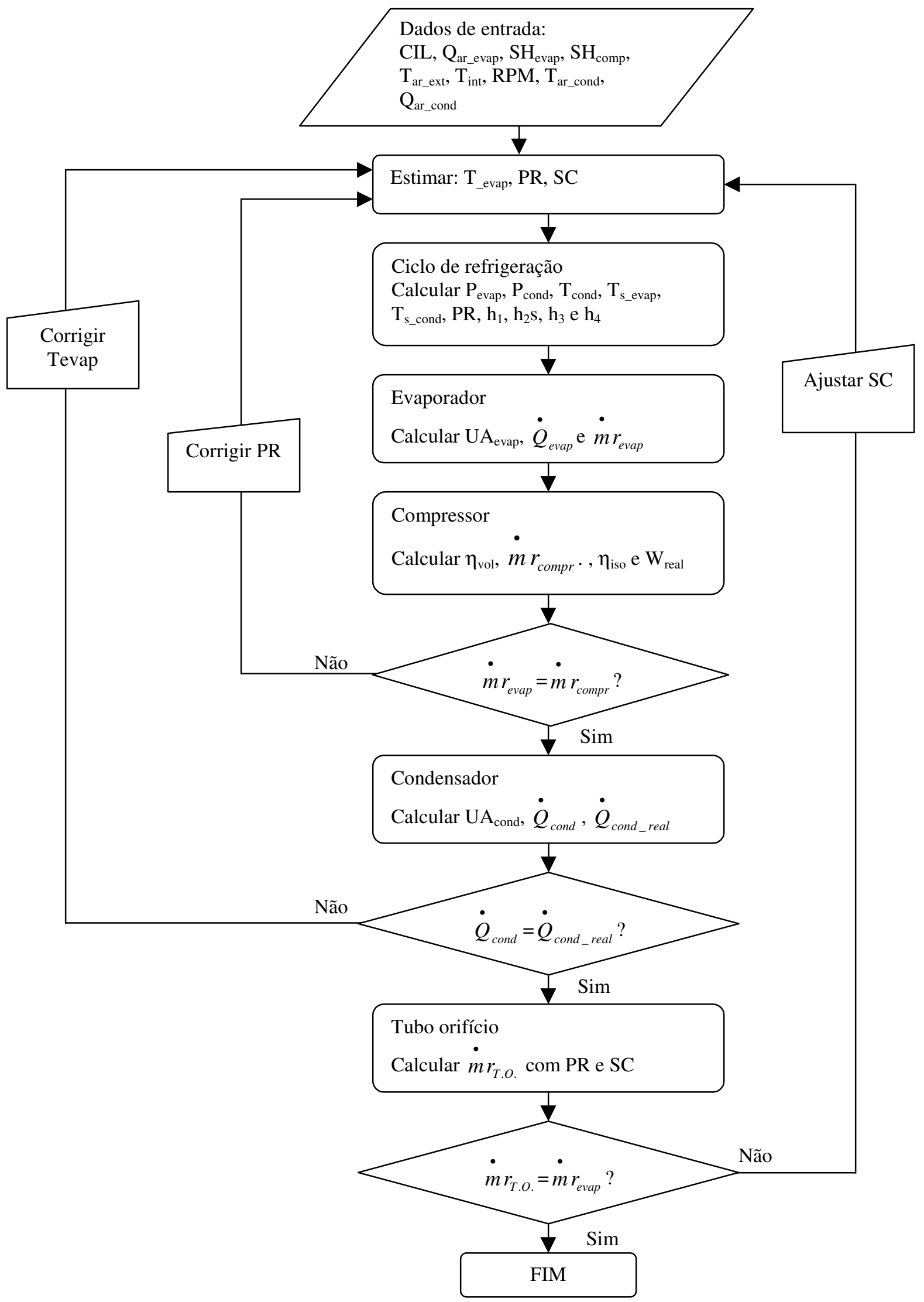

Figura 6. 4 - Fluxograma do processo de simulação do sistema. 


\subsection{DADOS DE ENTRADA E RESULTADOS}

A Tabela 6-1 apresenta os dados de entrada para simulação do sistema. Os dados são os mesmos obtidos no túnel de vento (Tabela 3-1) e utilizados no capítulo 5 para o projeto do sistema, sendo que a umidade relativa interna foi estimada no capítulo 3 considerando uma vazão de infiltração de 15 1/s estimada igualmente para as velocidades de $50 \mathrm{~km} / \mathrm{h}$ e $100 \mathrm{~km} / \mathrm{h}$. A vazão de ar do condensador $Q_{\text {ar_cond }}$ é um dado real da aplicação.

Tabela 6-1 Dados de entrada para a simulação do sistema.

\begin{tabular}{|c|c|c|c|c|c|}
\hline & & & \\
\hline & & & 1 & 2 & 3 \\
\hline & & & $50 \mathrm{~km} / \mathrm{h}$ & $100 \mathrm{~km} / \mathrm{h}$ & M. Lenta \\
\hline \multicolumn{6}{|l|}{ DADOS DE ENTRADA } \\
\hline Temperatura interna & T_int & {$\left[{ }^{\circ} \mathrm{C}\right]$} & 27,8 & 23,9 & 34,3 \\
\hline Umidade relativa interna & $\phi_{\text {int }}$ & $\%$ & $42 \%$ & $47 \%$ & $47 \%$ \\
\hline $\begin{array}{l}\text { Vazão volumétrica de ar do } \\
\text { evaporador }\end{array}$ & Qar_evap & {$[\mathrm{m} 3 / \mathrm{s}]$} & 0,120 & 0,120 & 0,120 \\
\hline Temperatura do ar externo & Tar_ext & {$\left[{ }^{\circ} \mathrm{C}\right]$} & 43 & 43 & 43 \\
\hline Umidade relativa do ar externo & $\phi_{e x t}$ & $\%$ & 40 & 40 & 40 \\
\hline $\begin{array}{l}\text { Temperatura do ar entrada } \\
\text { do condensador }\end{array}$ & Tar_cond & {$\left[{ }^{\circ} \mathrm{C}\right]$} & 44 & 44 & 64 \\
\hline $\begin{array}{l}\text { Vazão volumétrica de ar do } \\
\text { condensador }\end{array}$ & Qar_cond & {$[\mathrm{m} 3 / \mathrm{s}]$} & 0,535 & 0,678 & 0,445 \\
\hline $\begin{array}{l}\text { Superaquecimento na saída } \\
\text { do evaporador }\end{array}$ & SH_evap & {$\left[{ }^{\circ} \mathrm{C}\right]$} & 5 & 5 & 5 \\
\hline $\begin{array}{l}\text { Superaquecimento na entrada } \\
\text { do compressor }\end{array}$ & SH_comp & {$\left[{ }^{\circ} \mathrm{C}\right]$} & 10 & 10 & 10 \\
\hline Rotação do compressor & $\mathrm{n}$ & [min-1] & 2036 & 3204 & 898 \\
\hline $\begin{array}{l}\text { Capacidade volumétrica do } \\
\text { compressor }\end{array}$ & CIL & [m3] & $1,54 \mathrm{E}-04$ & $1,54 \mathrm{E}-04$ & 1,54E-04 \\
\hline
\end{tabular}

Os cálculos foram realizados conforme descrito no fluxograma com o uso do software Engineering Equation Solver (EES, 2003). Além da resolução das equações, o software fornece propriedades termodinâmicas de diversas substâncias, como o ar úmido e o refrigerante R134a. Os resultados são apresentados na Tabela 6-2. 
Tabela 6-2 Resultados dos pontos de equilíbrio da simulação.

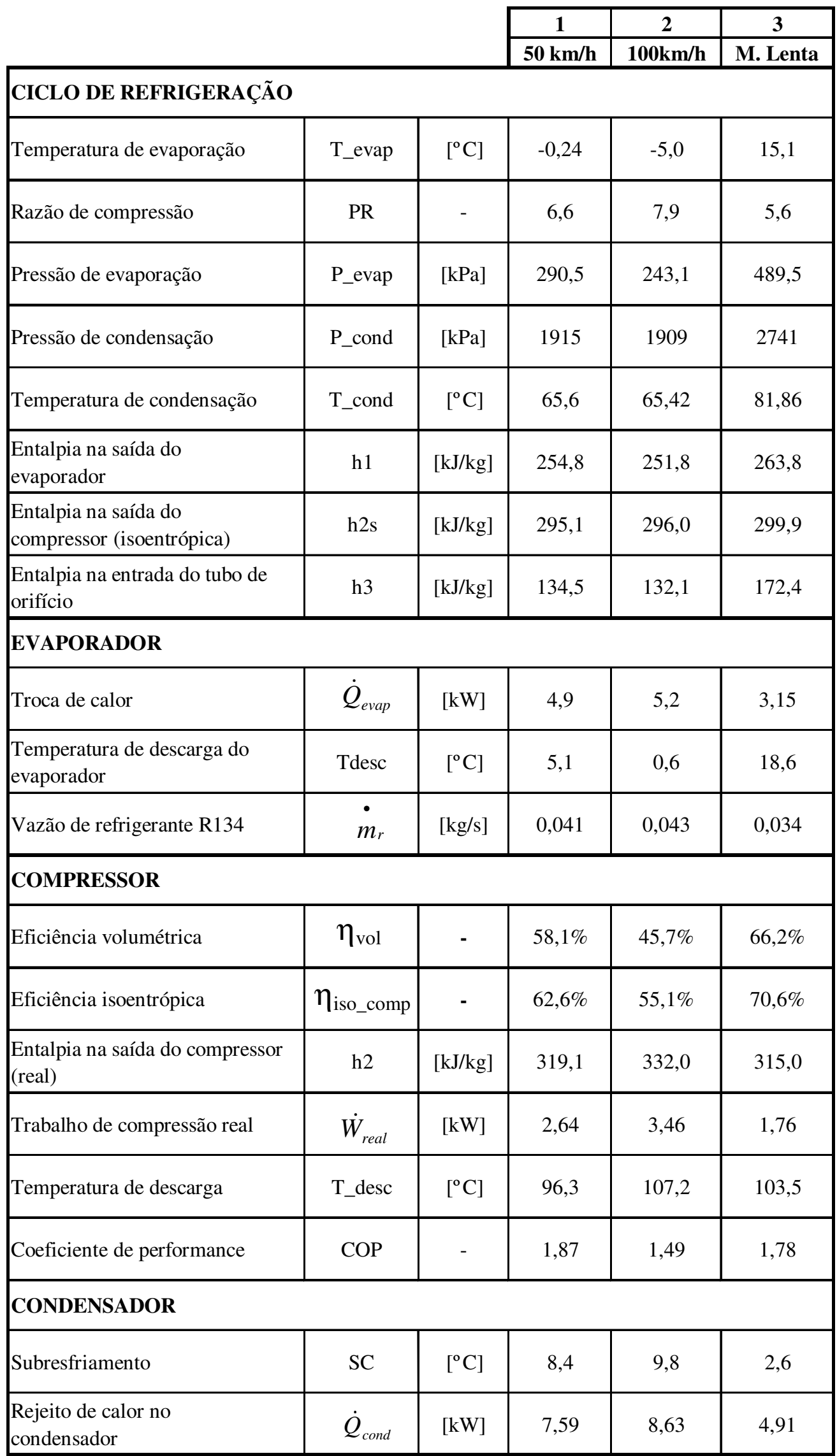




\subsection{RESULTADOS DO TÚNEL DE VENTO}

Como mencionado anteriormente, um dos objetivos deste capítulo é comparar os resultados da simulação do sistema com os dados reais do túnel de vento. As pressões de trabalho podem ser comparadas diretamente com os resultados medidos no ensaio. Porém, as temperaturas de condensação e evaporação, a vazão de refrigerante e a capacidade de refrigeração do sistema não são medidas diretamente, sendo necessário efetuar uma análise termodinâmica dos dados obtidos apresentados na Tabela 3-1.

As temperaturas de condensação e evaporação do refrigerante são assumidas como equivalentes às temperaturas de saturação nas pressões alta e baixa do sistema, respectivamente.

A vazão do refrigerante foi calculada por meio do uso da equação 6.10. A densidade do refrigerante é obtida a partir das propriedades do R134a nas condições de temperatura e pressão na sucção do compressor. A temperatura do refrigerante na sucção do compressor é um dado disponível, e a pressão de sucção é admitida como sendo igual à de evaporação (uma vez que a queda de pressão na linha de sucção está sendo desprezada). A eficiência volumétrica é obtida da curva do compressor já que a rotação e a razão de pressões são conhecidas.

Conhecendo-se as temperaturas do refrigerante na sucção e descarga do compressor e na entrada do tubo orifício é possível determinar as entalpias h1, h2, h3 e h4, correspondentes aos pontos 1, 2, 3 e 4 da Figura 6-1, respectivamente.

A capacidade de refrigeração e o trabalho real de compressão podem ser calculados pelas equações 6.9 e 6.11 , respectivamente, e o rejeito de calor no condensador pela equação 6.13 .

Os valores medidos no ensaio em túnel de vento podem ser encontrados na Tabela 6-3, e os resultados das análises termodinâmicas do sistema medido no túnel de vento, utilizando o software EES (EES, 2003), são apresentados na Tabela 6-4. 
Tabela 6-3 Valores reais medidos no ensaio em túnel de vento

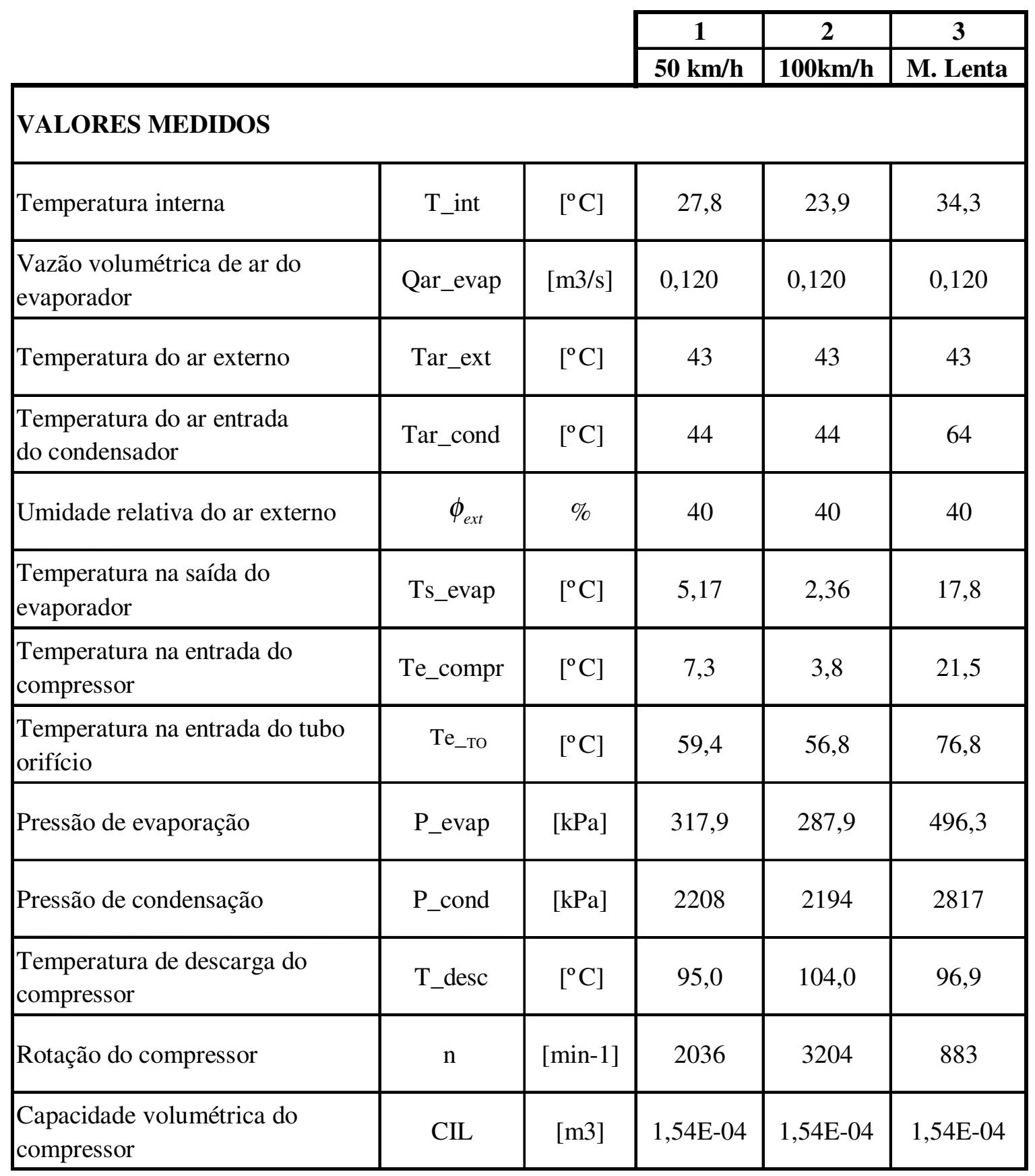


Tabela 6-4 Resultados da análise termodinâmica do sistema medido no túnel de vento

\begin{tabular}{|c|c|c|c|c|c|}
\hline & 1 & 2 & 3 \\
\hline & & & $50 \mathrm{~km} / \mathrm{h}$ & $100 \mathrm{~km} / \mathrm{h}$ & M. Lenta \\
\hline \multicolumn{6}{|l|}{ CICLO DE REFRIGERAÇÃO } \\
\hline Temperatura de evaporação & T_evap & {$\left[{ }^{\circ} \mathrm{C}\right]$} & 2,27 & $-0,50$ & 15,48 \\
\hline Razão de compressão & PR & - & 6,9 & 7,6 & 5,7 \\
\hline Temperatura de condensação & T_cond & {$\left[{ }^{\circ} \mathrm{C}\right]$} & 71,9 & 71,6 & 83,2 \\
\hline $\begin{array}{l}\text { Superaquecimento na saída } \\
\text { do evaporador }\end{array}$ & SH_evap & {$\left[{ }^{\circ} \mathrm{C}\right]$} & 2,9 & 2,8 & 2,4 \\
\hline $\begin{array}{l}\text { Superaquecimento na entrada } \\
\text { do compressor }\end{array}$ & SH_comp & {$\left[{ }^{\circ} \mathrm{C}\right]$} & 5,0 & 4,3 & 6,0 \\
\hline Subresfriamento & $\mathrm{SC}$ & {$\left[{ }^{\circ} \mathrm{C}\right]$} & 12,5 & 14,8 & 6,4 \\
\hline $\begin{array}{l}\text { Entalpia na saída do } \\
\text { evaporador }\end{array}$ & h1 & {$[\mathrm{kJ} / \mathrm{kg}]$} & 254,4 & 252,7 & 261,5 \\
\hline $\begin{array}{l}\text { Entalpia na saída do } \\
\text { compressor (isoentrópica) }\end{array}$ & h2s & {$[\mathrm{kJ} / \mathrm{kg}]$} & 295,1 & 295,5 & 297,2 \\
\hline $\begin{array}{l}\text { Entalpia na entrada do tubo de } \\
\text { orifício }\end{array}$ & h3 & {$[\mathrm{kJ} / \mathrm{kg}]$} & 138,0 & 133,8 & 167,5 \\
\hline \multicolumn{6}{|l|}{ COMPRESSOR } \\
\hline Eficiência volumétrica & $\eta_{\mathrm{vol}}$ & - & $56,9 \%$ & $46,1 \%$ & $65,8 \%$ \\
\hline Eficiência isoentrópica & $\eta_{\text {iso_comp }}$ & - & $69,6 \%$ & $59,7 \%$ & $83,7 \%$ \\
\hline Vazão de refrigerante R134 & $\dot{m}_{r}$ & {$[\mathrm{~kg} / \mathrm{s}]$} & 0,045 & 0,053 & 0,035 \\
\hline $\begin{array}{l}\text { Entalpia na saída do compressor } \\
\text { (real) }\end{array}$ & h2 & {$[\mathrm{kJ} / \mathrm{kg}]$} & 313,0 & 324,3 & 304,2 \\
\hline Trabalho de compressão real & $\dot{W}_{\text {real }}$ & {$[\mathrm{kW}]$} & 2,65 & 3,76 & 1,49 \\
\hline Coeficiente de performance & $\mathrm{COP}$ & - & 1,99 & 1,66 & 2,20 \\
\hline \multicolumn{6}{|l|}{ EVAPORADOR } \\
\hline Troca de calor & $\dot{Q}_{\text {evap }}$ & {$[\mathrm{kW}]$} & 5,3 & 6,2 & 3,3 \\
\hline \multicolumn{6}{|l|}{ CONDENSADOR } \\
\hline $\begin{array}{l}\text { Rejeito de calor no } \\
\text { condensador }\end{array}$ & $\dot{Q}_{\text {cond }}$ & {$[\mathrm{kW}]$} & 7,9 & 10,0 & 4,8 \\
\hline
\end{tabular}


DE REFRIGERAÇÃO

\subsection{COMPARAÇÃO DOS RESULTADOS}

Para maior clareza, a comparação entre os resultados de testes reais e os resultados da simulação são apresentados em quadro comparativo na Tabela 6-5.

Tabela 6-5 Quadro comparativo dos resultados da simulação e de testes reais.

\begin{tabular}{|c|c|c|c|c|c|c|c|c|c|c|c|}
\hline & \multirow{2}{*}{\multicolumn{3}{|c|}{1}} & \multirow{2}{*}{\multicolumn{3}{|c|}{2}} & \multirow{2}{*}{\multicolumn{3}{|c|}{3}} \\
\hline & & & & & & & & & & & \\
\hline & & & \multicolumn{3}{|c|}{$50 \mathrm{~km} / \mathrm{h}$} & \multicolumn{3}{|c|}{$100 \mathrm{~km} / \mathrm{h}$} & \multicolumn{3}{|c|}{ M. Lenta } \\
\hline & & & Real & Simul. & Difer. & Real & Simul. & Difer. & Real & Simul. & Difer. \\
\hline \multicolumn{12}{|l|}{ CICLO DE REFRIGERAÇÃO } \\
\hline Temperatura de evaporação & T_evap & {$\left[{ }^{\circ} \mathrm{C}\right]$} & 2,27 & $-0,24$ & $-110,6 \%$ & $-0,50$ & $-5,04$ & $-908,0 \%$ & 15,5 & 15,1 & $-2,8 \%$ \\
\hline Pressão de evaporação & P_evap & {$[\mathrm{kPa}]$} & 317,9 & 290,5 & $-8,6 \%$ & 287,9 & 243,1 & $-15,6 \%$ & 496,3 & 489,5 & $-1,4 \%$ \\
\hline Pressão de condensação & P_cond & {$[\mathrm{kPa}]$} & 2208 & 1915 & $-13,3 \%$ & 2194 & 1909 & $-13,0 \%$ & 2817 & 2741 & $-2,7 \%$ \\
\hline Razão de compressão & PR & - & 6,9 & 6,6 & $-5,1 \%$ & 7,6 & 7,9 & $3,1 \%$ & 5,7 & 5,6 & $-1,4 \%$ \\
\hline Temperatura de condensação & T_cond & {$\left[{ }^{\circ} \mathrm{C}\right]$} & 71,9 & 65,6 & $-8,8 \%$ & 71,6 & 65,4 & $-8,6 \%$ & 83,2 & 81,9 & $-1,6 \%$ \\
\hline $\begin{array}{l}\text { Superaquecimento na saída } \\
\text { do evaporador }\end{array}$ & SH_evap & {$\left[{ }^{\circ} \mathrm{C}\right]$} & 2,9 & 5,0 & $72,5 \%$ & 2,8 & 5,0 & $75,7 \%$ & 2,4 & 5,0 & $112,0 \%$ \\
\hline $\begin{array}{l}\text { Superaquecimento na entrada } \\
\text { do compressor }\end{array}$ & SH_comp & {$\left[{ }^{\circ} \mathrm{C}\right]$} & 5,0 & 10,0 & $98,9 \%$ & 4,3 & 10,0 & $133,3 \%$ & 6,0 & 10,0 & $65,9 \%$ \\
\hline Subresfriamento & $\mathrm{SC}$ & {$\left[{ }^{\circ} \mathrm{C}\right]$} & 12,5 & 8,4 & $-32,6 \%$ & 14,8 & 9,8 & $-33,6 \%$ & 6,4 & 2,6 & $-58,9 \%$ \\
\hline \multicolumn{12}{|c|}{ COMPRESSOR } \\
\hline Vazão de refrigerante R134 & $\dot{m}_{r}$ & {$[\mathrm{~kg} / \mathrm{s}]$} & 0,0453 & 0,0411 & $-9,2 \%$ & 0,0525 & 0,0432 & $-17,7 \%$ & 0,0348 & 0,0344 & $-1,0 \%$ \\
\hline Trabalho de compressão real & $\dot{W}_{\text {real }}$ & {$[\mathrm{kW}]$} & 2,65 & 2,64 & $-0,4 \%$ & 3,76 & 3,46 & $-7,9 \%$ & 1,49 & 1,76 & $18,7 \%$ \\
\hline $\begin{array}{l}\text { Temperatura de descarga do } \\
\text { compressor }\end{array}$ & T_desc & {$\left[{ }^{\circ} \mathrm{C}\right]$} & 95,0 & 96,3 & $1,3 \%$ & 104,0 & 107,2 & $3,1 \%$ & 96,9 & 103,5 & $6,8 \%$ \\
\hline Coeficiente de performance & $\mathrm{COP}$ & - & 1,99 & 1,87 & $-5,9 \%$ & 1,66 & 1,49 & $-10,1 \%$ & 2,20 & 1,78 & $-18,9 \%$ \\
\hline \multicolumn{12}{|l|}{ EVAPORADOR } \\
\hline Troca de calor & $\dot{Q}_{\text {evap }}$ & {$[\mathrm{kW}]$} & 5,3 & 4,9 & $-6,3 \%$ & 6,2 & 5,2 & $-17,1 \%$ & 3,3 & 3,1 & $-3,8 \%$ \\
\hline \multicolumn{12}{|l|}{ CONDENSADOR } \\
\hline $\begin{array}{l}\text { Rejeito de calor no } \\
\text { condensador }\end{array}$ & $\dot{Q}_{\text {cond }}$ & {$[\mathrm{kW}]$} & 7,9 & 7,6 & $-4,3 \%$ & 10,0 & 8,6 & $-13,7 \%$ & 4,8 & 4,9 & $3,2 \%$ \\
\hline
\end{tabular}

\subsubsection{Fluxos de calor}

Observa-se uma diferença significativa entre os fluxos de calor calculados de acordo com os dados reais do túnel de vento e pela simulação do sistema principalmente para a velocidade de $100 \mathrm{~km} / \mathrm{h}$, ficando muito próximo para a condição de marcha-lenta. O fluxo de calor $\dot{Q}_{\text {evap }}$ foi calculado de maneiras diferentes em cada caso. No caso da simulação, $\dot{Q}_{\text {evap }}$ foi calculado a partir das temperaturas, da vazão de ar e das características do evaporador, ou seja, foi determinado pelo lado do ar. No caso do ensaio em túnel de vento, $\dot{Q}_{\text {evap }}$ foi calculado a partir da vazão mássica de 
refrigerante pelo compressor, ou seja pelo lado do refrigerante. Este segundo método é normalmente utilizado, pois apresenta resultados com precisão aceitável.

As hipóteses para estas diferenças são que no cálculo pelo lado ar a carga térmica tenha sido subestimada ou que a vazão mássica de refrigerante calculada no compressor não está produzindo o efeito de refrigeração esperado.

\subsubsection{Temperaturas}

A simulação apresenta valores de temperatura de evaporação muito menores do que os valores calculados para o sistema real para as velocidades de $50 \mathrm{~km} / \mathrm{h}$ e $100 \mathrm{~km} / \mathrm{h}$. Para marcha-lenta os valores ficaram muito próximos. Este resultado confirma a hipótese de que a carga térmica do evaporador na simulação esteja provavelmente subestimada com o veículo em movimento. Os valores de temperatura de condensação também apresentam diferenças, porém não tão grandes como nas temperaturas de evaporação.

Nota-se que o superaquecimento adotado inicialmente para a simulação é significativamente maior do que no sistema real, o que sugere que seja necessário um ajuste no modelo. O sistema real também apresenta uma capacidade de subresfriamento maior que o estimado, provavelmente como resultado da queda de pressão ou de um subresfriamento adicional do refrigerante obtido na linha entre o condensador e o tubo de orifício.

\subsubsection{Pressões de trabalho}

Observa-se diferenças importantes entre as pressões de trabalho para as velocidades de $50 \mathrm{~km} / \mathrm{h}$ e $100 \mathrm{~km} / \mathrm{h}$, novamente com resultados muito próximos para a condição de marcha-lenta. A tendência de pressões de trabalho menores acompanha os resultados das temperaturas de condensação e evaporação.

\subsubsection{Coeficiente de performance}

A simulação subestima o coeficiente de performance do sistema. É importante observar que na simulação o trabalho real de compressão é calculado a partir da eficiência isoentrópica do compressor (assim como a temperatura de descarga do compressor). No caso do sistema real, como a temperatura de descarga do compressor era disponível, calculou-se a entalpia de descarga do compressor a partir deste valor, e então calculou-se o trabalho real de compressão.

Nota-se que a simulação estima uma temperatura de descarga sempre maior que a 
real. Esta diferença ocorre provavelmente pelo fato de que a simulação admite uma compressão adiabática, o que não ocorre na prática.

\subsection{AJUSTES DO MODELO DE SIMULAÇÃO}

Em face das diferenças apresentadas na primeira simulação, alguns ajustes no modelo foram realizados.

Um primeiro ajuste foi feito na temperatura de entrada do evaporador. Até este ponto adotou-se a temperatura de entrada do evaporador como sendo igual à temperatura interna da cabina, porém analisando os dados obtidos no ensaio de túnel de vento verificou-se que a temperatura do ar de retorno do evaporador é ligeiramente superior. Este novo valor de temperatura do ar de retorno foi adotado.

Um segundo ajuste refere-se aos valores adotados para o superaquecimento na saída do evaporador e na entrada do compressor. Valores mais próximos do que se encontra na prática foram adotados. Acredita-se que o valor do superaquecimento adotado tenha uma influência pequena sobre o resultado final da simulação.

O último ajuste refere-se à carga térmica calculada pelo lado do ar. Como a temperatura de retorno do ar é conhecida, a hipótese é de que a umidade relativa interna deva ser maior do que o inicialmente estimada, ou seja, a infiltração de ar externo com o veículo em movimento deve ser maior do que os 15 1/s adotados para se estimar a umidade relativa interna. Apenas para verificar o efeito da umidade relativa interna, novos valores foram adotados para as velocidades de $50 \mathrm{~km} / \mathrm{h}$ e $100 \mathrm{~km} / \mathrm{h}$, sendo um valor maior para a velocidade mais alta. $\mathrm{O}$ valor da umidade relativa para a condição de marcha-lenta foi mantido. Isto porque com o veículo parado não há diferença de pressão entre o interior da cabina e o exterior, não havendo infiltração e, portanto, não afetando a umidade relativa.

Os valores de ajustes são apresentados na Tabela 6-6. Os resultados de simulação, após os ajustes do modelo, são apresentados na Tabela 6-7.

Os novos resultados apresentados na Tabela 6-7 em comparação com os resultados da Tabela 6-2 apresentam alterações importantes:

a) Os novos valores adotados para a temperatura de retorno do ar e da umidade relativa interna resultaram em valores de $\dot{Q}_{\text {evap }}$ e $\dot{Q}_{\text {cond }}$ muito mais próximos do resultado real obtido através da análise do lado refrigerante, o que confirma principalmente a hipótese de que a infiltração de ar externo era subestimada.

b) Para a condição de marcha-lenta, onde não houve alteração da carga térmica, a 
modificação dos valores de superaquecimento não produziu nenhum efeito relevante nos resultados. Não é possível fazer esta avaliação para o veículo em movimento, pois outros parâmetros além do superaquecimento estão afetando os resultados.

c) Os valores de temperatura de evaporação continuam diferentes dos valores reais, porém muito mais próximos.

Tabela 6-6 Ajustes no modelo de simulação do sistema

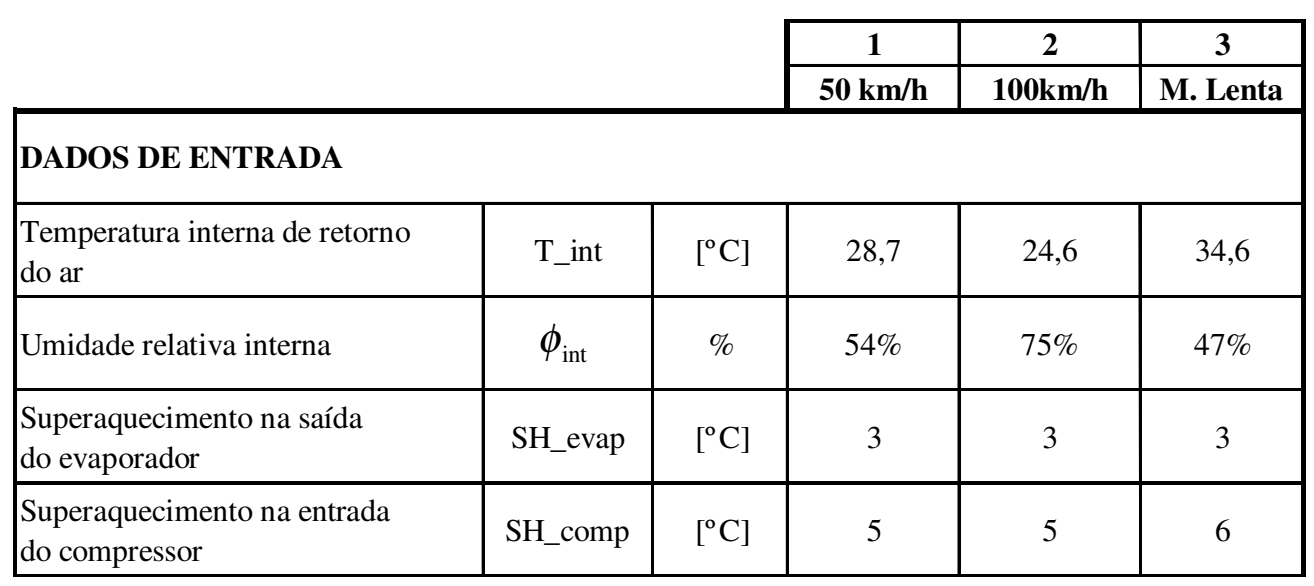

Para melhor visualização, os resultados do modelo ajustado e do teste do veículo são apresentados em quadro comparativo na Tabela 6-8, onde se verifica que, embora em termos percentuais a diferença de temperaturas de evaporação seja grande, em termos absolutos a diferença é pequena, de menos de $1^{\circ} \mathrm{C}$.

O modelo continua superestimando a temperatura de saída do compressor, como foi visto na simulação anterior. Por consequência, o valor de $\dot{Q}_{\text {cond }}$ também fica superestimado e o COP fica subestimado. A parte do modelo que calcula a entalpia de saída do compressor poderia também sofrer pequenos ajustes para corrigir o efeito da compressão não-adiabática, e assim fornecer uma previsão melhor de $\mathrm{T}_{\text {desc }}, \mathrm{W}_{\text {real }}, \mathrm{COP} \mathrm{e}$ $\dot{Q}_{\text {cond }}$. 
DE REFRIGERAÇÃO

Tabela 6-7 Resultados da simulação do sistema após ajuste do modelo.

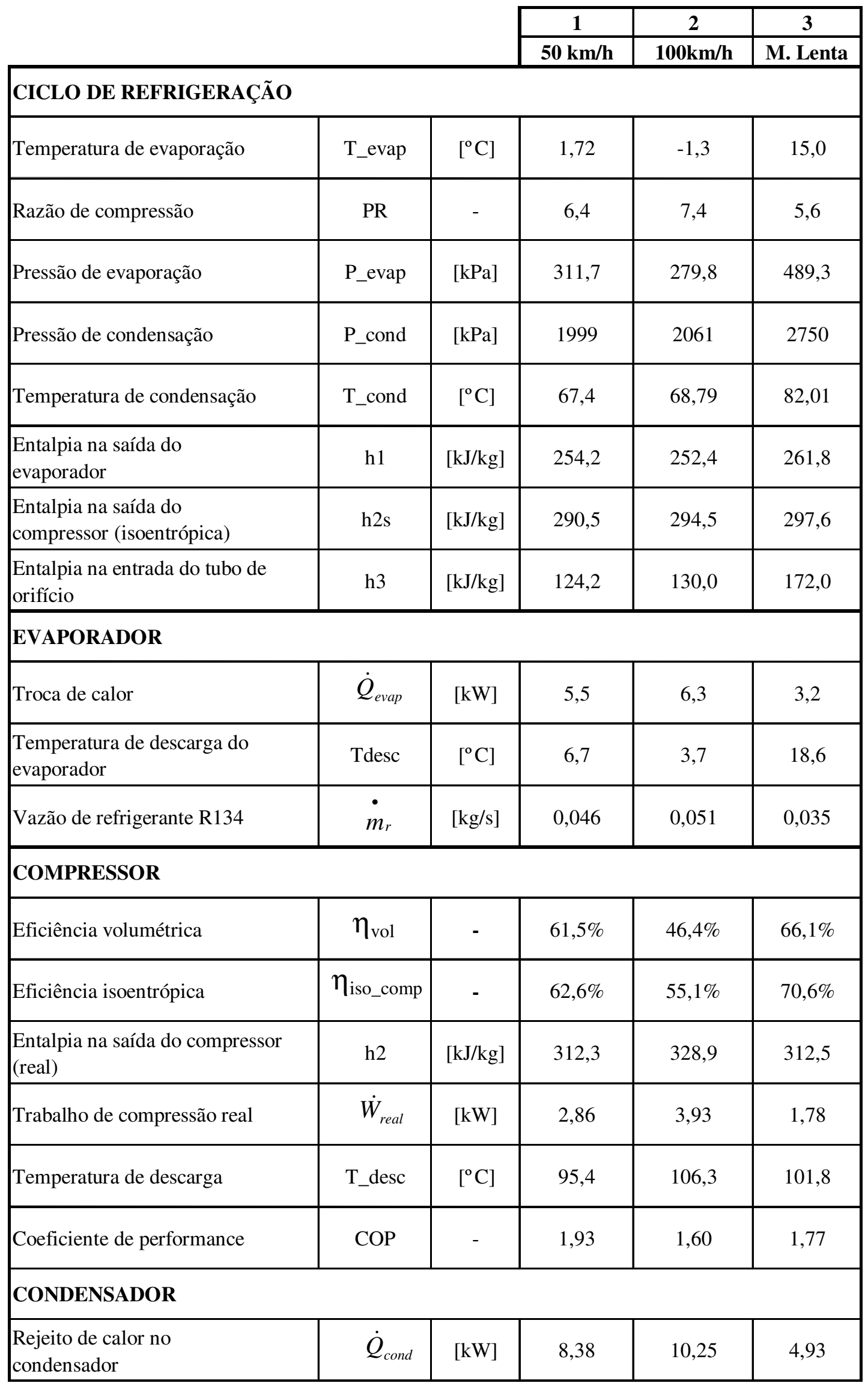


DE REFRIGERAÇÃO

Tabela 6-8 Quadro comparativo dos resultados da simulação após ajustes do modelo

\begin{tabular}{|c|c|c|c|c|c|c|c|c|c|c|c|}
\hline \multirow{3}{*}{\multicolumn{3}{|c|}{10}} & \multirow{2}{*}{\multicolumn{3}{|c|}{$\frac{1}{50 \mathrm{~km} / \mathrm{h}}$}} & \multirow{2}{*}{\multicolumn{3}{|c|}{$\frac{2}{100 \mathrm{~km} / \mathrm{h}}$}} & \multirow{2}{*}{\multicolumn{3}{|c|}{$\frac{3}{\text { M. Lenta }}$}} \\
\hline & & & & & & & & & & & \\
\hline & & & Real & Simul. & Difer. & Real & Simul. & Difer. & Real & Simul. & Difer. \\
\hline \multicolumn{12}{|l|}{ CICLO DE REFRIGERAÇÃO } \\
\hline Temperatura de evaporação & T_evap & {$\left[{ }^{\circ} \mathrm{C}\right]$} & 2,27 & 1,72 & $-24,3 \%$ & $-0,50$ & $-1,27$ & $-154,0 \%$ & 15,5 & 15,8 & $1,8 \%$ \\
\hline Pressão de evaporação & P_evap & {$[\mathrm{kPa}]$} & 317,9 & 311,7 & $-2,0 \%$ & 287,9 & 279,8 & $-2,8 \%$ & 496,3 & 500,7 & $0,9 \%$ \\
\hline Pressão de condensação & P_cond & {$[\mathrm{kPa}]$} & 2208 & 1999 & $-9,5 \%$ & 2194 & 2061 & $-6,1 \%$ & 2817 & 2750 & $-2,4 \%$ \\
\hline Razão de compressão & PR & - & 6,9 & 6,4 & $-7,6 \%$ & 7,6 & 7,4 & $-3,3 \%$ & 5,7 & 5,6 & $-1,0 \%$ \\
\hline Temperatura de condensação & $\mathrm{T}$ _cond & {$\left[{ }^{\circ} \mathrm{C}\right]$} & 71,9 & 67,4 & $-6,2 \%$ & 71,6 & 68,8 & $-3,9 \%$ & 83,2 & 82,0 & $-1,4 \%$ \\
\hline $\begin{array}{l}\text { Superaquecimento na saída } \\
\text { do evaporador }\end{array}$ & SH_evap & {$\left[{ }^{\circ} \mathrm{C}\right]$} & 2,9 & 3,0 & $3,5 \%$ & 2,8 & 3,0 & $5,4 \%$ & 2,4 & 3,0 & $27,2 \%$ \\
\hline $\begin{array}{l}\text { Superaquecimento na entrada } \\
\text { do compressor }\end{array}$ & SH_comp & {$\left[{ }^{\circ} \mathrm{C}\right]$} & 5,0 & 5,0 & $-0,6 \%$ & 4,3 & 5,0 & $16,7 \%$ & 6,0 & 6,0 & $-0,5 \%$ \\
\hline Subresfriamento & SC & {$\left[{ }^{\circ} \mathrm{C}\right]$} & 12,5 & 11,0 & $-11,7 \%$ & 14,8 & 14,5 & $-2,0 \%$ & 6,4 & 3,0 & $-53,5 \%$ \\
\hline \multicolumn{12}{|c|}{ COMPRESSOR } \\
\hline Vazão de refrigerante R134 & $\dot{m}_{r}$ & {$[\mathrm{~kg} / \mathrm{s}]$} & 0,0453 & 0,0457 & $0,9 \%$ & 0,0525 & 0,0514 & $-2,2 \%$ & 0,0348 & 0,0351 & $0,8 \%$ \\
\hline Trabalho de compressão real & $\dot{W}_{\text {real }}$ & {$[\mathrm{kW}]$} & 2,65 & 2,86 & $7,8 \%$ & 3,76 & 3,93 & $4,6 \%$ & 1,49 & 1,78 & $19,6 \%$ \\
\hline $\begin{array}{l}\text { Temperatura de descarga do } \\
\text { compressor }\end{array}$ & T_desc & {$\left[{ }^{\circ} \mathrm{C}\right]$} & 95,0 & 95,4 & $0,4 \%$ & 104,0 & 106,3 & $2,2 \%$ & 96,9 & 101,8 & $5,0 \%$ \\
\hline Coeficiente de performance & $\mathrm{COP}$ & - & 1,99 & 1,93 & $-2,9 \%$ & 1,66 & 1,60 & $-3,7 \%$ & 2,20 & 1,77 & $-19,4 \%$ \\
\hline \multicolumn{12}{|l|}{ EVAPORADOR } \\
\hline Troca de calor & $\dot{Q}_{\text {evap }}$ & {$[\mathrm{kW}]$} & 5,3 & 5,5 & $4,7 \%$ & 6,2 & 6,3 & $0,7 \%$ & 3,3 & 3,2 & $-3,6 \%$ \\
\hline \multicolumn{12}{|l|}{ CONDENSADOR } \\
\hline $\begin{array}{l}\text { Rejeito de calor no } \\
\text { condensador }\end{array}$ & $\dot{Q}_{\text {cond }}$ & {$[\mathrm{kW}]$} & 7,9 & 8,4 & $5,8 \%$ & 10,0 & 10,3 & $2,5 \%$ & 4,8 & 4,9 & $3,6 \%$ \\
\hline
\end{tabular}

\subsection{CONCLUSÕES}

Mesmo sendo um modelo com muitas simplificações, os resultados obtidos são bastante razoáveis. Uma vez ajustado, este modelo pode ser utilizado por exemplo para prever o resultado de modificações no sistema, como a troca de um componente, ou mesmo para prever o funcionamento do sistema sob outras condições de operação (por exemplo uma modificação da rotação do compressor, outras temperaturas de trabalho, operação com renovação de ar e outros). A utilização do modelo fica restrita aos limites da validade dos modelos semi-empíricos dos componentes, não sendo recomendada a utilização fora desses limites. Ainda assim, a faixa de aplicação é grande o suficiente para simular a maioria das condições de trabalho encontradas na climatização veicular.

Analisando o processo e os resultados, pode-se chegar às seguintes conclusões:

a) Pequenos ajustes são necessários para que o modelo tenha uma boa correlação com o veículo real, porém uma vez ajustado o mesmo pode ser utilizado para 
diversos tipos de simulações em regime permanente.

b) O modelo pode ser utilizado também para simular a operação do sistema com renovação de ar externo. Para renovação parcial de ar é necessário aplicar um cálculo de mistura adiabática do ar de renovação com o ar recirculado para determinar a condição de entrada do evaporador. Para $100 \%$ de renovação este cálculo não é necessário. Nos dois casos deve-se levar em conta o ganho de calor na passagem do ar pelos dutos de tomada de ar externo até a chegada ao evaporador.

c) Foi demonstrado que a umidade relativa do ar de entrada do evaporador é um fator importante para a determinação da carga térmica. Foi demonstrado também que é difícil se saber a quantidade de infiltração de ar externo. Por essas razões, o ensaio em túnel de vento poderia ser melhorado com a inclusão da medição da umidade relativa interna.

d) Uma futura expansão deste modelo poderia incluir outros tipos de componentes, como por exemplo compressor de deslocamento variável e sistema com válvula de expansão termostática. 


\section{CAPÍTULO 7 CONCLUSÃO}

O ser humano consome grandes quantidades de energia para satisfazer as suas necessidades de conforto. Dentro do setor automotivo, depois da energia consumida com a mobilidade em si, o ar condicionado é o maior consumidor (Ávila, 2002). De fato, como pode ser notado nos resultados do projeto e da análise do desempenho do sistema, o consumo de energia somente do compressor ultrapassa os $3 \mathrm{~kW}$ em condições extremas. Se for somado a este valor o consumo dos ventiladores do condensador e do evaporador, o valor total pode ultrapassar os $4 \mathrm{~kW}$. Vale lembrar que este dimensionamento foi feito para um veículo compacto, sendo que para um veículo maior o consumo será ainda maior. Embora o sistema não opere constantemente sob condições extremas, estes valores de consumo são muito maiores do que qualquer outro sistema de conveniência de um automóvel. Com as reduções de custos favorecendo o acesso a este item de conforto, a tendência é de um aumento no consumo de energia, de maneira que a melhoria da eficiência do sistema deve ser uma preocupação constante dos pesquisadores e engenheiros.

A avaliação do conforto térmico em veículos automotivos é uma área que vem apresentando muitos avanços com o desenvolvimento de modelos de conforto térmico mais sofisticados e o uso de manequins térmicos. Atualmente, a integração das rotinas de cálculo de desempenho do sistema com modelos do interior da cabina, utilizando ferramentas como CFD (computational fluid dynamics), e os modelos de conforto térmico, permitem que se faça uma avaliação das condições de conforto dos ocupantes mesmo na fase conceitual do projeto de um automóvel. Além de encurtar o prazo de desenvolvimento de um veículo automotivo, as técnicas modernas podem auxiliar na otimização dos sistemas visando a redução do consumo.

Quanto à carga térmica do equipamento de refrigeração, nota-se que o ganho de calor em regime permanente é menor do que a carga térmica real em uma condição transitória de resfriamento (cool down), devido à necessidade de se remover o calor armazenado nas massas internas do veículo. Isto significa que projetar o sistema de refrigeração baseado no ganho de calor (em condições de regime permanente) resulta em um subdimensionamento do sistema de climatização, que teria como resultado um tempo 
maior para se chegar à condição de conforto térmico. Terminado o período de resfriamento, o equipamento fica com sobra de capacidade. A carga térmica do equipamento foi avaliada para a condição de teste em túnel de vento, sem renovação de ar. A avaliação do ganho de calor com admissão de ar externo é uma sugestão para um trabalho futuro.

Preocupações com o aquecimento global, consumo de energia e mesmo a disponibilidade do refrigerante R134a (que vem se tornando um fator relevante devido ao aumento da demanda por veículos com ar condicionado) podem alavancar o desenvolvimento de sistemas alternativos de refrigeração para veículos no futuro (o uso do $\mathrm{CO}_{2}$ e o ciclo a ar vem sendo discutidos). No entanto o sistema de refrigeração por compressão mecânica de vapor ainda é o método mais utilizado em automóveis, por ser o que proporciona a capacidade de refrigeração necessária a um custo acessível, atendendo da melhor maneira os limites de peso e espaço, itens críticos nos projetos atuais. Para o sistema R134a o procedimento de projeto apresentado pode ser usado para o dimensionamento básico do sistema, pois apresentou boa correlação com o dimensionamento do veículo real.

Freqüentemente se faz necessário avaliar o desempenho do sistema de refrigeração quando o mesmo opera sob diversas condições, ou mesmo para a otimização do projeto básico. O procedimento para avaliação e simulação do desempenho do sistema apresentado no capítulo 6 pode ser utilizado para atingir esses objetivos, como também para avaliar o efeito da modificação em um componente do sistema. Uma vez ajustado aos resultados de desempenho do veículo real, o modelo apresenta um bom resultado, mesmo tendo sido feitas algumas hipóteses simplificativas. A utilização do procedimento fica restrita aos limites da validade dos modelos dos componentes, e para o caso apresentado estes limites de validade são grandes o suficiente para abranger a maioria das condições normais de operação do veículo.

O trabalho aqui apresentado pode ser expandido para estudos de outras condições de operação, como por exemplo com renovação de ar externo, ou mesmo para outros veículos ou outros sistemas, como por exemplo com compressores de capacidade variável ou válvulas de expansão. Um outro aperfeiçoamento da simulação de sistemas poderia incluir um modelo dinâmico, por exemplo para avaliar o regime transitório que ocorre no período de resfriamento. 


\section{CAPÍTULO 8 REFERÊNCIAS BIBLIOGRÁFICAS}

ABU-ISA, I.A. Thermal Properties of Automotive Polymers II - Thermal Conductivity Measurements. SAE paper 2000-01-1320 SAE World Congress, 2000.

AMBS, R., Improved Passenger Thermal Comfort Prediction in the Prototype Phase by Transient Interior CFD analysis Including Mannequins. SAE paper number 2002-010514, Society of Automotive Engineers, 2002.

ASPELUND, K. A. Optimization of Plate-Fin-And-Tube Condenser Performance and Design for Refrigerant R-410A Air-Conditioner. MSc. Thesis, Georgia Institute of Technology, 2001.

ASHRAE 62. Ventilation for acceptable indoor air quality, (ANSI/ASHRAE 62-1989), American Society of Heating, Refrigerating and Air Conditioning Engineers, New York, 1989.

ASHRAE, Handbook of Fundamentals. American Society of Heating, Refrigerating and Air Conditioning Engineers, Inc, New York, 2001.

ASHRAE 55. Thermal environmental conditions for human occupancy, American Society of Heating, Refrigerating and Air Conditioning Engineers, New York, 2004.

ÁVILA, J. A. Ar condicionado automotivo: Caracterização e avanços tecnológicos Trabalho de conclusão de curso. Mestrado Profissionalizante em Engenharia Automotiva. Escola Politécnica da Universidade de São Paulo, São Paulo, 2002.

BHATTI, M. S. A critical look at R-744 and R-134a mobile air conditioning systems. SAE paper number 970527, Society of Automotive Engineers, 1997.

BHATTI, M. S. Open air cycle air conditioning system for motor vehicles. SAE Special Publications, v1347, paper number 980289, Society of Automotive Engineers, 1998.

BHATTI, M. S. Riding in Comfort: Part II. ASHRAE Journal, September, p.p. 44-50, 1999a. 
BHATTI, M. S., Enhancement of R134a Automotive Air Conditioning System, SAE paper 1999-01-0870 - SAE International Congress and Exposition, 1999 b.

BOSCH, R. GmbH, Automotive Handbook, 5th edition, 2000

BROWN, J. S. e JONES, B. W., A New Transient Passenger Thermal Comfort Model. SAE Paper number 970528, Society if Automotive Engineers, 1997.

CALSONIC KANSEI EUROPE, Windtunnel facility in South Wales, 2002. Disponível em http://www.ckeurope.com/news/wind_tunnel.html - acesso em Novembro de 2003.

ÇENGEL, Y.A.; BOLES, M. A. Thermodynamics: An Engineering Approach, $3^{\text {rd }}$ Edition. McGraw Hill, 1998.

DOSSAT, R. J.; HORAN, T. J. Principles of Refrigeration, $5^{\text {th }}$ Edition. Prentice Hall, 2001.

EES . Engineering Equation Solver. F-chart. Atlanta, 2003.

FANGER, P. O. Thermal comfort, analysis and application in environmental engineering, McGraw-Hill, New York, 245 p, 1972.

FORREST, W. O. and BHATTI, M. S., Energy Efficient Automotive Air Conditioning System, SAE paper 2002-01-0229, SAE World Congress, 2002.

FURUSE, K e KOMORIYA, T., Study of passenger's comfort in non-uniform thermal environments of vehicle compartment. Society of Automotive Engineers of Japan, Inc. Technical notes, JSAE review 18, 1997 p.p. 411-414.

GAGGE, A. P.; STOLWIJK, J.A, NISHI, Y., An effective temperature scale based on a simple model of human physiological response, ASHRAE Transactions, v.77, n.1, 1971.

HERNANDEZ NETO, A., Análise do escoamento do fluido refrigerante R-134a em tubos de orifício. Tese de Doutorado. Escola Politécnica da Universidade de São Paulo, São Paulo, 1998.

HOSNI, M.H., GUAN Y., JONES, B. W. e GIELDA, T. P., Investigation of Human Thermal Comfort Under Highly Transient Conditions for Automotive Applications Part 1: Experimental Design and Human Subject Testing Implementation. ASHRAE Transactions, American Society of Heating, Refrigerating and Air Conditioning Engineers, Inc. 2003a. 
HOSNI, M.H., GUAN Y., JONES, B. W. e GIELDA, T. P., Investigation of Human Thermal Comfort Under Highly Transient Conditions for Automotive Applications Part 2: Thermal Sensation Modelling. ASHRAE Transactions, American Society of Heating, Refrigerating and Air Conditioning Engineers, Inc. 2003b.

HUANG, D. C.; OKER, E.; YANG, S. L.; ARICI, O. A Dynamic Computer-Aided Engineering Model for Automobile Climate Control System Simulation and Application Part I: A/C Component Simulations and Integration. SAE paper number 1999-01-1195, Society of Automotive Engineers, 1999.

INCROPERA, F. P.; DeWITT, D. P.; Fundamentos de Transferência de Calor e de Massa, 4 Edição, Rio de Janeiro. LTC - Livros Técnicos e Científicos Editora S.A., 1998.

ISNARD, D. Palestra: Técnicas NVH+ RH, $2^{\circ}$ Seminário SAE de Palestras, São Bernardo do Campo, SP - 2004 (informação verbal).

ISO 7243. Hot environments: Estimation of the heat stress on working man, based on the WBGT - index (wet bulb globe temperature). International Organization for Standardization, Geneva, 1989.

ISO 7933. Hot environments - Analytical determination and interpretation of thermal stress using calculation on required sweat rate. International Organization for Standardization, Geneva, 1989.

ISO 7730. Moderate thermal environments - Determination of the PMV and PPD indices and specification of the conditions of thermal comfort. International Organization for Standardization, Geneva, 1994.

ISO 7726.. Thermal environments - Instruments and methods for measuring physical quantities. International Organization for Standardization, Geneva, 1998.

ISO 14505-1. Ergonomics of the thermal environment - Evaluation of thermal environment in vehicles - Part 1: Principles and methods for assessment of thermal stress. International Organization for Standardization, Geneva, 2004.

ISO 14505-2. Ergonomics of the thermal environment - Evaluation of thermal environment in vehicles - Part 2: Determination of equivalent temperature. International Organization for Standardization, Geneva, 2004. 
JABARDO, J. M. S.; MAMANI, W. G. Modelling and experimental evaluation of parallel flow micro channel condensers. J. Braz. Soc. Mech. Sci. \& Eng. [online]. Apr./June 2003, vol.25, no.2 [cited 30 March 2005], p.107-114. Available from World Wide Web: <http://www.scielo.br/scielo.php?script=sci_arttext\&pid=S1678$58782003000200001 \& \operatorname{lng}=$ en $\& n r m=i s o>$. ISSN 1678-5878.

JABARDO, J.M., MAMANI, W. GONZALES e IANELLA, M.R. Modelling and experimental evaluation of an automotive air conditioning system with a variable capacity compressor: International Journal of Refrigeration 25, p.p.1157-1172, 2002.

KAYS, W.M.; LONDON A. L. Compact Heat Exchangers, $3^{\text {rd }}$ Edition. McGraw-Hill Book Company, 1984.

MADSEN, T. L.; OLESEN, B.; REID, K. New methods for evaluation of thermal environment in automotive vehicles, ASHRAE Trans., 92 part 1B, 38-54, 1986

MORAN, M.J.; SHAPIRO, H.N. Fundamentals of Engineering Thermodynamics, $5^{\text {th }}$ Edition. John Wiley \& Sons, Inc, 2004.

NILSSON, H. O., Comfort Climate Evaluation with Thermal Manikin Methods and Computer Simulation Models. Master Thesis, Department of Civil and Architectural Engineering, Royal Institute of Technology, Sweden, 2004.

RANSCO INDUSTRIES, Célula de testes de um túnel de vento, 1999. Disponível em http://www.ransco.com - acesso em Novembro de 2003.

RUTH, D. W., Simulation Modelling of Automobile Comfort Cooling Requirements, ASHRAE Journal, $n^{\circ}$ 5, pp 53-55, 1975

SAE-J639, Safety and Containment of Refrigerant for Mechanical Vapor Compression Systems Used for Mobile Air-conditioning Systems. Society of Automotive Engineers, 1999a.

SAE-J2210, HFC-134a (R134a) Recovery/Recycling Equipment for Mobile Air Conditioning Systems. Society of Automotive Engineers, 1999b.

SAE-J902, Passenger Car Windshield Defrosting Systems. Society of Automotive Engineers, 1999c.

SAE-J953, Passenger Car Backlight Defogging System. Society of Automotive Engineers, February 1999. SAE-J902, Passenger Car Windshield Defrosting Systems. 
Society of Automotive Engineers, 1999d.

SAE-J1732, HFC-134a (R134a) Refrigerant Recovery Equipment for Mobile Air Conditioning Systems. Society of Automotive Engineers, 1998.

SAE-J2197, HFC-134a (R134a) Service Hose Fittings for Automotive Air-conditioning Service Equipment. Society of Automotive Engineers, 1997.

SANDEN CORPORATION. Curvas de desempenho de compressor, 2005. Disponível em: <http://www.sanden.com/products/performance5data.html>. Acesso em 24 mar. 2005.

SHAH, R. K.; KRAUS A . D.; METZGER, D. Compact Heat Exchangers. Hemisphere Publishing Corporation, 1990.

STANCATO, F., Fontes térmicas em cabinas de veículos, sua avaliação e efeitos no ambiente interior - Dissertação de Mestrado. Escola Politécnica da Universidade de São Paulo, São Paulo, 1992.

STEEN, R., Preparing for safe winter travel. The American National Red Cross, 2001. Disponível em: http://www.redcross.org/news/hs/holidaysafety/011217wintertravel.html.Acesso em 18/Jan/2005.

STEWART, S. W. Enhanced Finned-Tube Condenser Design and Optimization. PhD. Thesis, Georgia Institute of Technology, 2003.

STOECKER, W. F. Refrigeração e ar condicionado; São Paulo: Mc Graw Hill do Brasil, 1985.

TAKEUCHI, T., KAKISHITA, N. e KHORI, I., The Prediction of Refrigeration Cycle Performance with Front End Airflow CFD Analysis of an Automotive Air Conditioner. SAE Paper number 2002-01-0512, Society of Automotive Engineers, 2002.

WEI, K. C. e DAGE, G.A., An intelligent Automotive Climate Control System. IEEE Institute of Electrical and Electronic Engineers, p.p. 2977-2982, 1995.

YAMANE, E.; SAITO, H., Tecnologia do Condicionamento de Ar, Edgard Blücher , São Paulo, 1986. 


\section{APÊNDICE A}

Na Tabela A.1 são apresentados os coeficientes de regressão linear dos dados de eficiência volumétrica e eficiência isoentrópica do compressor de deslocamento fixo de $154 \mathrm{~cm}^{3}$, objeto de estudo neste trabalho.

Tabela A.1 Coeficientes de regressão linear do compressor

\begin{tabular}{|c|c|c|}
\hline Coeficiente & $\eta_{\text {vol }}$ & $\eta_{\text {iso_comp }}$ \\
\hline $\mathrm{a} 0$ & $1,2 \mathrm{E}+00$ & $7,7 \mathrm{E}-01$ \\
\hline $\mathrm{a} 1$ & $1,3 \mathrm{E}-04$ & $-7,8 \mathrm{E}-05$ \\
\hline $\mathrm{a} 2$ & $-8,7 \mathrm{E}-08$ & $2,7 \mathrm{E}-09$ \\
\hline $\mathrm{a} 3$ & $9,2 \mathrm{E}-12$ & \\
\hline $\mathrm{a} 4$ & $-2,0 \mathrm{E}-01$ & \\
\hline $\mathrm{a} 5$ & $2,0 \mathrm{E}-02$ & \\
\hline $\mathrm{a} 6$ & $-9,7 \mathrm{E}-04$ & \\
\hline $\mathrm{a} 7$ & $-1,2 \mathrm{E}-05$ & \\
\hline $\mathrm{a} 8$ & $2,2 \mathrm{E}-06$ & \\
\hline $\mathrm{a} 9$ & $3,1 \mathrm{E}-09$ & \\
\hline $\mathrm{a} 10$ & $-3,4 \mathrm{E}-10$ & \\
\hline
\end{tabular}

\section{Polinômios de ajuste}

$$
\begin{aligned}
& \eta_{v o l}=a_{0}+a_{1} r p m+a_{2} r p m^{2}+a_{3} r p m^{3}+a_{4} P R+a_{5} P R^{2}+a_{6} P R^{3}+a_{7} r p m P R \\
& +a_{8} r p m P R^{2}+a_{9} r p m^{2} P R+a_{10} r p m^{2} P R^{2} \\
& \eta_{\text {iso_comp }}=a_{0}+a_{1} r p m+a_{2} r p m^{2}
\end{aligned}
$$

Unidades:

$\begin{array}{lll}\text { Rotação do compressor } & \text { rpm } & {\left[\mathrm{min}^{-1}\right]} \\ \text { Eficiências } & \eta_{\text {vol }}, \eta_{\text {iso_comp }} & \text { adimensional }\end{array}$




\section{APÊNDICE B}

Na Tabela B.1 são apresentados os coeficientes de regressão linear dos dados experimentais do trabalho de Hernandez Neto (1998) para tubos de orifício, utilizados neste trabalho.

Tabela B.1 Coeficientes de regressão linear para o tubo orifício

\begin{tabular}{|c|c|r|r|r|r|}
\cline { 2 - 6 } \multicolumn{1}{c|}{} & \multicolumn{5}{c|}{ Diâmetro do tubo } \\
\cline { 2 - 6 } \multicolumn{1}{c|}{} & 1,70 & 1,58 & 1,45 & 1,32 & 1,19 \\
\hline Coeficiente & {$[\mathrm{mm}]$} & {$[\mathrm{mm}]$} & {$[\mathrm{mm}]$} & {$[\mathrm{mm}]$} & {$[\mathrm{mm}]$} \\
\hline $\mathrm{a} 0$ & $8,49 \mathrm{E}+00$ & $6,01 \mathrm{E}+00$ & $2,46 \mathrm{E}+00$ & $5,22 \mathrm{E}+00$ & $4,68 \mathrm{E}+00$ \\
\hline a1 & $1,99 \mathrm{E}-02$ & $1,82 \mathrm{E}-02$ & $1,85 \mathrm{E}-02$ & $1,30 \mathrm{E}-02$ & $9,30 \mathrm{E}-03$ \\
\hline a2 & $-3,41 \mathrm{E}-06$ & $-2,73 \mathrm{E}-06$ & $-3,21 \mathrm{E}-06$ & $-2,28 \mathrm{E}-06$ & $-1,63 \mathrm{E}-06$ \\
\hline a3 & $1,80 \mathrm{E}+00$ & $1,92 \mathrm{E}+00$ & $1,53 \mathrm{E}+00$ & $1,30 \mathrm{E}+00$ & $1,08 \mathrm{E}+00$ \\
\hline a4 & $-1,69 \mathrm{E}-02$ & $-2,38 \mathrm{E}-02$ & $-1,89 \mathrm{E}-02$ & $-2,32 \mathrm{E}-02$ & $-1,48 \mathrm{E}-02$ \\
\hline a5 & $4,05 \mathrm{E}-04$ & $2,35 \mathrm{E}-04$ & $2,09 \mathrm{E}-04$ & $2,93 \mathrm{E}-04$ & $1,65 \mathrm{E}-04$ \\
\hline
\end{tabular}

Polinômios de ajuste

$\dot{m}_{r}=a_{0}+a_{1} P e+a_{2} P e^{2}+a_{3} S C+a_{4} S C^{2}+a_{5} P e S C$

Unidades:

Vazão

$m_{r} \quad \mathrm{~g} / \mathrm{s}$

Pressão de entrada

$\mathrm{Pe} \quad \mathrm{kPa}$ absoluto

Subresfriamento

$\mathrm{SC}$

${ }^{\circ} \mathrm{C}$ 


\section{APÊNDICE C}

Na Tabela C.1 são apresentados os coeficientes de regressão linear dos valores de $\mathrm{UA}_{\text {evap }}$ utilizados neste trabalho.

Tabela C.1 Coeficientes de regressão linear para o evaporador

\begin{tabular}{|c|c|}
\hline Coeficiente & Valor \\
\hline $\mathrm{a} 0$ & $8,2190 \mathrm{E}-02$ \\
\hline $\mathrm{a} 1$ & $1,2643 \mathrm{E}+00$ \\
\hline
\end{tabular}

Polinômios de ajuste

$$
U A_{\text {evap }}=a_{0}+a_{1} Q_{\text {ar_evap }}
$$

Unidades:

$\begin{array}{lll}\text { Coeficiente global } & \mathrm{UA}_{\text {evap }} & \mathrm{kW} /{ }^{\circ} \mathrm{C} \\ \text { Vazão } & \text { Qar_evap } & \mathrm{m}^{3} / \mathrm{s}\end{array}$

\section{APÊNDICE D}

Na Tabela D.1 são apresentados os coeficientes de regressão linear dos valores de $\mathrm{UA}_{\text {cond }}$ utilizados neste trabalho.

Tabela D.1 Coeficientes de regressão linear para o evaporador

\begin{tabular}{|c|c|}
\hline Coeficiente & Valor \\
\hline $\mathrm{a} 0$ & $-2,1307 \mathrm{E}-01$ \\
\hline $\mathrm{a} 1$ & $9,0635 \mathrm{E}-01$ \\
\hline $\mathrm{a} 2$ & $-4,9813 \mathrm{E}-01$ \\
\hline $\mathrm{a} 3$ & $2,3835 \mathrm{E}-02$ \\
\hline $\mathrm{a} 4$ & $-3,3313 \mathrm{E}-04$ \\
\hline
\end{tabular}

Polinômios de ajuste

$$
U A_{\text {cond }}=a_{0}+a_{1} Q_{a r_{-} \text {cond }}+a 2 Q_{a r_{-} \text {cond }}{ }^{2}+a 3(T c-T a)+a 4(T c-T a)^{2}
$$

Unidades:

Coeficiente global

$$
\begin{array}{ll}
\mathrm{UA}_{\text {cond }} & \mathrm{kW} /{ }^{\circ} \mathrm{C} \\
\mathrm{Q}_{\text {ar_cond }} & \mathrm{m}^{3} / \mathrm{s}
\end{array}
$$

Vazão

Temperatura

Tc-Ta

${ }^{\circ} \mathrm{C}$ 